Prepared in cooperation with the U.S. Environmental Protection Agency

Geophysical Characterization of Subsurface Properties Relevant to the Hydrology of the Standard Mine in Elk Basin, Colorado

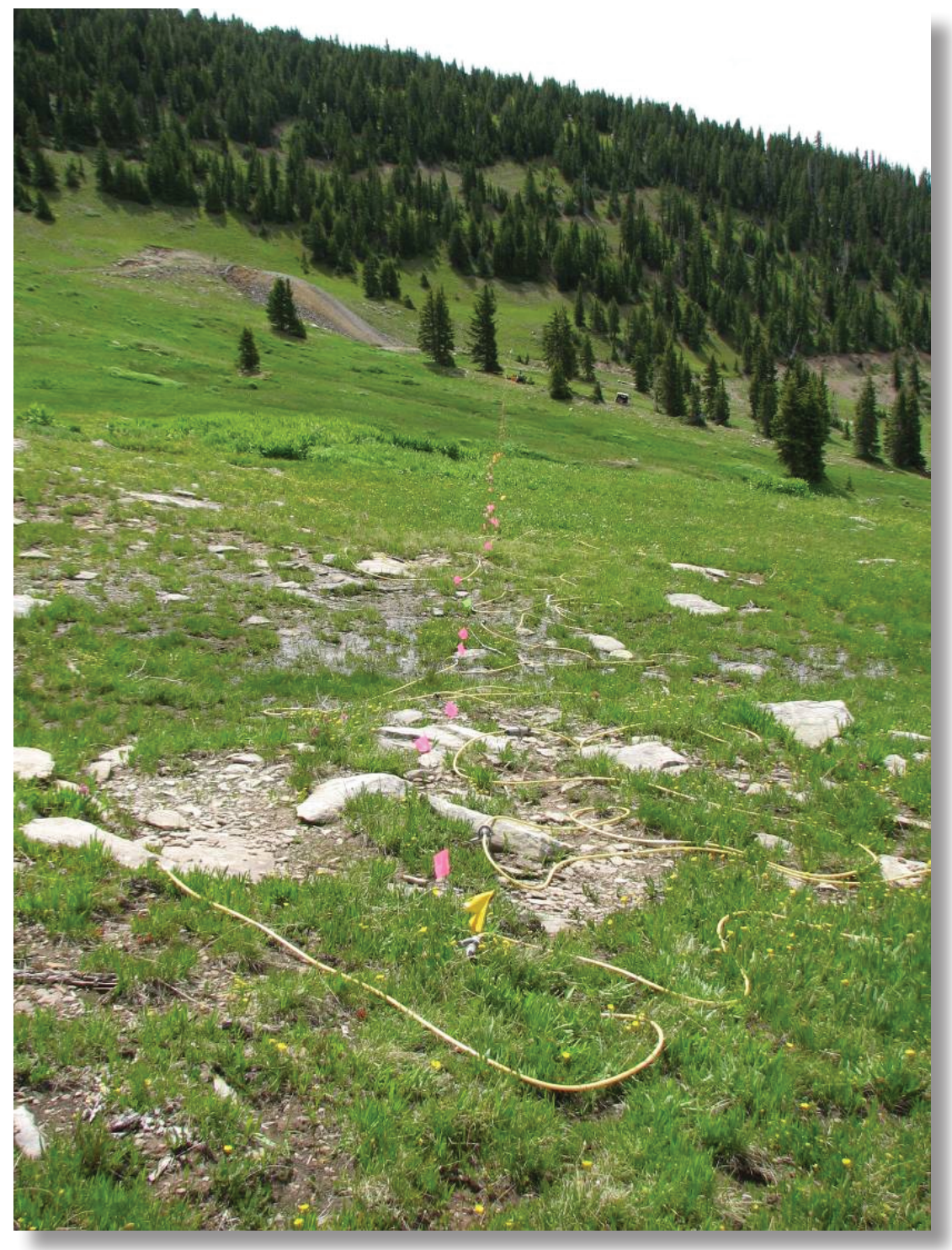

Open-File Report 2009-1284 



\section{Geophysical Characterization of Subsurface Properties Relevant to the Hydrology of the Standard Mine in Elk Basin, Colorado}

By Burke J. Minsley, Lyndsay B. Ball, Bethany L. Burton, Jonathan Saul Caine, Erika Curry-Elrod, and Andrew H. Manning

Prepared in cooperation with the U.S. Environmental Protection Agency

Open-File Report 2009-1284 


\section{U.S. Department of the Interior \\ KEN SALAZAR, Secretary \\ U.S. Geological Survey \\ Marcia K. McNutt, Director}

\section{U.S. Geological Survey, Reston, Virginia: 2010}

For more information on the USGS - the Federal source for science about the Earth, its natural and living resources, natural hazards, and the environment, visit http://www.usgs.gov or call 1-888-ASK-USGS

For an overview of USGS information products, including maps, imagery, and publications, visit http://www.usgs.gov/pubprod

To order this and other USGS information products, visit http://store.usgs.gov

Any use of trade, product, or firm names is for descriptive purposes only and does not imply endorsement by the U.S. Government.

Although this report is in the public domain, permission must be secured from the individual copyright owners to reproduce any copyrighted materials contained within this report.

Suggested citation:

Minsley, B.J., Ball, L.B., Burton, B.L., Caine, J.S., Curry-Elrod, E., and Manning, A.H., 2010, Geophysical characterization of subsurface properties relevant to the hydrology of the Standard Mine in Elk Basin, Colorado, U.S. Geological Survey Open-File Report 2009-1284, 46 p. 


\section{Contents}

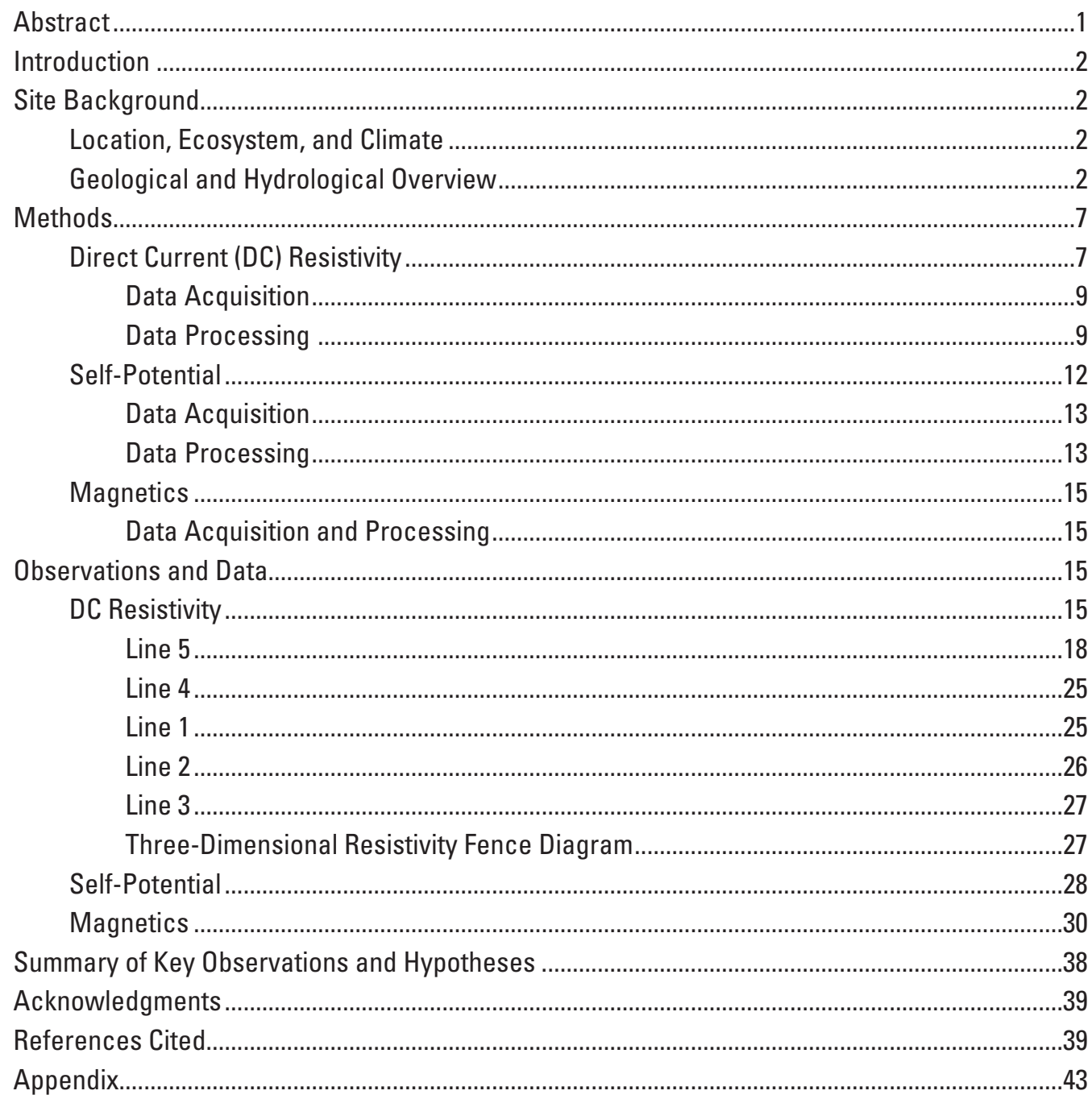

\section{Figures}

1. Location map of the Standard Mine in the regional physiographic setting and local geographic setting 3

2. Map of Elk Basin with geologic and geophysical study areas .........................................

3. Reconnaissance geologic map of upper Elk Basin ...............................................................

4. Photograph of upper Elk Basin looking east from the cirque ridge ........................................6

5. Typical resistivity ranges for common earth materials ...................................................

6. Graphical representation of Archie's empirical law showing the approximate values and trends of bulk electrical resistivity as a function of saturating-water resistivity and volumetric water content, which incorporates both porosity and saturation. 
7. Photograph of Elk Basin looking southeast along resistivity line 4 towards the Level 5 portal....................................................................................................

8. Two-dimensional electrical resistivity acquisition diagram ...........................................11

9. Conceptual model of self-potential signals related to groundwater flow ........................13

10. Conceptual model of self-potential signals related to an electrochemical cell generated by the presence of an ore zone embedded within a naturally-existing redox gradient in the earth ...............................................................14

11. Ranges of magnetic susceptibility values for various rock types ....................................16

12. Location of direct current resistivity profiles superimposed on the reconnaissance geologic map.

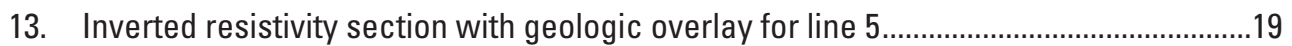

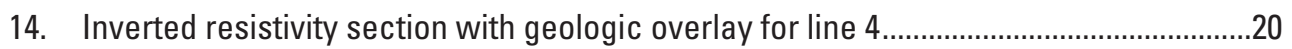

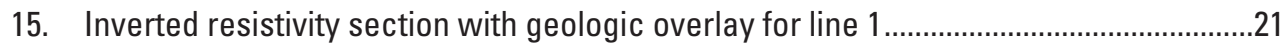

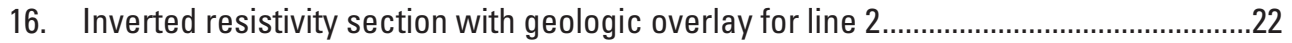

17. Inverted resistivity section with geologic overlay for line 3 .............................................23

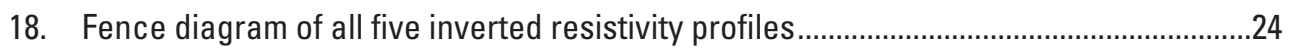

19. Processed self-potential data over the survey area superimposed on the reconnaissance geologic map.

20. Processed self-potential data over the survey area with overlay of topographic gradient vectors .........................................................................................

21. Graph showing self-potentials shown as a function of elevation ....................................32

22. Selected transects extracted from the self-potential map in figure

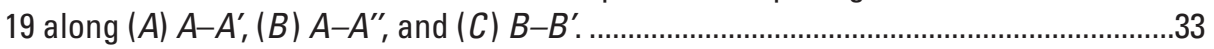

23. Magnetic gradiometer data overlaid as profiles on the geologic map ............................34

24. Profiles of all five transects of magnetic data ............................................................

25. Gridded magnetic data from the top sensor only, which helps to highlight longer wavelength/smaller amplitude variations in the data, on the geologic map .......36

26. Measured $(A)$ and model-predicted $(B)$ apparent resistivity pseudosections for $\mathrm{DC}$ resistivity line 1 .

27. Measured $(A)$ and model-predicted $(B)$ apparent resistivity pseudosections for $\mathrm{DC}$ resistivity line 2

28. Measured $(A)$ and model-predicted $(B)$ apparent resistivity pseudosections for $\mathrm{DC}$ resistivity line 3 .

29. Measured $(A)$ and model-predicted $(B)$ apparent resistivity pseudosections for $\mathrm{DC}$ resistivity line 4 .

30. Measured $(A)$ and model-predicted $(B)$ apparent resistivity pseudosections for DC resistivity line 5 .

\section{Tables}

1. Magnetic susceptibilities of selected minerals.............................................................16

2. Summary of direct current resistivity survey acquisition parameters .............................18

3. Summary of rock-sample descriptions and measured magnetic susceptibilities ..........37 


\section{Conversion Factors}

\begin{tabular}{|c|c|c|}
\hline Multiply & By & To obtain \\
\hline \multicolumn{3}{|c|}{ Length } \\
\hline centimeter $(\mathrm{cm})$ & 0.3937 & inch (in.) \\
\hline meter $(\mathrm{m})$ & 3.281 & foot $(\mathrm{ft})$ \\
\hline kilometer $(\mathrm{km})$ & 0.6214 & mile (mi) \\
\hline \multicolumn{3}{|c|}{ Area } \\
\hline square kilometer $\left(\mathrm{km}^{2}\right)$ & 0.3861 & square mile $\left(\mathrm{mi}^{2}\right)$ \\
\hline \multicolumn{3}{|c|}{ Flow Rate } \\
\hline centimeter per year $(\mathrm{cm} / \mathrm{yr})$ & 0.3937 & inch per year (in/yr) \\
\hline
\end{tabular}

Temperature in degrees Celsius $\left({ }^{\circ} \mathrm{C}\right)$ may be converted to degrees Fahrenheit $\left({ }^{\circ} \mathrm{F}\right)$ as follows:

$$
{ }^{\circ} \mathrm{F}=\left(1.8 \times^{\circ} \mathrm{C}\right)+32
$$

Vertical coordinate information is referenced to North American Vertical Datum of 1988 (NAVD 88).

Horizontal coordinate information is referenced to the North American Datum of 1983 (NAD 83).

Elevation, as used in this report, refers to distance above the vertical datum.

\section{Electrical Conductivity and Electrical Resistivity}

\begin{tabular}{lcl}
\hline \multicolumn{1}{c}{ Multiply } & By & \multicolumn{1}{c}{ To obtain } \\
\hline & Electrical conductivity & \\
\hline siemens per meter $(\mathrm{S} / \mathrm{m})$ & 1,000 & millisiemens per meter $(\mathrm{mS} / \mathrm{m})$ \\
siemens per meter $(\mathrm{S} / \mathrm{m})$ & 10,000 & microsiemens per meter $(\mu \mathrm{S} / \mathrm{cm})$ \\
\hline \multicolumn{3}{c}{ Electrical resistivity } \\
\hline $\begin{array}{l}\text { ohm-meters (ohm-m) } \\
\text { Electrical potential }\end{array}$ & 0.001 & kiloohm-meters (kohm-m) \\
volts $(\mathrm{V})$ & 0.001 & millivolts $(\mathrm{mV})$ \\
\hline
\end{tabular}

Electrical conductivity $\sigma$ in siemens per meter $(S / m)$ can be converted to electrical resistivity $\rho$ in ohm-meters (ohm-m) as follows: $\rho=1 / \sigma$.

Electrical resistivity $\rho$ in ohm-meters (ohm-m) can be converted to electrical conductivity $\sigma$ in siemens per meter ( $\mathrm{S} / \mathrm{m})$ as follows: $\sigma=1 / \rho$. 



\title{
Geophysical Characterization of Subsurface Properties Relevant to the Hydrology of the Standard Mine in Elk Basin, Colorado
}

\author{
By Burke J. Minsley, Lyndsay B. Ball, Bethany L. Burton, Jonathan Saul Caine, Erika Curry-Elrod, and \\ Andrew H. Manning
}

\section{Abstract}

Geophysical data were collected at the Standard Mine in Elk Basin near Crested Butte, Colorado, to help improve the U.S. Environmental Protection Agency's understanding of the hydrogeologic controls in the basin and how they affect surface and groundwater interactions with nearby mine workings. These data are discussed in the context of geologic observations at the site, the details of which are provided in a separate report. This integrated approach uses the geologic observations to help constrain subsurface information obtained from the analysis of surface geophysical measurements, which is a critical step toward using the geophysical data in a meaningful hydrogeologic framework. This approach combines the benefit of many direct but sparse field observations with spatially continuous but indirect measurements of physical properties through the use of geophysics. Surface geophysical data include: (1) electrical resistivity profiles aimed at imaging variability in subsurface structures and fluid content; (2) self-potentials, which are sensitive to mineralized zones at this site and, to a lesser extent, shallow-flow patterns; and (3) magnetic measurements, which provide information on lateral variability in near-surface geologic features, although there are few magnetic minerals in the rocks at this site.

Results from the resistivity data indicate a general twolayer model in which an upper highly resistive unit, 3 to 10 meters thick, overlies a less resistive unit that is imaged to depths of 20 to 25 meters. The high resistivity of the upper unit likely is attributed to unsaturated conditions, meaning that the contact between the upper and lower units may correspond to the water table. Significant lateral heterogeneity is observed because of the presence of major features such as the Standard and Elk fault veins, as well as highly heterogeneous joint distributions. Very high resistivities (greater than 10 kiloohmmeters) are observed in locations that may correspond to more silicified, lower porosity rock. Several thin (2 to 3 meters deep and up to tens of meters wide) low-resistivity features in the very near surface coincide with observed surface-water drainage features at the site. These are limited to depths less than 3 meters and may indicate surface and very shallow groundwater flowing downhill on top of less permeable bedrock. The data do not clearly point to discrete zones of high infiltration, but these cannot be ruled out given the heterogeneous nature of joints in the shallow subsurface. Disseminated and localized electrically conductive mineralization do not appear to play a strong role in controlling the resistivity values, which generally are high throughout the site.

The self-potential analysis highlights the Standard fault vein, the northwest (NW) Elk vein near the Elk portal, and several polymetallic quartz veins. These features contain sulfide minerals in the subsurface that form an electrochemical cell that produces their distinct self-potential signal. A smaller component of the self-potential signal is attributed to relatively moderate topographically driven shallow groundwater flow, which is most prevalent in the vicinity of Elk Creek and to a lesser extent in the area of surface-water drainage below the Level 5 portal. Given the anomalies associated with the electrochemical weathering near the Standard fault vein, it is not possible to completely rule out downward infiltration of surface water and shallow groundwater intersected by the fault, though this is an unlikely scenario given the available data.

Magnetic data show little variation, consistent with the mostly nonmagnetic host rocks and mineralization at the site, which is verified by magnetic susceptibility measurements and X-ray diffraction mineralogy data on local rock samples. The contact between the Ohio Creek Member of the Mesaverde Formation and Wasatch Formation coincides with a change in character of the magnetic signature, though there is some ambiguity that is possibly because of variations in surficial deposits over portions of the Ohio Creek. Magnetic anomalies are associated with several, though certainly not all, mapped polymetallic veins, which may be related to the heterogeneous distribution of magnetic minerals at the site. 


\section{Introduction}

The Standard Mine in the upper Elk Basin, near Crested Butte, Colorado (fig. 1), was a precious-and base-metal mine initially established in the late nineteenth century. The deposit was intermittently mined from about 1880 through the mid1960s (Wood and Oerter, 2007). The Standard, Micawber, Elk, and several other mineral deposits in the upper Elk Basin are part of a network of epithermal, polymetallic quartz veins likely associated with Oligocene to Miocene intrusive activity in west-central Colorado (Gaskill and others, 1967; Ludington and Ellis, 1983; Obradovich and others, 1969; Thomas and Galey, 1982). The primary metals mined from the upper Elk Basin were silver, copper, lead, and zinc associated with a host of common sulfide minerals including galena, sphalerite, chalcopyrite, and pyrite (Wood and Oerter, 2007).

Throughout the intermountain west, metalliferous mineral deposits such as those found in the upper Elk Basin have caused both natural and mining-related surface and groundwater contamination. Because of mine-related contamination, the Standard Mine and the upper part of the Elk Creek watershed have been listed by the U.S. Environmental Protection Agency (USEPA) as one of about 27 Superfund sites in Colorado (U.S. Environmental Protection Agency, 2009). Elk Creek is a tributary to Coal Creek, which is a source of domestic water for Crested Butte. The Standard Mine drainage contributes dissolved and suspended concentrations of zinc, cadmium, lead, copper, and other metals into Elk Creek (Manning and others, 2007; U.S. Environmental Protection Agency, 2009; Wood and Oerter, 2007). Although many abandoned mines, adits, and prospects are found within and adjacent to the Elk basin, the Standard Mine is one of only a few that perennially drains significant amounts of water and as a result, has become a concern of local residents, downstream users, and the USEPA.

This report discusses the analysis of surface geophysical measurements collected in a continued effort to assist the USEPA in characterizing the geology of the upper Elk Basin and its surface and groundwater-flow systems (fig. 2 and fig. 3). We follow the nomenclature of Caine and others, (2010) that describe the main geologic structures at the sitethe Standard and Elk fault veins; the northwest Elk vein, which refers to the series of discontinuous veins that are north of, and subparallel to, the Elk fault vein; and several other polymetallic quartz veins located within the study area (fig. 3). The focus of the geophysical surveys primarily is on determining the physical characteristics of the near surface (approximately 20 meters) in the proximity of the Standard and Elk fault veins between mine Levels 3 and 5 .

Geophysical methods used in this study include: (1) electrical resistivity profiles aimed at imaging variability in subsurface structural properties and water content; (2) self-potentials, which are primarily sensitive to mineralized zones at this site, but also provide some information about shallow-flow groundwater patterns; and (3) magnetic measurements, which provide information on lateral variability in near-surface geologic features, although the minerals at this site are not strongly magnetized. Resistivity and magnetic measurement locations are mapped with a high accuracy Real Time Kinematic Global Positioning System (RTKGPS), whereas the self-potential measurement locations are mapped with a handheld GPS unit. The spatially dense surface geophysical results complement the direct geologic and borehole observations made by Caine and others, (2010) and are discussed in this context within this report.

Although the function of this report is primarily to present and describe the geophysical data, some speculative hypotheses regarding major geological controls on the surface and groundwater-flow systems are provided. An in-depth treatment of the geology, mineral deposits, mining history, groundwater and surface-water occurrence and geochemistry, various environmental issues, and key references related to the Standard Mine and upper Elk Basin can be found in Manning and others (2007). This report complements two other concurrent U.S. Geological Survey reports on the Standard Mine site (Caine and others, 2010; Verplanck and others, 2010) that present geologic observations and aqueous geochemistry data for mine waters.

\section{Site Background}

\section{Location, Ecosystem, and Climate}

The Standard Mine is located in the upper Elk Creek watershed (Elk Basin) in the Ruby Range between the Elk and West Elk mountains, about $6 \mathrm{~km}$ west-northwest of Crested Butte, Colorado (fig. 1). The watershed is in an alpine setting at about 3,290 to 3,720 meters (m) above sea level. Topographic gradients range from 0.2 to 0.6 and the watershed is approximately $2.6 \mathrm{~km}^{2}$ in size (fig. 2). Elk Basin is drained by the perennial Elk Creek that enters Coal Creek at the mouth of the watershed. The soils and surficial deposits are thin yet rich in organic matter with Tertiary sedimentary bedrock at or near the surface in most of the upper watershed. Conifers dominate the vegetation with mixed spruce and fir in the forest and subalpine tundra that covers much of the upper basin floor (fig. 4). Fauna are typical of subalpine environments in central Colorado with larger mammals including black bear, elk, deer, and mountain lions. Data from nearby meteorological stations indicate that Elk Basin has a mean annual air temperature of about $1{ }^{\circ} \mathrm{C}$ and mean annual precipitation of about 79 centimeters per year $(\mathrm{cm} / \mathrm{yr})$, approximately 65 percent of which is snow that typically covers the basin from November through May (Manning and others, 2007).

\section{Geological and Hydrological Overview}

Elk Basin is underlain by Upper Cretaceous and Tertiary fluvial and fluvial-lacustrine sedimentary rocks (fig. 3). During the Oligocene, a series of intermediate composition sills and 


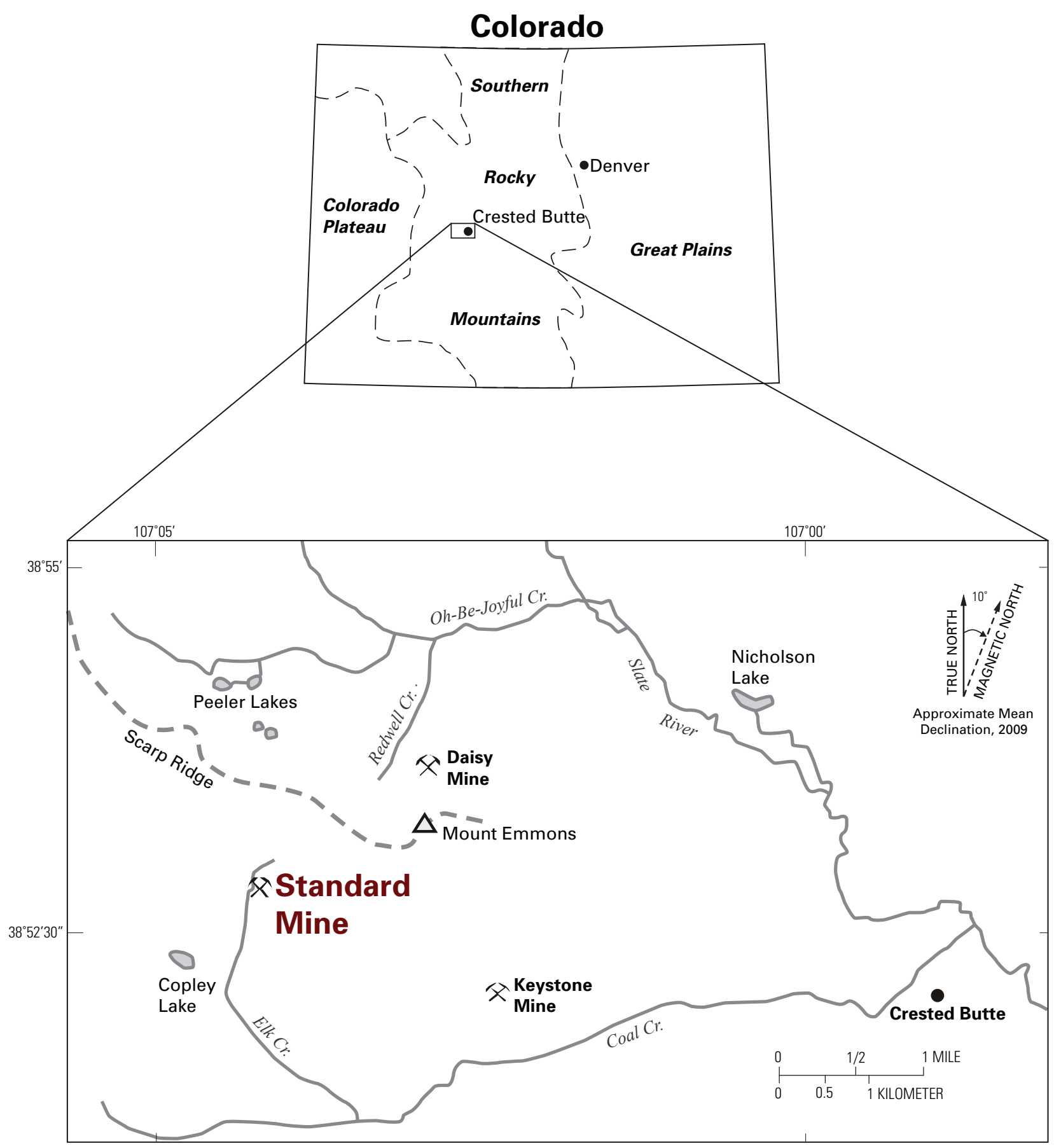

Figure 1. Location of the Standard Mine in the regional physiographic setting and local geographic setting. 


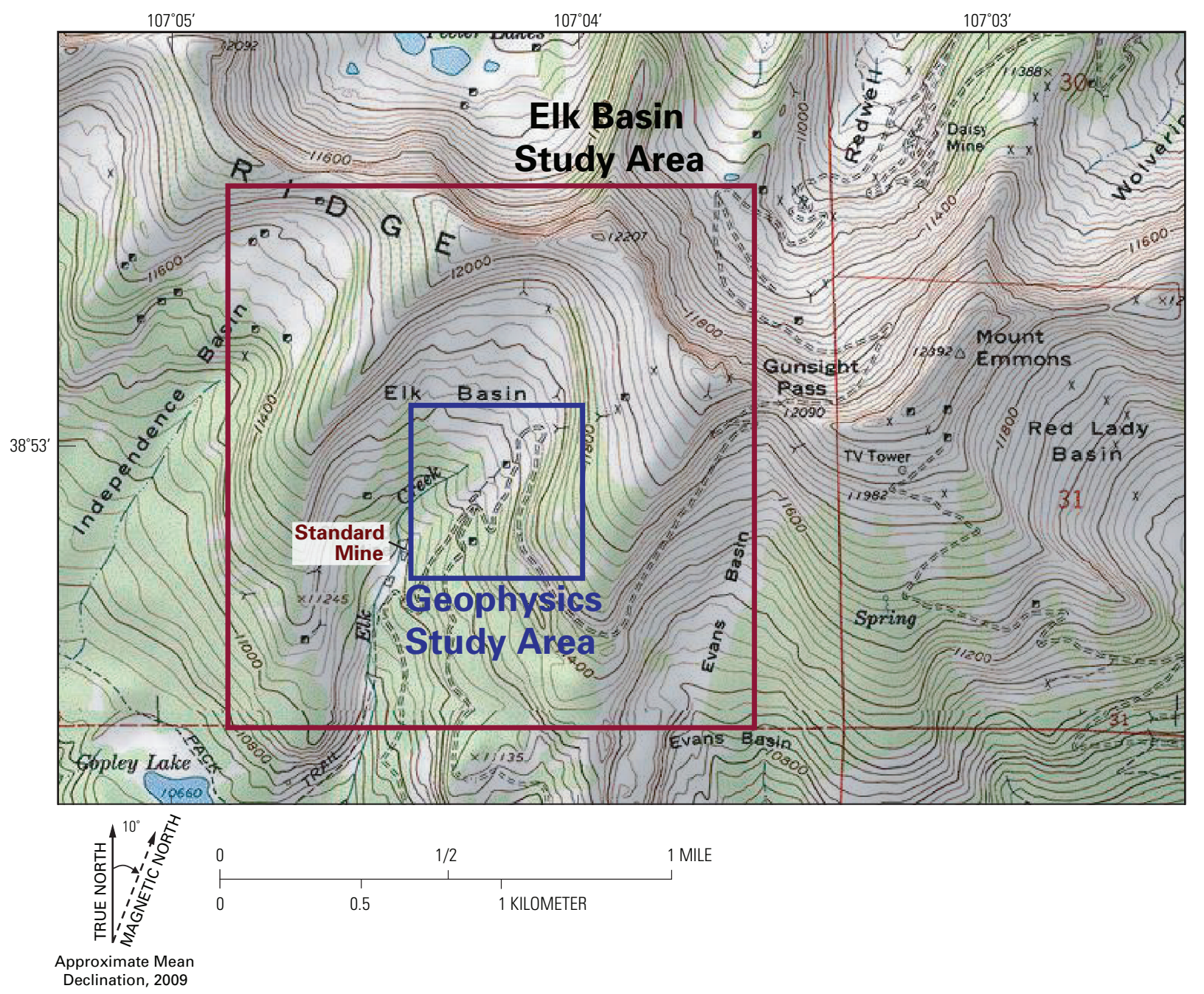

Figure 2. Elk Basin with geologic (red box) and geophysical (blue box) study areas. 


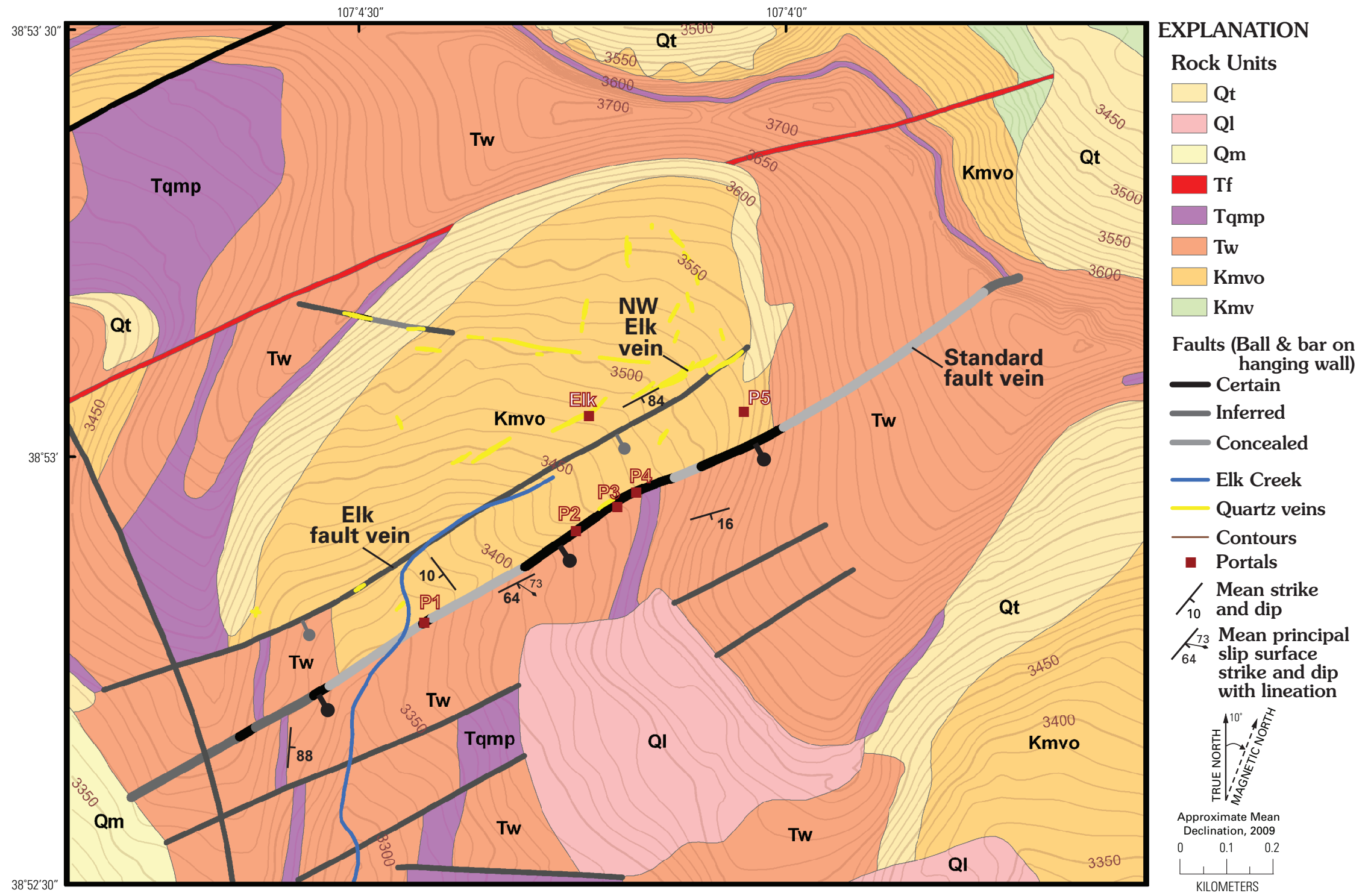

Figure 3. Reconnaissance geologic map of upper Elk Basin modified from Gaskill and others (1967), revised by Caine and others (2010). Qt, Quaternary talus deposit; Ol, Quaternary talus deposit; Qm, Quaternary glacial deposit; Tf, Tertiary felsite; Tqmp, Tertiary quartz monzonite porphyry; Tw, Tertiary Wasatch Formation; Kmvo, Ohio Creek Member of the Cretaceous Mesaverde Formation; Kmv, Cretaceous Mesaverde Formation. 


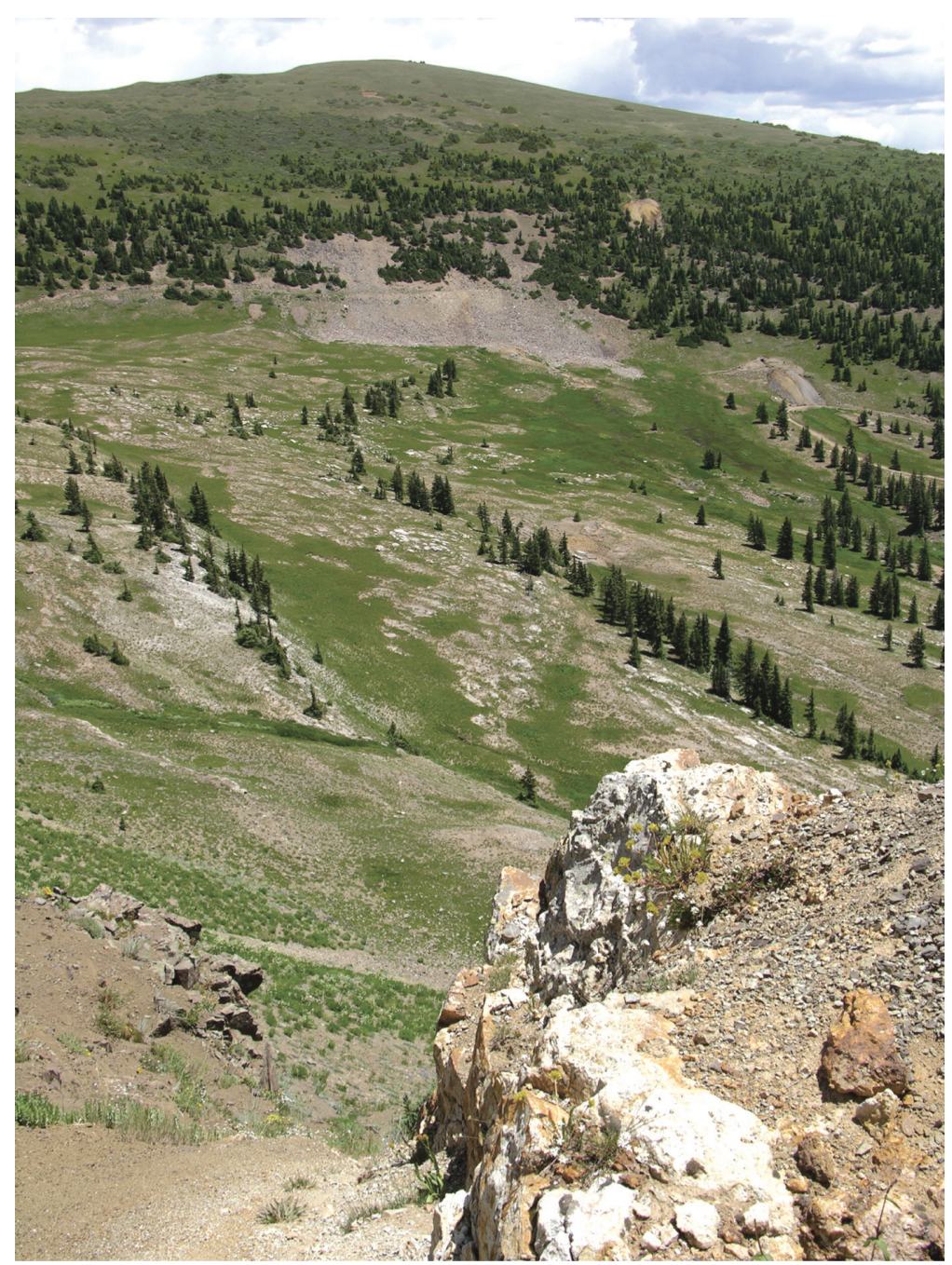

Figure 4. Photograph of upper Elk Basin looking east from the cirque ridge. The white rocks at the center base of the photograph are part of a fault vein mapped by Gaskill and others (1967). Stratigraphic and geomorphic benches can be seen on the floor of the cirque. The Level 5 portal and an upper adit of the Standard Mine also can be seen in the upper right hand side of the photo.

dikes intruded the sediments followed by intrusion of a Miocene felsic rhyolite plug and associated dikes in the Mount Emmons area (Gaskill and others, 1967; Obradovich and others, 1969; Thomas and Galey, 1982). Polymetallic mineral deposits and pervasive disseminated base metal mineralization are associated with these intrusive episodes (Ludington and Ellis, 1983). The Miocene and felsic intrusive activity just outside of Elk Basin is associated with significant molybdenum deposits not found in any significant abundance within the mines of Elk Basin (Sharp, 1978; Thomas and Galey, 1982). Intrusive activity likely occurred at relatively shallow depths of less than $3 \mathrm{~km}$, and caused volumetrically extensive but generally weak hydrothermal alteration.

Geomorphologically, the upper Elk Basin is a cirque. Other evidence for Quaternary glaciation and surface uplift include abundant glacial polish and striations on many outcrop pavements. Numerous small springs exist in the upper basin (Manning and others, 2007); many feed small perennial and ephemeral low-order streams that ultimately flow into the main stem of Elk Creek. Other than thin organic-rich soils, surficial deposits in Elk Basin are sparse but include a few small talus deposits as well as moraines and small landslide debris fields (fig. 3).

The Paleocene-Eocene Wasatch Formation (Tw) is the uppermost sedimentary bedrock unit. It is a well-indurated and complex series of ferromagnesian-silicate-rich, fine- to coarse-grained sandstones, siltstones, and mudstones, with thick lenses of conglomerate at the base and intermittently dispersed throughout. Given the relatively high iron content in these rocks and their deposition in a reducing environment with abundant organics, the rocks show a distinctive green color in outcrop. The Ohio Creek member of the Mesaverde Formation (Kmvo) formed during the Late Cretaceous and underlies the Wasatch Formation (Gaskill and others, 1967; Johnson and May, 1980). The Ohio Creek is made up of moderately to poorly indurated, aluminosilicate-rich sandstones, siltstones, shales, and carbonaceous shales, with massive pebbly sandstones and conglomerates near its base. The rich organic content in the Ohio Creek is indicative of deposition in a reducing environment; however, the distinct lack of iron-rich phases results in a distinctive light gray to beige color in many of the sand beds exposed in Elk Basin. Although not exposed in Elk Basin, the Wasatch and Ohio Creek are underlain by the main body of the Upper Cretaceous Mesaverde Formation (Kmv) composed of interbedded sandstone, shale, coal, and carbonaceous shale. The hydraulic properties such as porosity and permeability of these rocks currently are poorly defined. The elevation of the water table, degree of confined compared to unconfined conditions, the occurrence of localized perched groundwater, and the coincidence of topographic divides with groundwater divides also are all poorly understood in the watershed.

Geological structures in Elk Basin include joints, faults, veins, fault veins, dikes, sedimentary structures, and tilted sedimentary strata. These features, discussed in detail below, may to one degree or another control and (or) act as hydrological heterogeneities in the near surface and subsurface affecting the infiltration, storage, and flow of groundwater. The structural deformation, igneous activity, and metallic mineralization in the region occurred as part of the complex series of tectonic occurrences associated with the Laramide orogeny, its waning stages, and also possibly reflect processes 
associated with Rio Grande rifting to the south and east (Coogan and others, 2005). Although there are no absolute age constraints on the structures specifically in Elk Basin, Thomas and Galey (1982) point out that the Standard vein is part of a set of structures, including the Daisy and Keystone veins, that have radial symmetry about the rhyolite plug at Mount Emmons. This plug is associated with a $18-16$ Ma granite porphyry stock underlying the area (Sharp, 1978). Thomas and Galey (1982) also hypothesized that because igneous rocks have not intruded the faults, the faults did not predate or control the emplacement of the stock and associated mineralizing fluids. Although the radial symmetry of these veins is consistent with this hypothesis, there are a number of crosscutting age relations between joints, faults, veins, dikes, and other features that complicate a simple hypothesis which is beyond the scope of this report.

\section{Methods}

\section{Direct Current (DC) Resistivity}

Electrical resistivity, expressed in ohm-m, is an intrinsic material property that is defined by the electrical current that flows through an object because of an applied potential (voltage) difference, independent of the object geometry. The main factors that affect the resistivity of earth materials are: (1) the amount of interconnected pore water present; (2) the resistivity of the pore water, which is in turn related primarily to the water salinity; (3) the amount of mineralogical clay; and (4) the fraction of metallic minerals present. The combination of these factors results in a range of resistivities for typical earth materials that spans many orders of magnitude (fig. 5). While this dramatic contrast can be useful in delineating different lithologic units, there also is significant overlap between different materials, as well as variability for a single material, which can lead to ambiguity when interpreting resistivity values in a geologic context.

Most rock-forming minerals are insulators. The bulk resistivity of a volume of earth primarily is determined by the resistivity of the saturating water, as well as the amount and geometry of interconnected water within the volume, which is a function of both porosity (intergranular and fracture-related) and degree of saturation. Water resistivity (the reciprocal of conductivity) typically is expressed as a function of the concentration of various solutes in the water. Solutions with high concentration of dissolved solids typically have low resistivity (high conductivity). An empirical relation developed by Archie (1942) commonly is used to predict the resistivity of saturated geological materials and is represented graphically in figure 6A. This figure shows a rough estimate of predicted bulk-rock resistivity as a function of saturatingwater resistivity (or conductivity) and volumetric water content, which combines the effects of both porosity and saturation. Water resistivities in figure 6A are representative of the values recorded at the Standard Mine site (Manning and others, 2007). In general, higher resistivity values can be associated with: (1) the unsaturated (vadose) zone; (2) regions of low porosity or poorly connected pore space; and (3) regions saturated with relatively fresh waters. Note that figure $6 \mathrm{~A}$ is provided to represent approximate values and general trends for the resistivity of water-saturated rocks and specific values can vary for different rock types and geologic settings.

Additional factors that can affect the resistivity of a volume of rock are clay and ore content. Clays act to reduce the resistivity of a material because of surface conduction effects associated with the clay-mineral structure (for example,

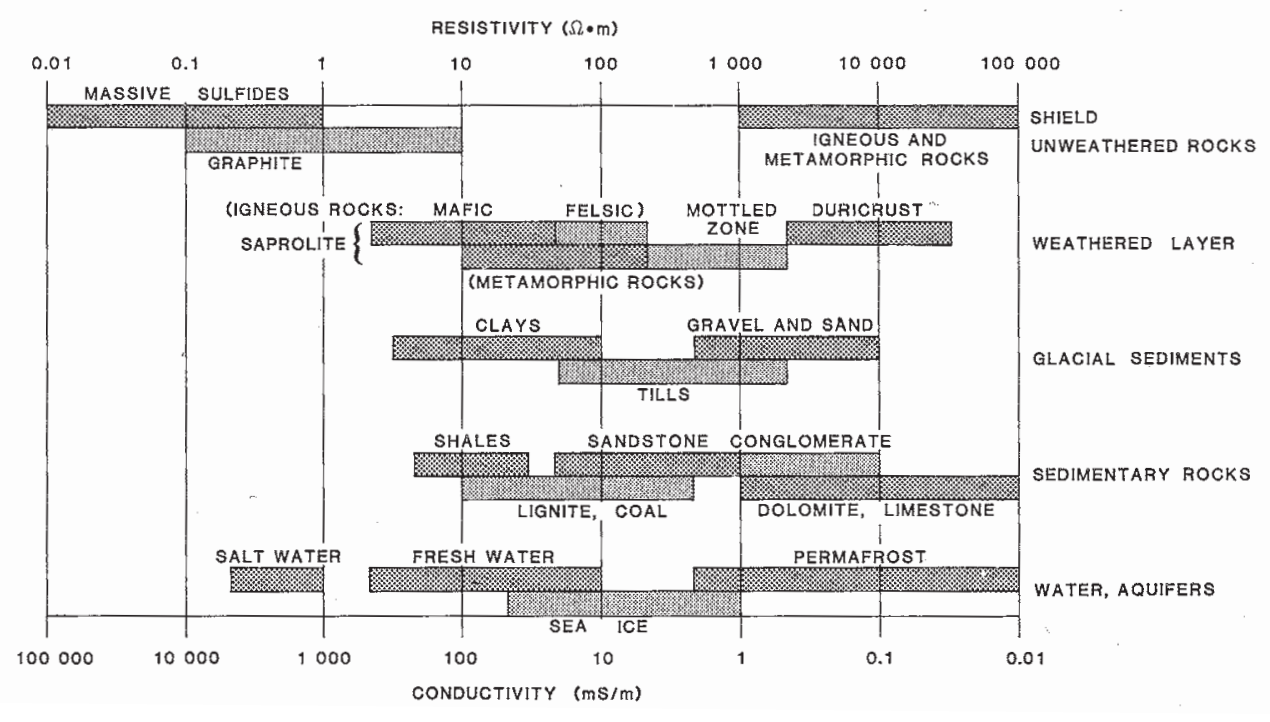

Figure 5. Typical resistivity ranges for common earth materials (reproduced from Palacky, 1987). 

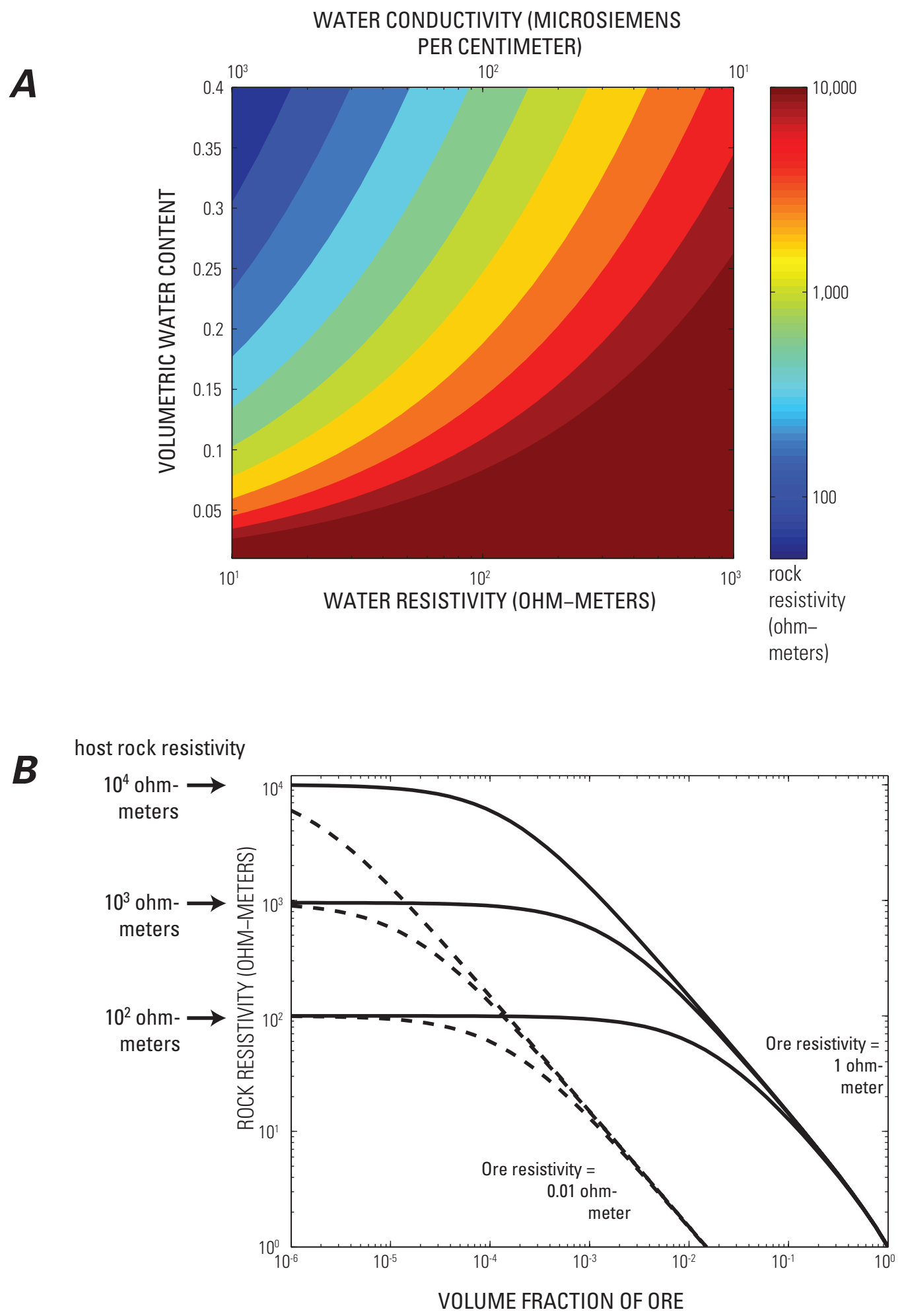

Figure 6. (A) Graphical representation of Archie's empirical law (Archie, 1942) showing the approximate values and trends of bulk electrical resistivity as a function of saturating-water resistivity and volumetric water content, which incorporates both porosity and saturation. The color scale is clipped at 10,000 ohm-meters. (B) Rock resistivity as a function of ore volume fraction for ore resistivity $1 \mathrm{ohm}$-meters (solid curves) and $0.01 \mathrm{ohm}$-meters (dashed curves). The three sets of curves represent host-rock resistivities of 100,1,000, and 10,000 ohm-meters. 
Keller and Frischknecht, 1966; Lesmes and Friedman, 2005). Ore minerals often have low resistivity values on the order of $1 \mathrm{ohm}-\mathrm{m}$ or less (Keller and Frischknecht, 1966; Telford and others, 1990), but are disseminated within host-rock material of higher resistivity. Figure 6B illustrates the effect of ore content on the bulk resistivity of a rock as a function of the volume fraction of ore minerals. Solid and dashed curves represent ore resistivity values of $1 \mathrm{ohm}-\mathrm{m}$ and 0.01 ohm-m, respectively. Different sets of curves are illustrated for host-rock resistivity values of $100,1,000$, and 10,000 $\mathrm{ohm}-\mathrm{m}$. Again, figure 6B is provided to illustrate the approximate trends that can be expected when conductive minerals are added to a host matrix, while actual resistivity values may vary from those in figure $6 \mathrm{~B}$ in more complex geologic settings.

While the wide variability of resistivity values in the earth can provide valuable information about the subsurface, there also are significant ambiguities that can complicate the interpretation of resistivity data in a hydrogeologic framework. For this reason, site-specific observations from Manning and others (2007) and Caine and others, (2010) are incorporated into the discussion of the resistivity data analysis.

\section{Data Acquisition}

Direct-current (DC) resistivity measurements are made by injecting a known current into the subsurface through two "transmitter" current electrodes and measuring the resulting voltage difference between two "receiver" electrodes. In two-dimensional surveys such as this one, an array of stainless steel electrodes spaced at regular intervals is placed in the ground (fig. 7), and many different combinations of transmitting and receiving electrodes are used. Information about lateral variability in the subsurface is gained as the measuring electrodes are translated across the array, while information about greater depths is obtained by increasing the separation between electrodes. Details about the practical aspects of resistivity surveying techniques can be found within existing literature (for example, Binley and Kemna, 2005; Reynolds, 1997; Telford and others, 1990).

An "inverse Schlumberger" array geometry is used for this survey, which allows for rapid data acquisition and provides a good balance between lateral and depth resolution. With this geometry, the four electrodes used for each measurement are symmetric about a central location, as depicted in figure 8 . For each central current pair, up to 22 differently spaced potential electrode pairs are used to gain depth information. An apparent resistivity value, which refers to the homogeneous earth resistivity that would produce the measured data, is calculated for each point from the injected current, measured voltage, and electrode geometry. Apparent resistivities are plotted at the center of the active four-electrodes, and at a "depth" equal to one half of the outer electrode spacing ( $\mathrm{L} / 2$ ). Images of the data presented in this form are called pseudosections and they are a conventional way to plot the data, but do not represent the true spatial distribution of resistivity values within the earth.

Resistivity data were collected using a SuperSting R8 resistivity/IP meter by Advanced Geosciences, Inc (AGI). This is an 8-channel multi-electrode resistivity meter that uses a command file to acquire measurements from predetermined current and potential electrode configurations. The resistivity meter is powered by two 12-volt batteries and is capable of injecting up to 2,000 milliamperes $(\mathrm{mA})$ of current into the ground. For this survey, transmitted currents were between 1 and $700 \mathrm{~mA}$, though over half of the values were less than $100 \mathrm{~mA}$. The relatively low injected current levels are typical in highly resistive environments such as this. Measurements were made over a period of 0.8 seconds, during which the polarity of the current electrodes is reversed in order to minimize electrode polarization effects and further improve contact resistance.

An initial array of 120 electrodes is laid out for each line. Each solid stainless steel electrode is about 45 centimeters $(\mathrm{cm})$ long and $1 \mathrm{~cm}$ in diameter. All electrodes are hammered into the ground as far as possible and then watered with a dilute saltwater solution to minimize electrical contact resistance between the electrode and the ground. High contact resistances can cause lower quality data because of greater difficulties in both injecting current into the ground and measuring accurate voltages. The observed contact resistances were variable at this site, ranging from approximately 1 to more than $9 \mathrm{kohm}$. A few areas with resistances greater than 10 kohm required the addition of a bentonite mud to the base of the electrodes to further decrease the contact resistance (typically 4 to $7 \mathrm{kohm}$ after the addition of bentonite). For lines longer than the initial 120 electrode layout, continuous profiles were collected by moving a group of electrodes from the start of the line to the end, also known as the "roll-along" method. Multiple roll-alongs of 24 electrodes each were done until the total desired line length was achieved.

Electrode locations along each line were positioned using a Leica GPS1200 RTKGPS. A base station is set up over an unknown position, and raw observational data are converted to receiver independent exchange format and submitted to the National Geodetic Survey's Online Positioning User Service (OPUS) to determine the base station true location, including elevation. The rover GPS data, then are corrected using the OPUS base station location solution, with typical overall positional accuracies of approximately 5 to $10 \mathrm{~cm}$.

\section{Data Processing}

Forward modeling and inversion are mathematical techniques that are used to recover a subsurface resistivity model from the recorded data, which consists of measured voltage and injected current values, as well as the down-line locations and elevations of the four electrodes used for each measurement. Forward modeling refers to the process of predicting the data that would be measured from a given resistivity model, and is based on the physics of electrical current flow 


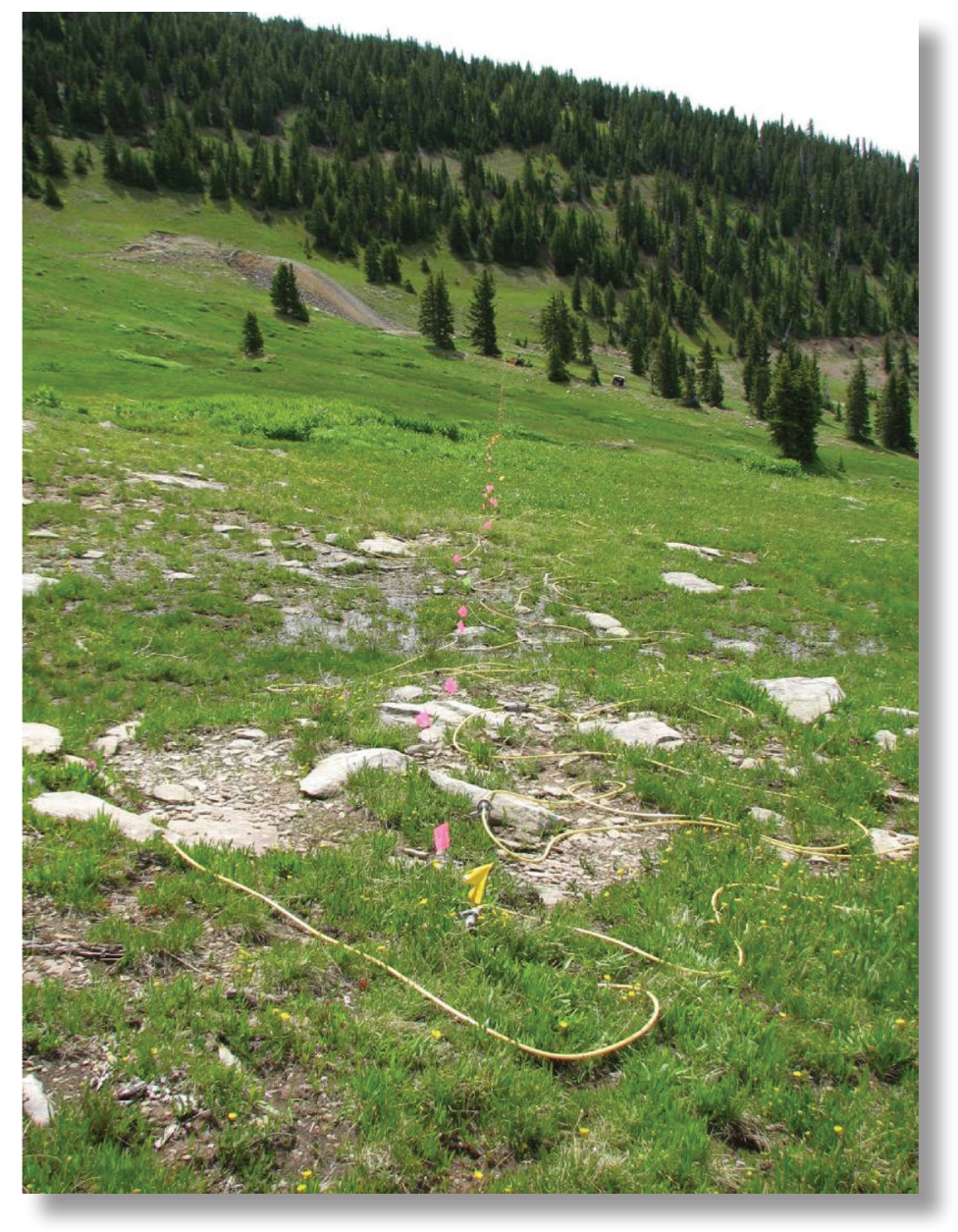

Figure 7. Elk Basin, looking southeast along resistivity line 4 towards the Level 5 portal. Electrodes are placed at 1.5-meter intervals.

in resistive media. The forward modeling process is well posed; that is, there is a unique set of predicted data for a given resistivity model. Inversion, on the other hand, refers to the derivation of a resistivity model from the measured data. Resistivity inversion is non-unique and there are many models that are consistent with the measured data. To overcome this problem, additional user-specified constraints are placed on the model, which require it to be smooth and (or) close to a reference model. These additional constraints often incorporate reasonable prior geologic information and produce more stable inversion results. A detailed discussion of the resistivity inverse problem is widely available in the published literature (Binley and Kemna, 2005; Loke and Barker, 1996; Oldenburg and Li, 1994; Zhang and others, 1995).

The data were inverted using AGI's EarthImager 2D ver. 2.3.3 build 586 (Advanced Geosciences Inc., 2008) using the "robust" inversion method, which performs well on noisy data sets because it is based on the assumption of an exponential distribution of data errors. Topographic information was incorporated into the inversion in order to account for the affect of the irregular earth surface on the distribution of subsurface electrical currents, which is an important step towards determining a more accurate subsurface resistivity model. The inversion process seeks to find the subsurface distribution of resistivity values that: (1) produce modeled data that match the measured data within an acceptable tolerance; (2) satisfy constraints that the model is both smooth and close to a userspecified reference model; and (3) is as simple as possible.

Inversions start from a homogeneous resistivity model (simplest possible), then are iteratively updated to produce more complex heterogeneous models that have improved data misfit. The inversions were allowed to run for a maximum of 10 iterations with a stop criteria of 6 percent or less root-mean-square (RMS) error between the measured and forward modeled data, or an L2-norm (sum of squares) value of one or less for the error-weighted data misfit. If neither of the stopping criteria are met after reaching the end of the tenth iteration, noisy data points are removed by eliminating 


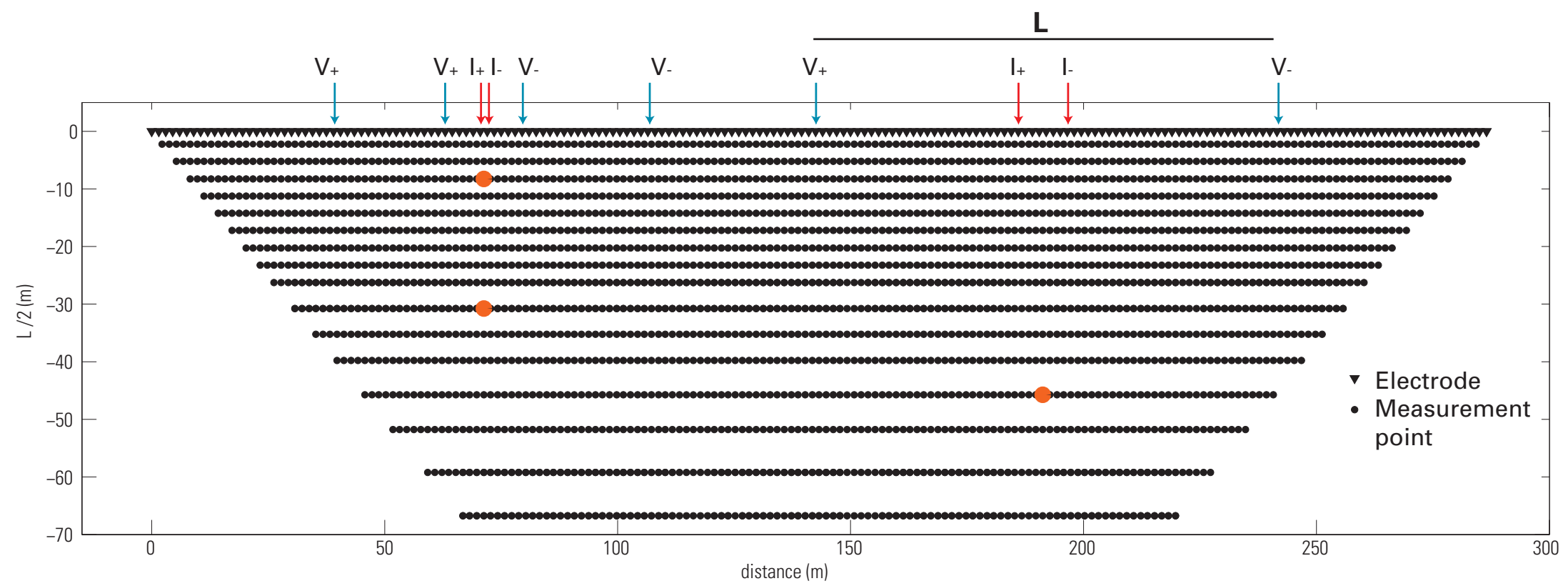

Figure 8. Two-dimensional electrical resistivity acquisition diagram: Each point represents a four-electrode measurement, and is plotted at the center of the four electrodes, at a "depth" equal to one half (L/2) of the outer electrode spacing (L). The colored points illustrate the plot points for three different current (I) and voltage (V) electrode combinations. Note that the vertical scale is not equal to the horizontal scale in this figure. 
measurements that have the poorest data misfit. Multiple inversions are run with various reference models, data errors, and smoothing parameters in order to get a sense for the robustness, or stability, of the model results.

\section{Self-Potential}

The self-potential method measures the naturally occurring electrical potential (voltage) on the earth surface. Selfpotentials are somewhat unique among geophysical methods in that they are sensitive to active processes in the subsurface, in contrast with methods such as resistivity that are sensitive to physical properties. There are several mechanisms that can generate self-potential signals and two mechanisms that are relevant to the Standard Mine site are groundwater flow and electrochemical reactions. In cases such as this where there are multiple possible sources to the self-potential signal, it can be difficult to independently determine the primary source components from the data.

In the case of groundwater flow, an excess positive charge that develops near grain surfaces in saturated porous geologic media is transported along with the water, creating a streaming electrical current density. This subsurface electrokinetic phenomenon generates a balancing conduction current density, which flows through the earth resistivity structure and is manifested as the measurable self-potential on the earth surface (Ishido and Mizutani, 1981; Morgan and others, 1989; Revil and others, 1999; Sill, 1983). The degree of coupling between fluid and electrical flows varies with fluid and rock chemistry, but is generally such that the electrical potential gradient is in the opposite direction of the hydraulic gradient. That is, increasingly positive self-potentials typically are measured in the direction of fluid flow (or decreasing hydraulic head). In mountainous terrain where flow is topographically driven, this corresponds to increasingly negative self-potentials in the uphill direction.

This concept is illustrated in figure 9 , which shows the expected character of measured self-potential signals when: $(A)$ groundwater flow is topographically driven, resulting in a self-potential trend that is opposite to the hydraulic gradient; $(B)$ topographically driven groundwater flow is intercepted by a fault zone that directs groundwater downwards, resulting in a negative self-potential anomaly superimposed on the overall trend; and $(C)$ upflow within the fault zone results in a positive self-potential anomaly superimposed on the topographic trend. These fault-zone conceptualizations are consistent with those presented by Caine and others (2010), where the fault primarily is a barrier to flow across the feature but allows fault-parallel flow. It is important to remember that lateral flow along a fault also is possible, particularly in cases such as the Standard fault vein where the hydraulic gradient may be at an angle to the fault strike. In this case, the general rule of increasingly positive self-potentials in the direction of flow still applies.

A second mechanism for the generation of self-potential signals is electrochemical and is frequently associated with the presence of sulfide mineralization. The details of this phenomenon were developed by Sato and Mooney (1960), and have since been widely discussed in the literature (Hamilton, 2000; Sivenas and Beales, 1982a, b). The basic concept is illustrated in figure 10 where an ore zone that spans a background redox gradient in the subsurface creates a shortcircuited electrochemical cell that drives the flow of electrical currents in the host rock. This results in measurable selfpotentials on the earth surface as these currents traverse the earth resistivity structure.

The background redox potential, which generally decreases with depth in the earth, is the driving force behind this mechanism, resulting in the upper end of the ore acting as the cathode and the lower end as the anode. Electrical currents flow through the host rock in order to balance the currents within the ore zone. Because the redox field typically decreases with depth, often controlled by the diffusion of oxygen, the orientation of the electrochemical cell predominantly is such that the cathode is at the upper extent, resulting in negative self-potentials observed over mineralization, as depicted in figure 10. This is sometimes referred to as the "geobattery" model, as it is analogous to a battery naturally discharging within the earth.

Electrochemical self-potentials of this nature are relatively stable over time, to the extent that the driving background redox field remains unchanged. The magnitude of selfpotentials over mineralization can reach up to approximately -700 millivolts $(\mathrm{mV})$. Factors that increase the magnitude of self-potentials include ore zones which: (1) have low internal electrical resistance; (2) extend vertically across a strong redox contrast such as the water table; and (3) exist close to the ground surface (Sato and Mooney, 1960). In contrast, selfpotentials associated with groundwater flow often are on the order of $100 \mathrm{mV}$ or less, though very large anomalies on the order of 1,000 $\mathrm{mV}$ have been measured in volcanic areas with strong topography and hydrothermal circulation (Fournier, 1989; Revil and others, 2004).

One complicating factor at the Standard Mine site is the potential superposition of flow- and electrochemical-related self-potential mechanisms. In the case where a zone of mineralization intersects groundwater flow (such as portions of the Standard or Elk faults), the combination of a negative anomaly due to electrochemical effects (fig. 10) with the trend due to downhill groundwater flow (fig. 9A) can produce a net signal that is indistinguishable from the case of downhill groundwater flow being intercepted by the fault (fig. 9B). In fact, it is possible that all three components of the signal can be present if the mineralized zone exhibits such conduit-barrier behavior. Therefore, it is important to keep these factors in mind when interpreting the self-potential data, and use other sources of information to help deduce the most likely hydrogeologic scenario. 

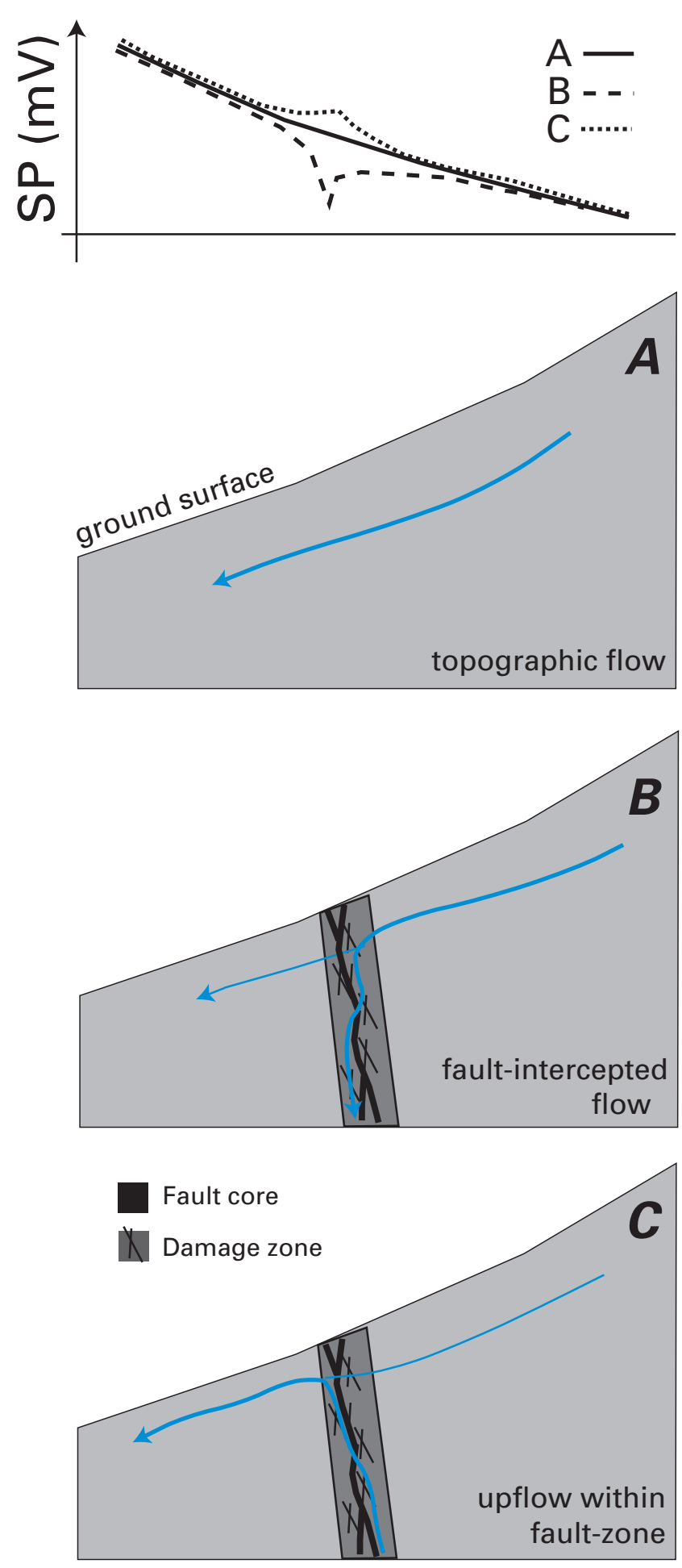

Figure 9. Conceptual model of self-potential signals related to groundwater flow. $(A)$ Topographically-driven flow: the self-potential gradient is opposite the hydraulic gradient. $(B)$ Topographically-driven flow intercepted by a fault: downward flow into the fault zone produces a negative self-potential anomaly superimposed on the background curve. $(C)$ Upward flow within the fault zone produces a positive self-potential anomaly superimposed on the background curve.

\section{Data Acquisition}

Self-potentials are measured by recording the electrical potential difference between non-polarizing electrodes placed at various points on the ground surface using a high impedance $\left(>10^{7} \mathrm{ohm}\right)$ voltmeter. Lines of data are acquired by measuring the potential difference between a fixed reference electrode and a roving electrode that is connected to a long (approximately $1 \mathrm{~km}$ ) spool of wire. This results in a profile of voltage versus distance along the line relative to the reference electrode. Large areas can be covered using multiple lines of data, which must be tied together to recover the self-potential at any location relative to a single survey-wide reference point (Corwin, 1990). Maps of self-potential values are then plotted relative to this survey-wide reference, which is assigned a value of zero volts.

Non-polarizing lead/lead chloride Petiau electrodes (Petiau, 2000) were used for all self-potential measurements. At each station, three shallow holes (approximately $10 \mathrm{~cm}$ ) were dug to obtain good electrical contact with the earth. Five self-potential measurements were recorded in each of the three holes, for a total of 15 measurements per station, using an Agilent U1252A digital voltmeter and laptop computer with data-logging software. Each station was assigned a unique identifier to facilitate further processing and locations were recorded with a handheld GPS unit.

Sources of noise during a self-potential survey often are anthropogenic, such as grounded power lines, buried metallic structures, or cathodic protection systems, though these are not present at the Standard Mine site. Natural sources of noise include variable electrode contact and background telluric fields. Poor electrode contact with the ground can cause spurious measurements, and can be minimized by careful electrode placement. Telluric fields refer to electric currents that flow through the earth because of fluctuating currents in the ionosphere. These earth currents are associated with an electrical potential field as they traverse the earth-resistivity structure, and often exhibit a diurnal variability that can reach magnitudes on the order of $10 \mathrm{mV} \cdot \mathrm{km}^{-1}$ (Telford and others, 1990), but often are much smaller. For surveys such as this one that cover a distance of less than $1 \mathrm{~km}$, telluric corrections typically are unnecessary and were not made.

\section{Data Processing}

The raw self-potential data consist of measurements of the electrical potential between the base electrode and roving electrode for each line, as well as electrode drift measurements at the beginning and end of each line. These data are processed to produce a unique map of the electrical potential at every station relative to a survey-wide reference location, which is assigned a value of zero $\mathrm{mV}$. Measurements taken at locations where two lines intersect are critical in producing the final self-potential map because these data provide information about the relative levels between lines needed to tie all of the individual data together. The final map is generated using 

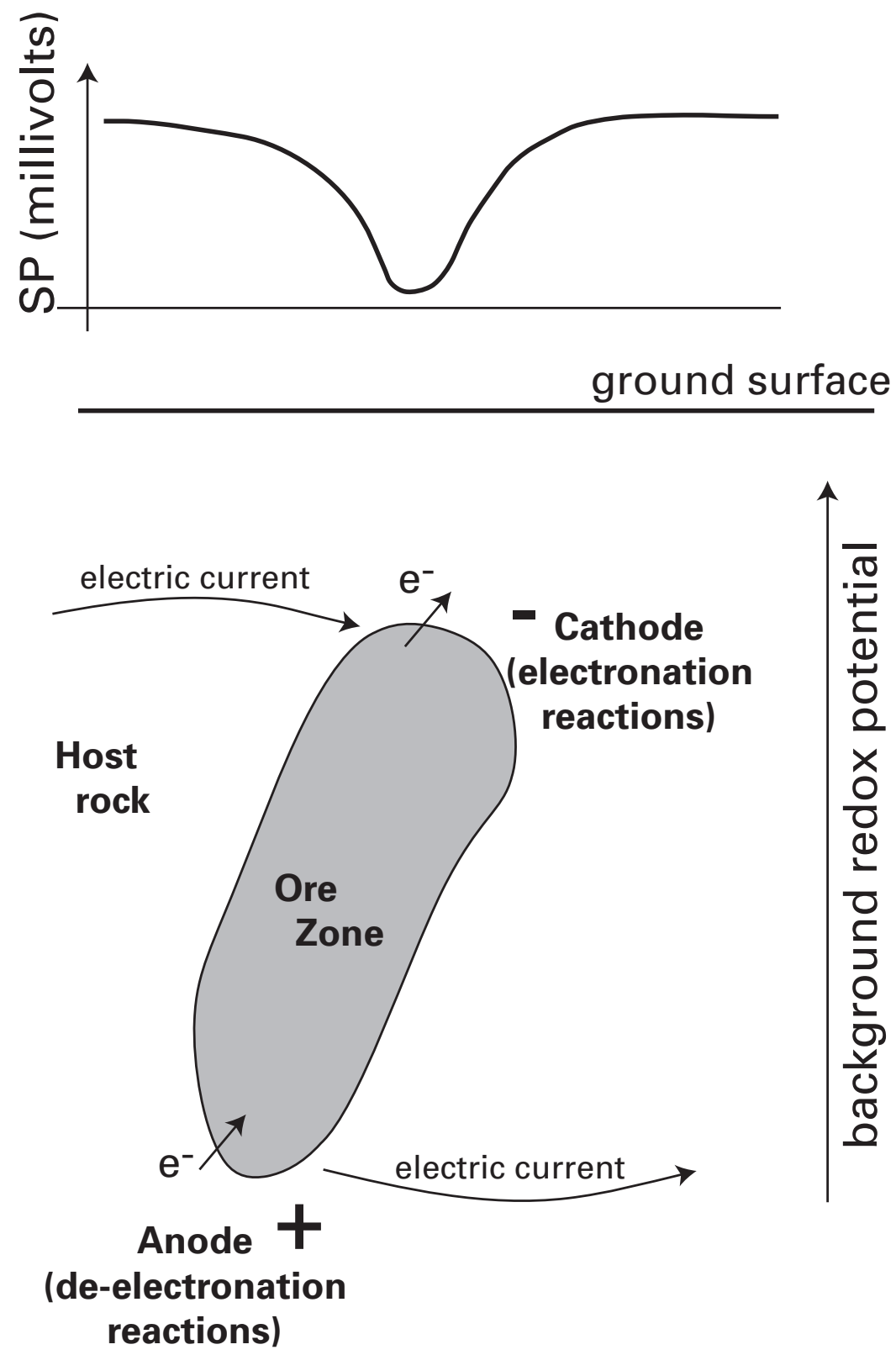

Figure 10. Conceptual model of self-potential signals related to an electrochemical cell generated by the presence of an ore zone embedded within a naturally-existing redox gradient in the earth (adapted from Castermant and others, 2008; Minsley, 2007; Sato and Mooney, 1960). 
the procedure discussed in more detail by Minsley and others (2008), which produces a smoothly varying self-potential map that honors: (1) measurements along each line; (2) errors estimated from the 15 measurements at each station; (3) electrode drift corrections; (4) a unique potential value at line intersection points; and (5) Kirchhoff's law, which requires that the total potential drop along any closed loop equal zero.

\section{Magnetics}

The magnetic method uses Earth's magnetic field to measure variations in the magnetic properties of the surface and subsurface. Field measurements, typically referred to as total magnetic intensity or total field measurements, are scalar sums of several vector magnetic field sources. The sources include: (1) the ambient geomagnetic field created by convection currents in Earth's outer core; (2) the time-varying fields created by the interaction of charged particles from the sun with the geomagnetic field in the ionosphere; and (3) the magnetic fields of the surrounding geologic units induced by the presence of magnetic minerals. The geomagnetic field is a vector quantity that varies in direction and magnitude across Earth and is the largest component of the total field measurement. From the magnetic equator to the poles, the geomagnetic field ranges from about 25,000 to 65,000 nanoTeslas (nT), the unit for magnetic induction. The field induced by solar activity, such as solar wind or sunspots, typically has a total amplitude range of $60 \mathrm{nT}$ with a relatively smooth daily, or diurnal, period. The measured magnetic field of geologic units is the desired component of the total field measurement and is dependent on the composition, abundance, orientation, and grain size of magnetic minerals present in the study area and can have amplitude ranges from a few tens of nT to greater than 1,000 nT over a survey site (Hansen and others, 2005).

The most prevalent magnetic mineral is magnetite, a ferrous and ferric iron oxide mineral, but there are many other magnetizable minerals that contribute to the measured total field, the majority of which are iron bearing. A measure of the abundance of magnetic minerals in a volume of rock is known as bulk magnetic susceptibility. Magnetic susceptibility is a material property that describes the extent to which that material may be magnetized in the presence of an applied magnetic field. It is a dimensionless quantity that is the ratio of the induced magnetization of a sample to the magnitude of Earth's magnetic field. Materials with higher concentrations of magnetic minerals typically will have higher absolute susceptibility values. Generally, igneous and metamorphic rocks have larger magnetic susceptibilities than sedimentary rocks. Susceptibility ranges in sedimentary rocks and unconsolidated materials are highly dependent on depositional environments, source rock types and distances, and secondary processes such as diagenesis, weathering, and regional or hydrothermal fluid flow that can alter magnetic minerals (Hansen and others, 2005; Reynolds, 1997). Figure 11 shows typical magnetic susceptibility value ranges in the International System of Units
(SI) for several rock types and unconsolidated sediments, and susceptibility values for several individual minerals are shown in table 1. Hansen and others (2005), Reynolds (1997), Reynolds and others (1990), and Clark (1997) provide more detailed descriptions of the magnetic method and additional magnetic susceptibility values for common geologic materials.

\section{Data Acquisition and Processing}

The ground magnetic survey of the Standard Mine site was conducted using a Geometrics G-858 cesium-vapor magnetometer in vertical gradiometer mode. Two sensors were vertically spaced $0.8 \mathrm{~m}$ apart and positioned parallel to one another in an orientation that achieved the maximum field signal strength. The bottom and top sensors were nominally $0.35 \mathrm{~m}$ and $1.15 \mathrm{~m}$ above the ground, respectively. The magnetometer was integrated with a Leica GPS1200 RTK GPS for positioning of the magnetic data. The magnetic and GPS data were acquired at $10 \mathrm{hertz}(\mathrm{Hz})$ and $1 \mathrm{~Hz}$ sample rates, respectively. During data acquisition with the roving gradiometer, a stationary GEM Systems GSM-19 Overhauser base station magnetometer measured the ambient field and diurnal variations. Measurements were acquired at a $0.33 \mathrm{~Hz}$ sample rate, which is the fastest sample rate possible for this unit.

After data download, the gradiometer data positions were corrected based on the GPS base station OPUS solutions. Obvious data spikes and dropouts in the gradiometer data are considered noise and were removed. A 60-point (3-minute) low-pass filter was applied to the magnetic base station data to remove high-frequency data scatter. Using the time stamps in the data from both magnetometers, the filtered base station data were interpolated to a $10 \mathrm{~Hz}$ sample rate and subtracted from the gradiometer data. This process removes both the ambient field and diurnal variations, with the resultant data showing only variations due to the local surroundings.

Additionally, magnetic susceptibility measurements were made on 22 rock samples collected from the site (Caine and others, 2010) using a handheld Geofyzika SM-20 magnetic susceptibility meter. Three individual measurements were taken on each sample and averaged. The rock samples are from the various geologic units in the study area and sample different fault zone architectural components.

\section{Observations and Data}

\section{Resistivity}

Five resistivity profiles were acquired in the vicinity of the Standard and Elk fault veins between Standard Mine Levels 2 and 5 (fig. 12). Lines are numbered in the order in which they were acquired. Lines 1 through 4 are oriented northwest-southeast, perpendicular to the strike of the Standard and Elk fault veins. These lines were extended to the northwest far enough to capture the Elk fault vein, though 


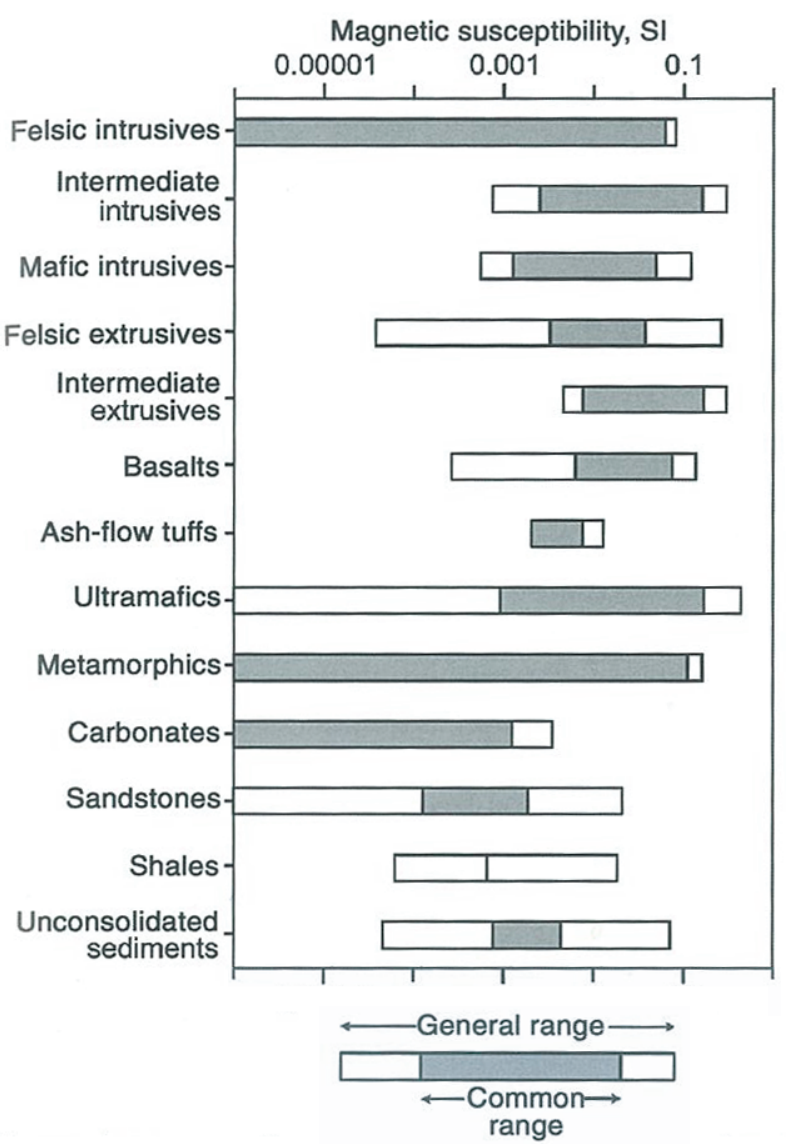

Figure 11. Ranges of magnetic susceptibility values for various rock types (reproduced from Hansen and others, 2005).

Table 1. Magnetic susceptibilities of selected minerals (from Telford and others, 1990).

\begin{tabular}{lc}
\hline Mineral & Magnetic susceptibility $\mathbf{x} \mathbf{1 0}^{\mathbf{3}} \mathbf{( S I )}$ \\
\hline Sphalerite & $\approx 0.7$ \\
Pyrite & 0.05 to 5 \\
Hematite & 0.5 to 35 \\
Pyrrhotite & 1 to 6,000 \\
Ilmenite & 300 to 3,500 \\
Magnetite & 1,200 to 19,200 \\
\hline
\end{tabular}

line 2 ends where it approaches the Elk portal. They were not extended farther to the southeast because the steep topography complicated the deployment of electrodes in this area. Line 5 is oriented northeast-southwest between the Standard and Elk fault veins, starting near the Level 5 portal and intersects lines 1 through 4 at roughly 90 degrees.

The acquisition parameters for these lines are summarized in table 2 and the "inverse Schlumberger" electrode geometry, discussed previously, was used for all five lines. The nominal electrode spacing of $1.5 \mathrm{~m}$ was chosen to provide good near-surface resolution and a total depth of investigation of approximately $20-25 \mathrm{~m}$. Each measurement consisted of two cycles, and during each cycle the polarity of the injected current was alternated three times over a period of $0.8 \mathrm{~s}$.

Electrode locations were recorded with a Leica GPS unit to provide accurate coordinates and elevations needed for inverting the data. Each line of data, which consists of several thousand measurements (table 2), was inverted independently using the EarthImager 2D (Advanced Geosciences Inc., 2008) software discussed previously. Pseudosections that represent the measured data as well as data predicted by the final inversion model are provided in the Appendix (fig. 26 through fig. 30).

Final inverted resistivity sections are presented in figures 13-18, and are overlaid with the geologic information from Caine and others, (2010) using standard cross-section methods. Average strike and dip values collected in Elk Basin were used to depict bedding, the fault veins, and veins (see Caine and others, 2010, for data). Bedding dip angles were corrected for proper orientation in the plane of each section, however variations in bedding orientations and the locations of any particular bed in each section are schematic. The vertical extent of the veins is schematic, however the Standard fault vein is well constrained from underground inspection. The horizontal scale is equal to the vertical scale, and the resistivity scale is the same for all cross sections. The geologic map shows the location and orientations of each section line, and coordinates are annotated in Universal Transverse Mercator (UTM) Zone 13North meters. Specific features of hydrogeologic relevance are discussed below each image.

Where wells are close to the resistivity lines (within approximately $20 \mathrm{~m}$ ), their location is projected onto the resistivity section based on the shortest distance from the well to the line. Given the steep and irregular topography, this can result in some mismatch between observed water levels in the wells and water levels inferred from the resistivity data, particularly in locations with significant subsurface heterogeneity. For this reason, the match between observed and inferred water levels should be interpreted somewhat qualitatively.

In general, the inverted resistivity values are high, with values ranging between approximately $50 \mathrm{ohm}-\mathrm{m}$ and several tens of thousands of ohm-m. Because it is difficult to distinguish very large resistivity values from one another, the inverted images are clipped at a value of 5,000 ohm-m. The extremely high resistivity values typically are associated with exposed quartz veins and the slope heading uphill to the 


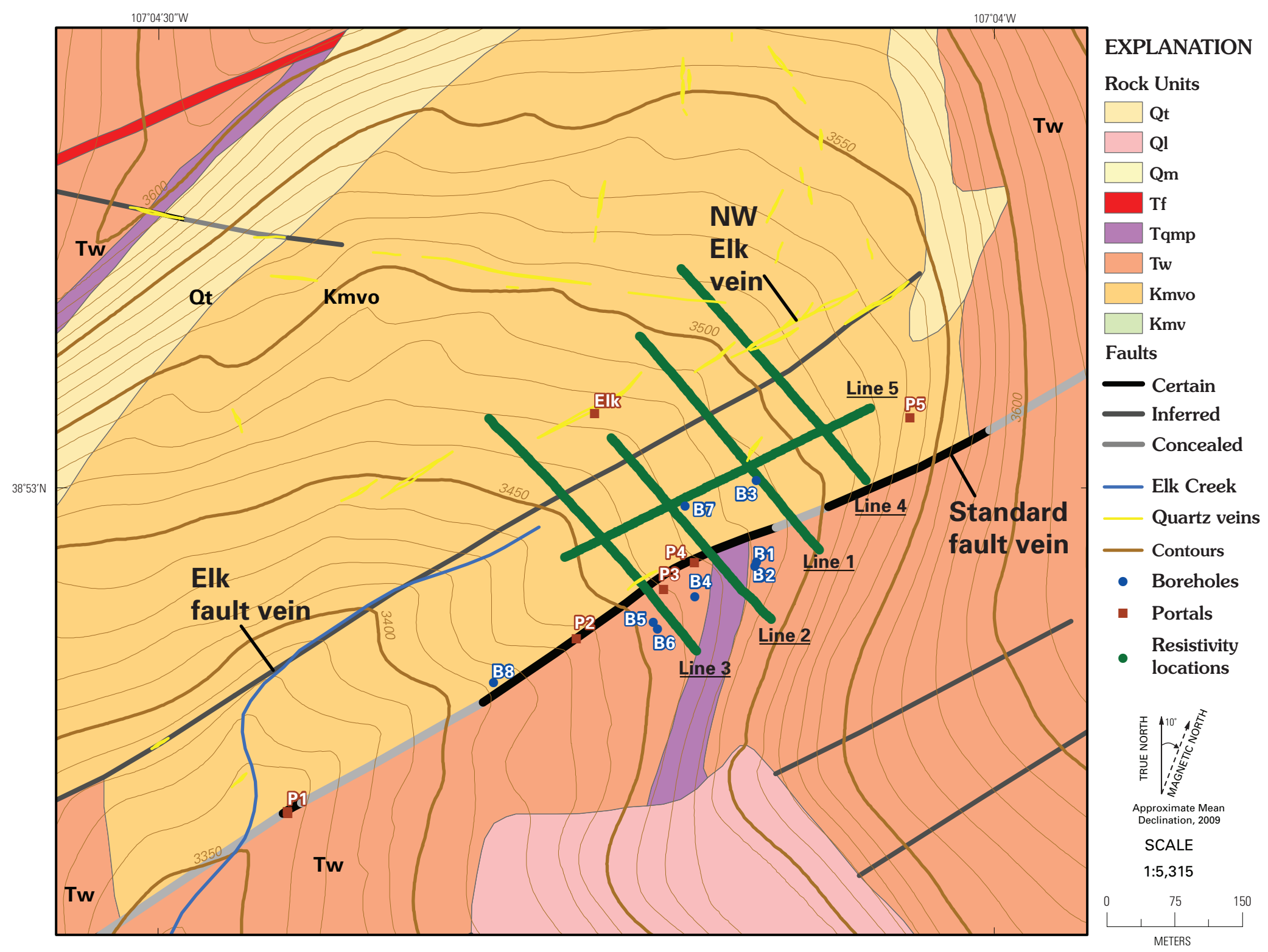

Figure 12. Location of direct current resistivity profiles superimposed on the reconnaissance geologic map by Caine and others (2010). Qt, Quaternary talus deposit; $\mathrm{Ol}$, Quaternary talus deposit; $\mathrm{Qm}$, Quaternary glacial deposit; Tf, Tertiary felsite; Tqmp, Tertiary quartz monzonite porphyry;

Tw, Tertiary Wasatch Formation; Kmvo, Ohio Creek Member of the Cretaceous Mesaverde Formation; Kmv, Cretaceous Mesaverde Formation. 
Table 2. Summary of direct current resistivity survey acquisition parameters.

\begin{tabular}{|c|c|c|c|c|c|c|}
\hline Line number & 1 & 2 & 3 & 4 & 5 & Total \\
\hline Acquisition direction & NW-SE & NW-SE & NW-SE & NW-SE & NE-SW & \\
\hline Line length (m) & 286.5 & 250.5 & 322.5 & 286.5 & 322.5 & $1,468.5$ \\
\hline Number of electrodes & 192 & 168 & 216 & 192 & 216 & 984 \\
\hline Electrode spacing (m) & \multicolumn{6}{|c|}{1.5} \\
\hline Array type & \multicolumn{6}{|c|}{ Inverse Schlumberger } \\
\hline Measurement time (s) & \multicolumn{6}{|c|}{0.8} \\
\hline Number of current cycles & \multicolumn{6}{|c|}{2} \\
\hline Number of measurements (after editing) & 3,110 & 2,643 & 3,560 & 3,119 & 3,683 & 16,115 \\
\hline
\end{tabular}

southeast of the Standard fault vein. Only a few locations have resistivities below $100 \mathrm{ohm}-\mathrm{m}$; therefore, the low end of the resistivity images is clipped at $250 \mathrm{ohm}-\mathrm{m}$.

To first order, the resistivity sections are consistent with a two-layer model in which the upper layer is the more resistive unit. Superimposed on this basic pattern are: (1) several steeply dipping highly resistive features often associated with polymetallic quartz veins; (2) steeply dipping low-resistivity features that coincide with the Standard fault; and (3) nearsurface subhorizontal low-resistivity zones that likely are associated with shallow perched zones of high saturation. Some lateral resistivity variability also may be associated with localized changes in porosity possibly related to silicification or variations in joint intensity.

The effect of conductive minerals within the host rock, such as disseminated pyrite as well as localized polymetallic vein minerals associated with the Standard and Elk fault veins, cannot be dismissed. Conductive minerals likely play some role in reducing the observed resistivity, as shown in figure $6 \mathrm{~B}$, and may be a contributing factor for the observed heterogeneity in the resistivity sections. However, the general absence of resistivity values below $100 \mathrm{ohm}-\mathrm{m}$ suggests that the volume fraction of conductive minerals is low and the influence of such minerals is minor. This assumption also is supported by the mineralogy data presented by Caine and others (2010), which indicate weight percentages of metalbearing minerals generally less than one percent (and often below detection limits).

The following sections present the inverted resistivity models, starting with the northeast-southwest oriented line, then proceeding from northeast to southwest for the remaining four parallel lines. Line numbers refer to the order in which the data were acquired.

\section{Line 5}

Figure 13 shows the inverted resistivity cross-section along Line 5, which is the northeast to southwest oriented line located in between the Elk and Standard fault-vein features. Because this line is subparallel to the general strike of the veins and fault veins and does not cross any major features, it is the simplest to interpret. Some observations and comments are listed below.

- The two-layer, resistive near-surface model holds particularly well for this cross section. Resistivity values of approximately $1,000 \mathrm{ohm}-\mathrm{m}$ (green) and greater may be a reasonably good indicator of the unsaturated zone where the inferred water table typically occurs at depths between 3 to $10 \mathrm{~m}$ along this section. However, it is important to remember that resistivity variability is due to the combination of saturation and total porosity (intergranular plus fractures). The water levels in B3 and B7 (located $15 \mathrm{~m}$ and $8 \mathrm{~m}$ to the southeast of line 5 , respectively) were roughly $1 \mathrm{~m}$ below the ground surface during the same week the resistivity data were collected (A.H. Manning, written commun., 2009). This observed water level is shallower than the inferred water table, though these very shallow wells $(1.8 \mathrm{~m}$ total depth) may only be reflective of shallow perched water.

- 320,590 E to 320,610 E: An approximately 2-m thick low-resistivity zone in the near-surface corresponds to the wet meadow area below the Level 5 portal. The low resistivity observed here is consistent with the fully saturated ground conditions, as well as high water conductivity values $(840 \mu \mathrm{S} / \mathrm{cm})$ reported by Manning and others (2007) at this location (spring 1).

- The resistivity values below the wet meadow are somewhat elevated (approximately 1,000 ohm-m) compared with the rest of the cross section at similar depths. One explanation is that this is an area of decreased water content due to lower porosity. A second possibility (potentially acting in tandem with the first) is that the water table is deeper at this location, perhaps because of the shallow saturated zone in the meadow area being perched on top of a less permeable layer that inhibits recharge to the deeper saturated zone. 

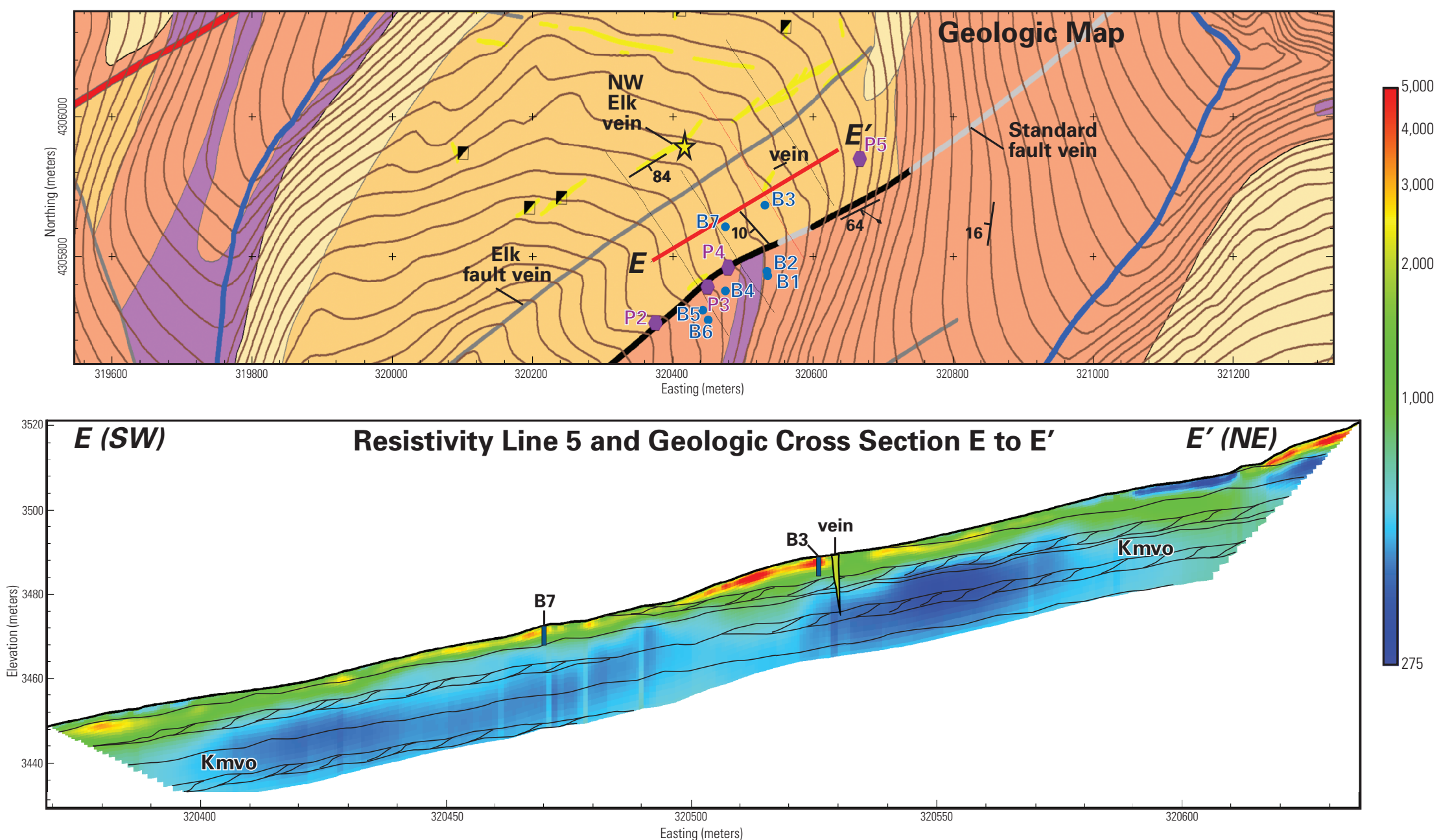

Inverted resistivity section with geologic overlay (Caine and others, 2010) for line 5. The depth of the veins and locations of sedim beds are schematic. Approximate well locations and well depths are indicated. Portals are designated by $\mathrm{P}$ and an identifying number. Boreholes are designated by $B$ and an identifying number. The Level 5 portal is located approximately 30 meters southeast of the eastern end of the $E-E^{\prime}$ profile. Coordinates are in UTM Zone 13North meters. Kmvo, Ohio Creek Member of Cretaceous Mesaverde Formation. 

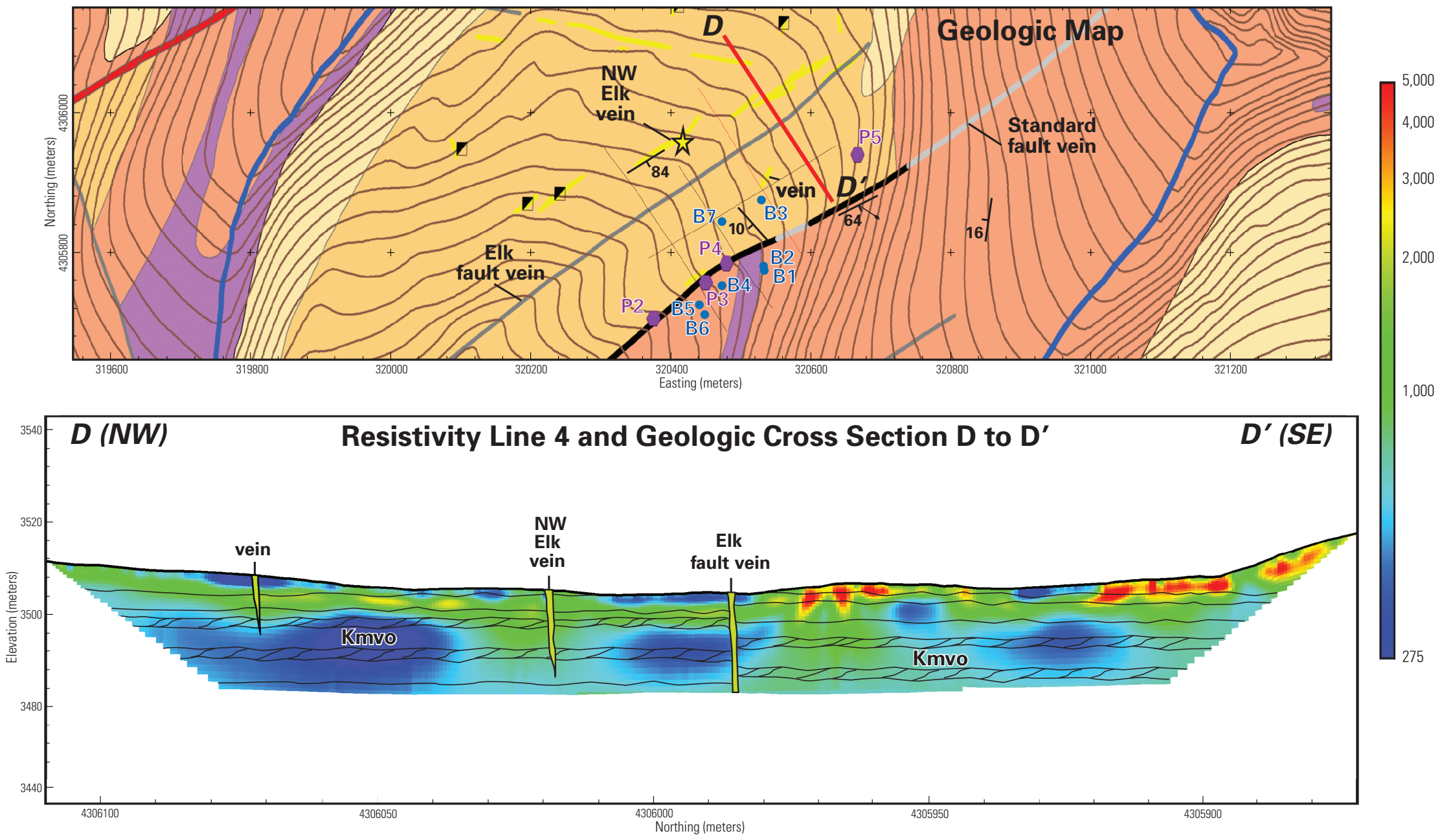

Figure 14. Inverted resistivity section with geologic overlay (Caine and others, 2010) for line 4. The depth of the veins and locations of sedimentary beds are schematic. Portals are designated by $\mathrm{P}$ and an identifying number. Boreholes are designated by $\mathrm{B}$ and an identifying number. The Level 5 portal is located approximately 75 meters northeast of the southern end of the $D-D^{\prime}$ profile. Coordinates are in UTM Zone 13 North meters. Kmvo, Ohio Creek Member of Cretaceous Mesaverde Formation. 

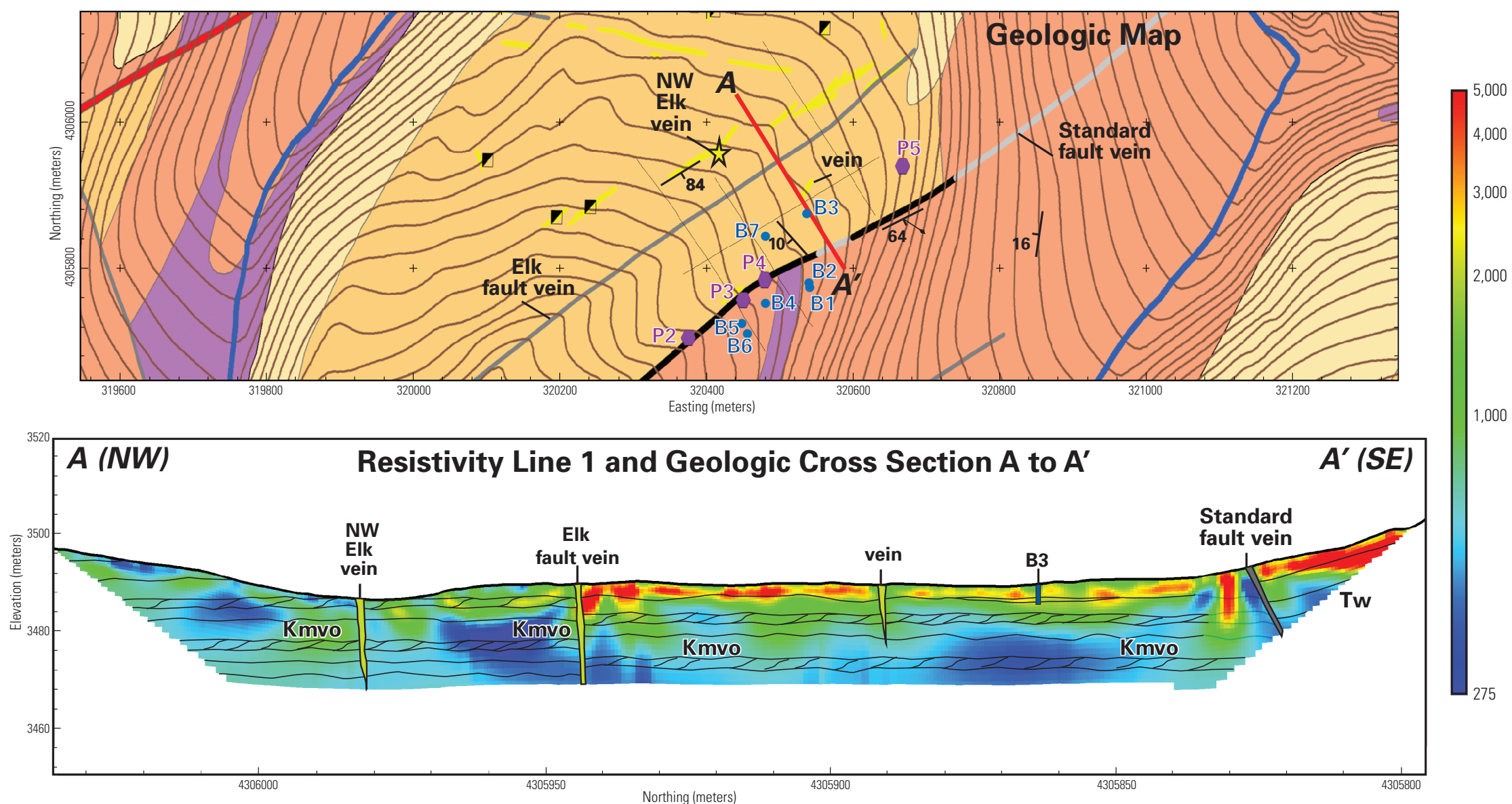

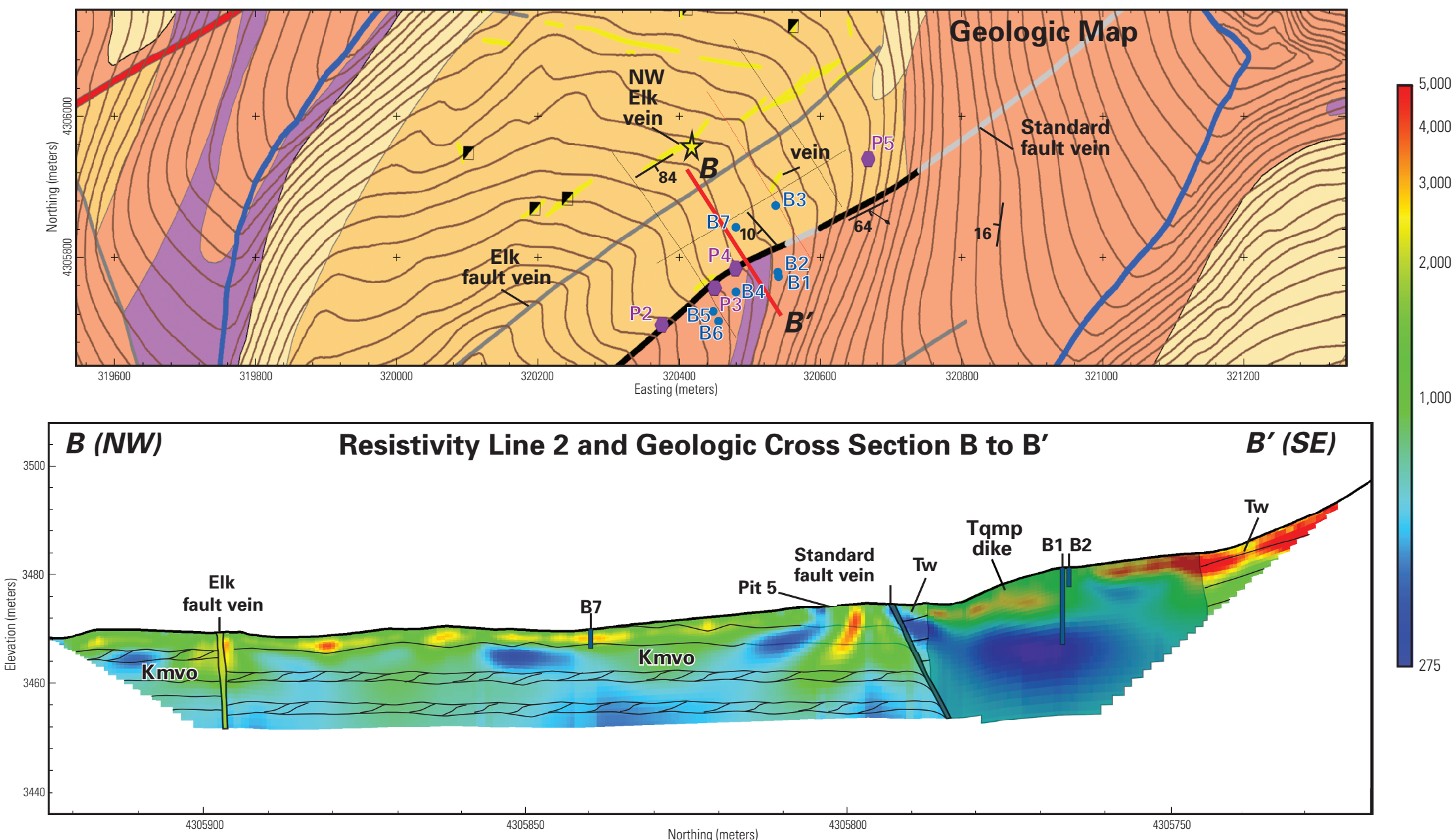

Figure 16. Inverted resistivity section with geologic overlay (Caine and others, 2010) for line 2. The depth of the veins and locations of sedimentary beds are schematic. Approximate well locations and well depths are indicated. Coordinates are in UTM Zone 13North meters. Kmvo, Ohio Creek Member of Cretaceous Mesaverde Formation; Tw, Tertiary Wasatch Formation; Tqmp, Tertiary quartz monzonite porphyry. 

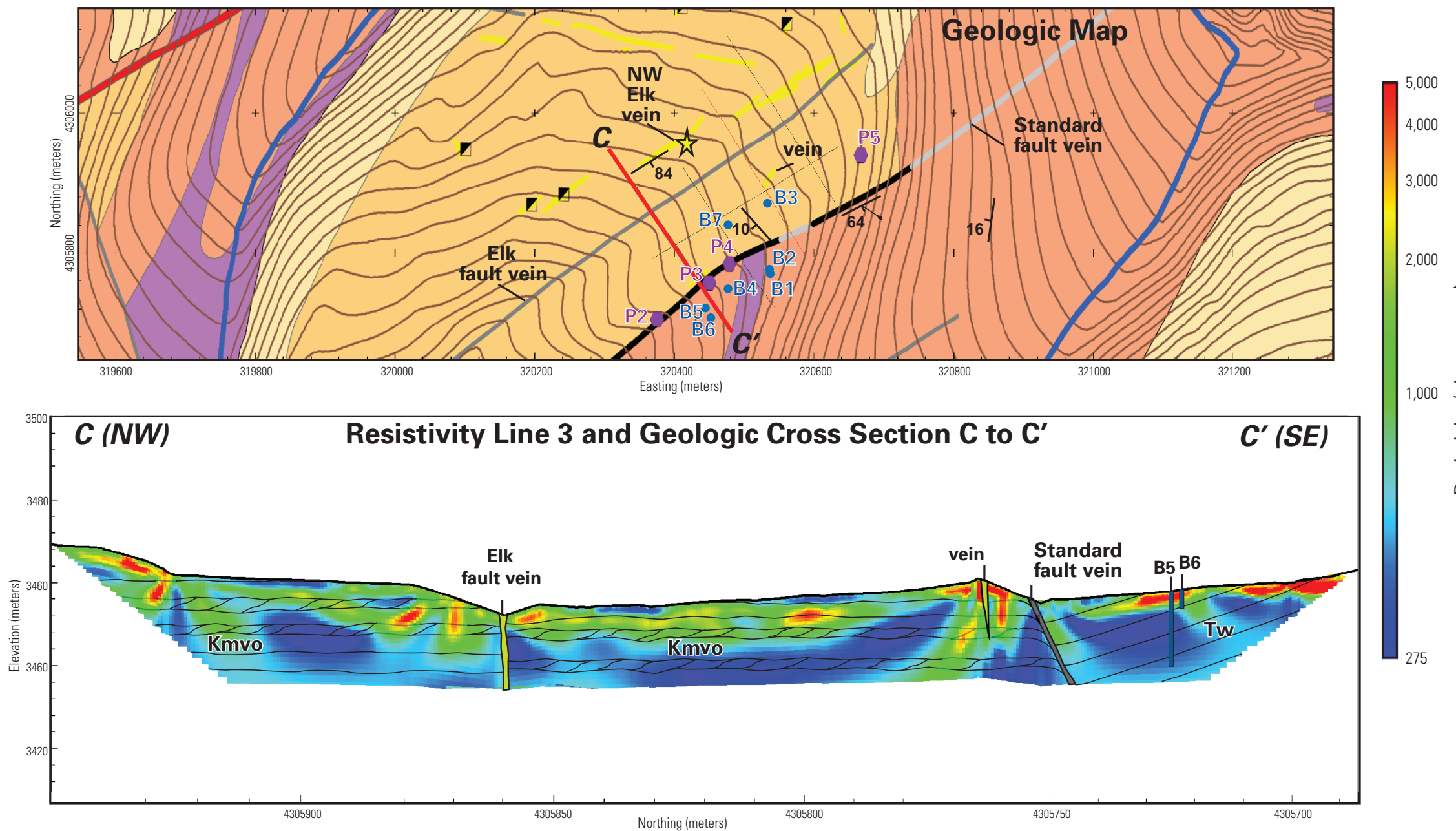


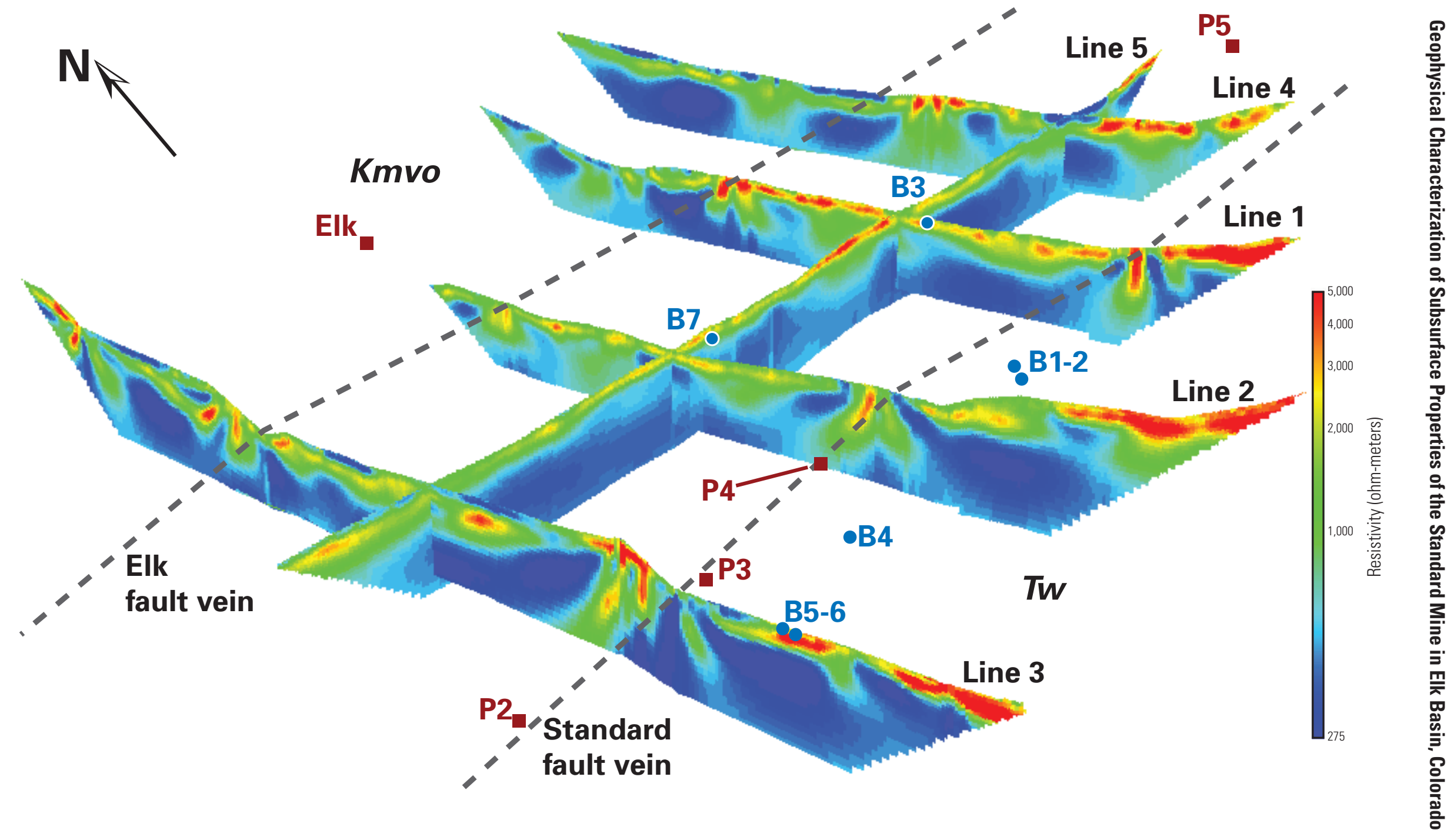

Figure 18. Fence diagram of all five inverted resistivity profiles. Resistivity sections are displayed at their true locations and depths, but positions of faults, portals, and boreholes are approximate. 
- 320,610 E to $320,635 \mathrm{E}$ : The low resistivity feature at approximately 5 -m depth immediately northeast and uphill from the meadow area also may be related to the drainage from the Level 5 waste rock pile that eventually discharges into the meadow.

- 320,500 E to 320,520 E: Observed high near-surface resistivity is characteristic of the lateral heterogeneity observed at the site.

- $320,368 \mathrm{E}$ to $320,400 \mathrm{E}$ : A thicker section of intermediate resistivity values also is observed on the southwestern end of the cross section, which may again correspond to either: (1) a zone of decreased porosity; or (2) a greater water-table depth. Lower resistivities in the upper 1 to $2 \mathrm{~m}$ at this end of the line also coincides with saturated ground conditions, which may be perched on top of a lower permeability zone that promotes surface runoff and inhibits recharge to the deeper saturated zone.

The remaining four resistivity sections that are oriented northwest to southeast are presented in order from northeast (closest to the Level 5 portal) to southwest. Observations and comments follow for sections Line 4, Line 1, Line 2, and Line 3 of this report.

\section{Line 4}

Line 4 (fig. 14) is approximately centered on, and was laid out perpendicular to, the Elk fault vein, and ends just northwest of the Standard fault vein (and Wasatch Formation) because of the rapidly steepening topography. At its closest point, line 4 is approximately $60 \mathrm{~m}$ to the southwest of the Level 5 portal.

- $4,306,108 \mathrm{~N}$ to $4,305,980 \mathrm{~N}$ : The portion of the line to the northwest of the Elk fault vein is characterized by several vertically thin ( 2 to $3 \mathrm{~m}$ ) low resistivity zones in the near surface with lateral extent varying from one to tens of meters. These low-resistivity zones coincide very well with areas of observed surface saturation and surface-water runoff, as well as the diffuse spring discharge area highlighted by Manning and others (2007). These low resistivity surface features are clearly isolated from deeper low-resistivity zones, and may be attributed to perched water that is flowing downhill on top of lower permeability rock.

- The low-resistivity features at depths greater than 5 to $10 \mathrm{~m}$ on the northwestern portion of the line are consistent with the hypothesized saturated zone on line 5. This deeper zone is disrupted by more intermediate resistivity values beneath the mapped NW Elk vein, which may be associated with reduced porosity within the vein. However, it is important to note that a reduction in porosity does not necessarily correlate with a reduction in permeability. Good hydraulic connection may be maintained by cross cutting joints within the low-porosity silicified rock that makes up the vein.

- 4,305,980 N to 4,305,956 N: Several discontinuous and highly resistive features are observed at this location, which is to the southeast of the inferred Elk fault vein location, and may be related to the discontinuity of this feature. Dry-and rocky-surface conditions also were observed in this area.

- 4,305,935 $\mathrm{N}$ to $4,305,920 \mathrm{~N}$ : This thin near-surface low-resistivity zone corresponds to the same wet meadow area discussed on line 5 below the Level 5 portal. Again, this feature appears to be perched on top of a more resistive unit, which may be limiting infiltration to deeper levels in the subsurface.

- 4,305,920 N to 4,305,870 N: The southeastern section of this line is characterized by very high near-surface resistivity. This area was observed to be dry with several large outcrops and little soil moisture that likely contributes to the elevated resistivity values.

\section{Line 1}

Line 1 (fig. 15) extends across both the Elk and Standard fault veins, approximately $80 \mathrm{~m}$ downhill from line 4 , before terminating at the steep topography on the southeastern end of the line over the Wasatch Formation.

- 4,306,035 $\mathrm{N}$ to 4,305,945 N: As with line 4, the near surface of the northwestern portion of this line is characterized by several thin low-resistivity zones that correspond to observed areas of surface saturation.

- Elevated resistivity is observed beneath the NW Elk vein to the northwest, while lower resistivity is observed to the southeast of the vein. It is not possible to determine whether this resistivity contrast is controlled primarily by water content or by metallic minerals associated with the vein.

- 4,305,945 N to 4,305,935 N: Discontinuous and highly resistive features are again observed just to the southeast of the inferred Elk fault vein location. This is very similar in appearance to the resistive feature observed to the southeast of the inferred Elk fault vein location on line 4 , and is likely another expression of this discontinuous feature.

- 4,305,935 $\mathrm{N}$ to $4,305,832 \mathrm{~N}$ : The portion of this line between the Standard and Elk fault veins is characterized by high, though variable, near-surface resistivity and a relatively thick zone of intermediate resistivity. The deeper low-resistivity layer appears to dip more steeply close to the Standard fault vein. There is no expression of the vein mapped near 4,305,910 N, 
though the vein does not quite intersect the cross section.

- The approximate location of borehole B3 is annotated, though the borehole is approximately $6 \mathrm{~m}$ to the southwest of the line. As with line 5, the water level in this very shallow well may be reflective of near-surface perched water, as the observed water level of approximately $1 \mathrm{~m}$ (A.H Manning, written commun., 2009) is significantly shallower than the inferred water level from the resistivity data.

- 4,305,832 N to $4,305,825 \mathrm{~N}$ : The Standard fault vein is co-located with a steeply dipping resistive feature juxtaposed with a low resistivity feature immediately to the southeast. This is consistent with the fault-vein architecture proposed by Caine and others (2010), where the quartz vein is resistive and an argillic alteration halo that surrounds the fault core has low resistivity due to the increased clay content, which also may hold more water.

- 4,305,825 $\mathrm{N}$ to $4,305,796 \mathrm{~N}$ : The southeast portion of the line over the Wasatch Formation shows a very resistive near-surface layer, thickening to the southeast. The very high resistivity likely is because of unsaturated conditions coupled with the observed low porosity [less than one percent from a single mercury injection capillary pressure measurement (Caine and others, 2010)] in the Wasatch Formation. Fresh disseminated pyrite observed in the Wasatch Formation, compared with leached pyrite in the Ohio Creek Member, does not appear to affect the resistivity, possibly because it is poorly connected due to the minimal porosity. Very dry near-surface soils also were observed heading uphill.

\section{Line 2}

Line 2 (fig. 16) is approximately $80 \mathrm{~m}$ downhill from line 1, and extends from just southeast of the Elk portal across the Elk and Standard fault vein features. The southeastern portion of the line also intersects the Tertiary quartz monzonite porphyry (Tqmp). This line is slightly shorter than the others because of the large vein at the Elk portal that could not be traversed with the resistivity electrodes.

- 4,305,923 N to 4,305,805 N: The northwest portion of this line does not show any of the surface saturation and surface-water runoff observed on the previous two uphill lines. Surface and near-surface water may be intercepted by a channel just to the northwest of this line near the Elk portal. The upper 2 to $3 \mathrm{~m}$ of this portion of the line generally are resistive and overlies laterally-variable low-to-intermediate resistivities. This lateral variability at depth may be due to variations in porosity, saturation, or both.

- 4,305,900 N to 4,305,895 N: A shallow, vertically oriented resistive feature coincides with the inferred location of the Elk fault vein. This feature is similar to those observed just to the southeast of the inferred Elk fault vein on lines 4 and 1, and is likely a part of this same discontinuous feature.

- The approximate location of borehole B7 is annotated on the cross section, though the borehole is actually $12 \mathrm{~m}$ to the northeast of the line. Again, the shallow water level observed in this well (approximately $1 \mathrm{~m}$ ) may be representative of near-surface perched water.

- 4,305,802 N: A near-vertical, low-resistivity anomaly that is connected to a deeper low-resistivity zone is observed at this location, which is approximately $4 \mathrm{~m}$ to the southwest of exploration pit 5 discussed by Manning and others (2007). The exploration pit was full of water at the time of the resistivity survey, and the resistivity results indicate a possible connection between this surface feature and deeper groundwater. This appears to be connected to the more steeply dipping low-resistivity feature at depth immediately to the northwest of the Standard fault vein on both adjacent lines.

- 4,305,800 N to 4,305,790 N: The Standard fault vein is again associated with a steeply dipping resistive feature (possibly the quartz vein) adjacent to a lower resistivity dipping feature (possibly the argillic alteration halo combined with the fault core) to the southeast. While the low-resistivity feature dips to the southeast as expected, the high-resistivity zone is a broader 'wedge'. Given the elevation of 3,459 $\mathrm{m}$ for the Level 3 portal, the Level 3 tunnel falls somewhere near the bottom portion of this resistivity section in the vicinity of the Standard fault vein at depth. However, the tunnel is too small to be directly detected by the resistivity measurements at depth below line 2 .

- 4,305,786 $\mathrm{N}$ to $4,305,747 \mathrm{~N}$ : Line 2 intersects the unit Tqmp at an oblique angle, though there is no clear expression of this unit in the resistivity section that differentiates it from the surrounding units. The low resistivity at approximately $10 \mathrm{~m}$ depth also is seen on adjacent lines, and is more likely related to the conditions within the Wasatch Formation.

- 4,305,767 N: The approximate location of wells B1 and B2 are annotated, though they are actually $23 \mathrm{~m}$ to the northeast of the resistivity line. During the week of the resistivity survey (July 7-12, 2009), the water level in the deeper well (B1) was approximately $14 \mathrm{~m}$ below the ground surface, and no water was observed in the 
shallower well B2 (A.H. Manning, written commun., 2009). This is consistent with the depth of the top of the low-resistivity zone that occurs at approximately $11 \mathrm{~m}$ depth on this section. Assuming a relatively flat-lying water table (compared with the surface topography), the shallower estimate from the resistivity data is expected given that the line is downhill from well B1.

- 4,305,760 N to 4,305,720 N: A thickening, very resistive, near-surface layer again is observed going uphill towards the southeast end of the line. This again is likely attributable to the low porosity of the Wasatch Formation and unsaturated conditions. Very dry soils also were observed in this part of the section.

\section{Line 3}

Line 3 (fig. 17) approximately is $80 \mathrm{~m}$ downhill from line 2, and extends across the Elk and Standard fault vein features, crossing the Standard fault vein approximately $10 \mathrm{~m}$ from the Level 3 portal. The southeastern portion of the line covers a portion of the Wasatch Formation, and ends just before the mapped unit Tqmp.

- 4,305,950 N to 4,305,925 N: The northwestern end of this line is characterized by high near-surface resistivity, as well as a steeply dipping resistive feature, which coincides with a large outcrop at this location that may be part of the discontinuous NW Elk vein.

- 4,305,925N to 4,305,890 N: A thin (approximately $2.5 \mathrm{~m}$ ) low resistivity zone occurs in the near surface and, as with lines 4 and 1, is correlated with an area of notably wet soils.

- 4,305,870 $\mathrm{N}$ to $4,305,850 \mathrm{~N}$ : The near surface in the vicinity of the Elk fault vein is resistive, though somewhat different in character than observed on the previous three lines. As mapped, the fault vein falls at the center of a steep, narrow valley that contained a flowing stream at the time of the resistivity survey. A relatively shallow (approximately $4 \mathrm{~m}$ ) low-resistivity zone is seen immediately below and to the southeast of the Elk fault vein, which is possibly related to recharge from the stream above.

- 4,305,850 $\mathrm{N}$ to 4,305,770 N: The line segment between the Elk and Standard fault veins is characterized by a relatively thick (approximately $10 \mathrm{~m}$ ) upper layer with intermediate-to-high resistivity on top of a lower resistivity unit. The deeper low-resistivity unit is relatively flat lying, though it clearly dips more steeply immediately northwest of the Standard fault vein, which also was observed on lines 1 and 2. Two thin near-surface, low-resistivity zones are apparent, both of which are associated with observed saturated soils and small flowing streams.

- 4,305,770 N to 4,305,752 N: The Standard fault vein again is characterized by a large resistive unit associated with a quartz vein (well exposed at this location) adjacent to a steeply dipping low-resistivity feature likely associated with argillic alteration within the fault vein.

- 4,305,752 $\mathrm{N}$ to $4,305,685 \mathrm{~N}$ : The southeastern portion of the line again is characterized by very high nearsurface resistivity within the Wasatch Formation. There also is a low-resistivity area in the near surface closer to the Standard fault vein, which is the only potential source of very near-surface water observed in the resistivity data on the hanging wall side of the fault. This area had noticeably moist soil, though was not nearly as wet as the other low-resistivity zones associated with surface water features.

- Wells B5 and B6 are shown on figure 17, though they are actually located approximately $15 \mathrm{~m}$ southwest of the resistivity line. The water level in B5 during the week of the resistivity survey was approximately $12 \mathrm{~m}$ below the ground surface, and no water was observed in the shallower well B6 (A.H. Manning, written commun., 2009). Depth to the low-resistivity zone near well B5 is approximately $5 \mathrm{~m}$, which disagrees somewhat with the observed water level. This discrepancy may be because the well is not coincident with, and is further down gradient from, the resistivity line. Depth to the low resistivity zone also increases to approximately $10 \mathrm{~m}$ just southeast of where well B5 was projected onto the resistivity line, reflecting potential heterogeneity on this portion of the line and uncertainty involved with projecting well locations onto the resistivity sections.

\section{Three-Dimensional Resistivity Fence Diagram}

Figure 18 provides a three-dimensional view of all five resistivity lines, displayed with spatially correct locations and depths. The approximate locations of the Standard and Elk fault veins, portals, and boreholes also are displayed on figure 18 , and it highlights several features that are consistent across the survey, which follows.

- The Standard fault vein appears as a high-resistivity feature to the northwest juxtaposed with a low-resistivity feature to the southeast. This agrees well with the architecture of the fault zone and juxtaposition of the Wasatch Formation on the Ohio Creek Member discussed by Caine and others (2010). The silicified quartz vein likely is the resistive feature because of its reduced porosity. Increased clay content within the argillic alteration halo and fault core likely reduce the 
resistivity on the hanging wall, though conductive minerals in the fault also may contribute to the decreased resistivity. It also is possible that the decreased resistivity is because of increased saturation, though additional data would be needed to determine if this water is bound in clays or is infiltrating into the subsurface.

- The Elk fault vein appears as a discontinuous, highresistivity feature of varying form in the near surface on the four lines that cross it. Its variable expression suggests that it may be a discontinuous and disorganized structure. On line 4, the high-resistivity feature appears to the southeast of the inferred location of the fault vein.

- Numerous thin (2 to $3 \mathrm{~m}$ ) low-resistivity layers are observed in the near surface that coincide with observed surface saturation and surface-water flow, mostly on the northwest portion of the survey area. These interrupt what primarily is a resistive 3 to $10 \mathrm{~m}$ thick near-surface layer apparently associated with the unsaturated zone. These low-resistivity features clearly are associated with areas of high near-surface saturation, and generally appear disconnected from deeper low-resistivity zones.

- Low resistivity generally is observed at depth. This feature sometimes is broken by more intermediate resistivity values that may be associated with zones of lower porosity in the subsurface. The low-resistivity unit is relatively flat lying in the central portion of the survey (along line 5), though it appears to dip more steeply immediately to the northwest of the Standard fault vein on lines 1 through 3 .

- Very high resistivity is observed on the southeastern portion of lines 1 through 3 within the Wasatch Formation. This feature extends to depths of up to approximately $10 \mathrm{~m}$, becoming thicker with increasing distance up the hill slope. The feature likely is caused by a combination of unsaturated conditions and the relatively low porosity of the Wasatch Formation.

\section{Self-Potential}

A total of 546 self-potential stations were acquired, primarily along nine profiles illustrated in figure 19 (black dots), totaling approximately 3.2 line-km of data. Five of the self-potential profiles are co-located with the resistivity lines (shown in dark green), though the self-potential data along resistivity line 5 was continued approximately $300 \mathrm{~m}$ further to the southwest towards the Level 1 portal. Additional lines of data also were acquired between resistivity lines 1 through 4, as well as one northeast-southwest line along the northwestern edge of the survey that eventually intersects Elk Creek and ends near the Level 1 portal. All self-potential station locations were recorded with a handheld GPS unit with typical accuracy of several meters.

Individual lines of data were collected by spooling out the roving electrode at $6 \mathrm{~m}$ intervals (nominal station spacing) along the line from a base electrode location. A new base electrode location was established for each line, and individual lines of data were tied together by re-occupying existing stations at line intersections. Electrode drift was checked at the end of each line by placing both electrodes in a bucket of saline water and measuring their potential difference, which was generally less than $1 \mathrm{mV}$. The self-potential data were processed using the methods described by Minsley and others (2008) to generate a unique, smoothly varying map of the electrical potential field (in $\mathrm{mV}$ ) over the survey area (fig. 19). The self-potential values at each location are relative to the survey-wide reference location, which was chosen as the northeastern-most station near the Level 5 portal, and is labeled "Ref." The choice of a reference location fixes an arbitrary "zero-level" in the self-potential map, but does not alter the relative values within the map or influence the interpretation.

As mentioned previously, the self-potential signal at this site likely is made up of the superposition of groundwater flow- (fig. 9) and electrochemical- (fig. 10) related phenomena. It should be noted that free-flowing surface water does not contribute to the self-potential signal because the phenomenon relies on the transport of excess charge developed in the vicinity of grain surfaces within pore space, which is not present in surface flow. The most prominent features in figure 19 are the strong negative (blue) self-potential values observed along and to the southeast of the Standard fault vein, as well as along the NW Elk vein mapped by Caine and others (2010) near the Elk portal. A few other less-prominent lows (green and light blue colors) in the self-potential map are observed in the vicinity of the Elk fault vein and other polymetallic quartz veins mapped in the northeastern part of the self-potential survey. The fact that these lows correspond to veins or fault veins where high concentrations of sulfide minerals are either known (in the case of the Standard fault vein and the NW Elk vein) or suspected (in the case of the other veins) to occur in the subsurface strongly suggests that these self-potential anomalies are related to the electrochemical mechanism discussed earlier (fig. 10).

However, because downward vertical groundwater flow also would create similar lows in the self-potential field, it is possible that these anomalies partly are caused by localized downward groundwater flow. The correlation of the selfpotential lows with the Standard and Elk fault veins is consistent with the lows being groundwater flow related because damage zones associated with faults commonly enhance fault-parallel permeability. The correlation of the lows with the other veins, however, seems inconsistent with the lows being groundwater flow related because there is little reason to suspect enhanced vertical permeability and downward flow within the veins. In short, it appears that the self-potential lows primarily are caused by the electrochemical mechanism, 


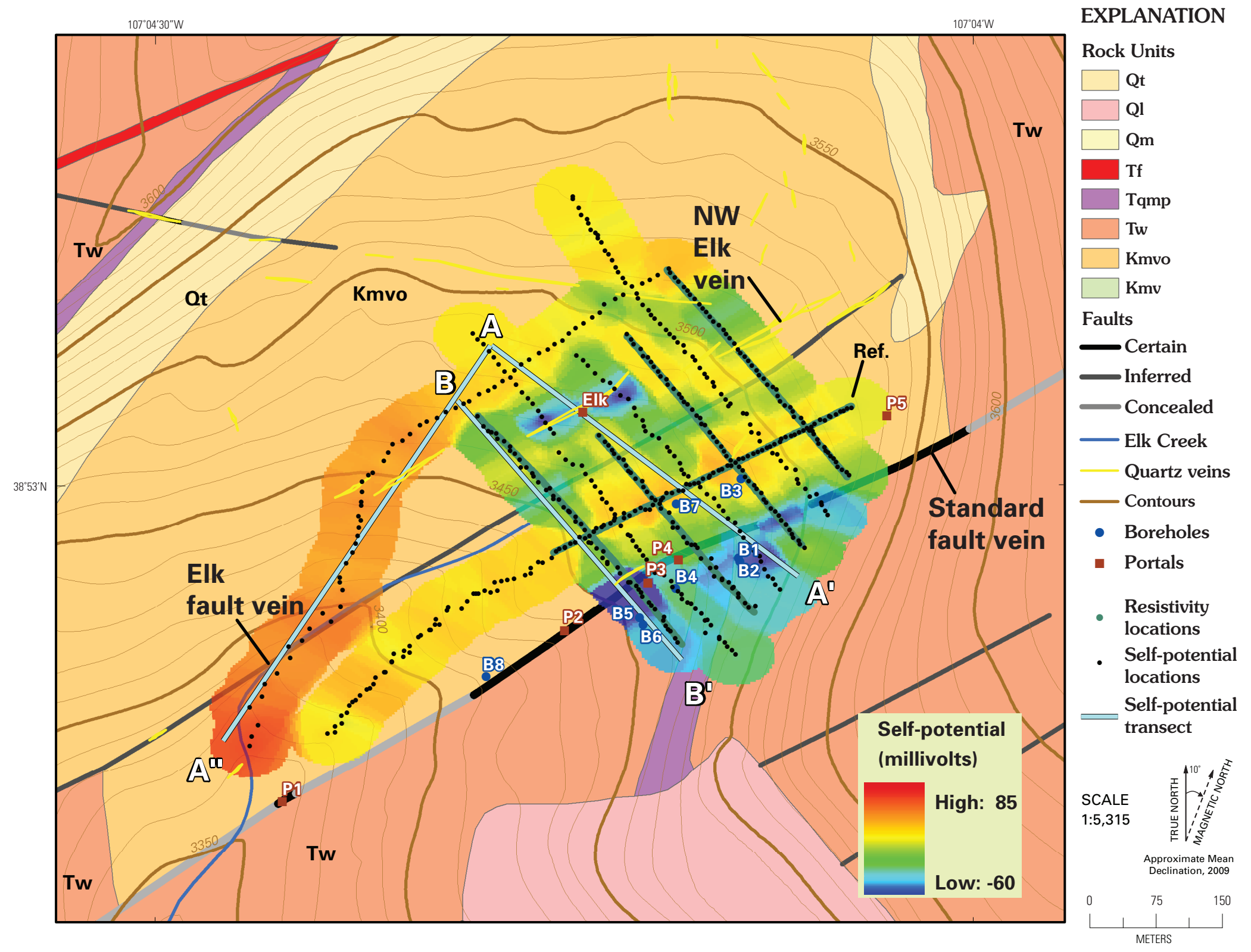

Figure 19. Processed self-potential data over the survey area superimposed on the reconnaissance geologic map by Caine and others (2010). The survey reference location is marked "Ref." Qt, Quaternary talus deposit; 0l, Quaternary talus deposit; $0 \mathrm{~m}$, Quaternary glacial deposit; Tf, Tertiary felsite; Tqmp, Tertiary quartz monzonite porphyry; Tw, Tertiary Wasatch Formation; Kmvo, Ohio Creek Member of the Cretaceous Mesaverde Formation; Kmv, Cretaceous Mesaverde Formation. 
but the possibility that these lows are enhanced by localized downward groundwater flow (particularly along the Standard and Elk fault veins) cannot be ruled out.

Figure 20 shows an overlay of the topographic gradient vectors produced by Caine and others (2010, fig. 14), which can be thought of as a proxy for surface-water flow and to a lesser extent shallow-groundwater flow directions, on top of the self-potential map. As discussed previously, if the selfpotential signal were purely related to topographically-driven groundwater flow, one would expect to see a strong correlation between self-potentials and elevation, with the self-potential values becoming increasingly positive in the downhill direction. Inspection of figure 20 suggests that this correlation is generally weak. Figure 21 is a plot of the self-potential values versus elevation. The strongly negative data that likely are attributed to the electrochemical mechanism are plotted as open circles, while the remaining data are displayed as closed dots. A linear-regression line fit to the closed dots indicates a negative correlation between this portion of the data and elevation. In other words, the potentials do on average become more positive at lower elevations. However, the correlation shows considerable scatter and the slope of the regression line is small $(-0.23 \mathrm{mV} / \mathrm{m})$ compared with other published examples that report slopes of -1 to $-10 \mathrm{mV} / \mathrm{m}$ (Revil and others, 2004; Zlotnicki and others, 1998). Therefore, figure 20 and figure 21 suggest that topographically-driven flow accounts for a relatively small component of the self-potential signal, and volumetric flow rates (parallel to the ground surface) within the shallow groundwater system may be relatively low within the survey area. However, it is quite possible that more significant topographically-driven flow occurs earlier in the season when there is increased snowmelt.

Figure 22 illustrates three transects that are extracted along the white lines superimposed on the self-potential map in figure 19 for the purpose of highlighting several features of interest, which are discussed in further detail below.

- Transect $A-A^{\prime}$ (fig. 22A) crosses both the Standard and Elk features, and shows prominent negative anomalies on the order of $50 \mathrm{mV}$ in magnitude over the NW Elk vein near the Elk portal and the Standard fault vein. No notable anomaly is observed over the Elk fault vein, which is consistent with the discontinuous character of this feature postulated by Caine and others (2010). The anomaly over the Standard fault vein is centered on the Wasatch Formation (hanging wall) side of the fault vein, possibly because of a higher concentration of sulfide minerals at depth within the structure coupled with its southeastward dip, as well as the relatively unleached disseminated pyrite found in these rocks as compared to the leached pyrite in the Ohio Creek Member.

- The maximum self-potential observed in figure $22 \mathrm{~A}$ is near borehole $\mathrm{B} 7$, and is part of a larger "ridge" of elevated self-potentials between the Standard and Elk faults (fig. 20). This also is the approximate area where there is a convergence of "flow" vectors towards the axis of the basin. Convergent flow is consistent with the elevated self-potentials observed, as well as relatively shallow water levels observed in boreholes B3 and B7 (A.H. Manning, written commun., 2009).

- Transect $A-A$ " (fig. 22B) shows steadily increasing self-potential values in the downhill direction along the transect, which descends towards and eventually follows Elk Creek to near the Level 1 portal. This section is the only portion of the survey area where the selfpotential field appears strongly affected by topographically-driven groundwater flow. Several relatively small $(5$ to $10 \mathrm{mV}$ ) negative anomalies are superimposed on this trend, one of which coincides with a mapped polymetallic quartz vein, while the others also may be related to similar unmapped veins.

- Transect $B$ - $B^{\prime}$ (fig. 22C) shows another transect that crosses the Elk and Standard features and is subparallel to the $A-A^{\prime}$ transect. Characteristic negative anomalies again are observed over the fragmented NW Elk vein, the Elk fault vein, and the Standard fault vein.

Overall, the self-potential data suggest a shallow-groundwater flow system with relatively modest ground-surface parallel volumetric flow within the survey area, which reaches a maximum in the vicinity of Elk Creek. Superimposed on this weak trend are pronounced self-potential lows that appear to be primarily the result of electrochemical effects associated with elevated concentrations of metallic minerals along the major fault veins and veins.

One perplexing aspect of the self-potential data is the lack of an increasing self-potential trend along the line that is subparallel with the transect presented in figure 22B ( $A$ to $\left.A^{\prime \prime}\right)$. Given the proximity of these lines of data, which both are acquired downhill towards the Level 1 portal, one would expect both to exhibit similar trends. A possible explanation is that the Level 1 tunnel may act as a local groundwater drain, capturing water that would otherwise flow downhill towards Elk Creek. The absence of an increasing self-potential trend on the southernmost line subparallel to the Standard fault vein could be because of either: (1) a lack of shallow groundwater flow above the Level 1 tunnel between the Level 1 and Level 2 portals (because this ground largely is unsaturated); or (2) a lack of ground-surface-parallel flow in this area (because flow mainly is vertically downward toward the tunnel).

\section{Magnetics}

Approximately 2.1 line-km of magnetic data were acquired along the five resistivity profiles, though the magnetic lines also were extended further to the northwest into the basin. Additionally, magnetic susceptibility was measured on the 22 rock samples that also were submitted for mineralogy and elemental geochemical analysis by Caine and others (2010). Positioning for the magnetic data comes from the 


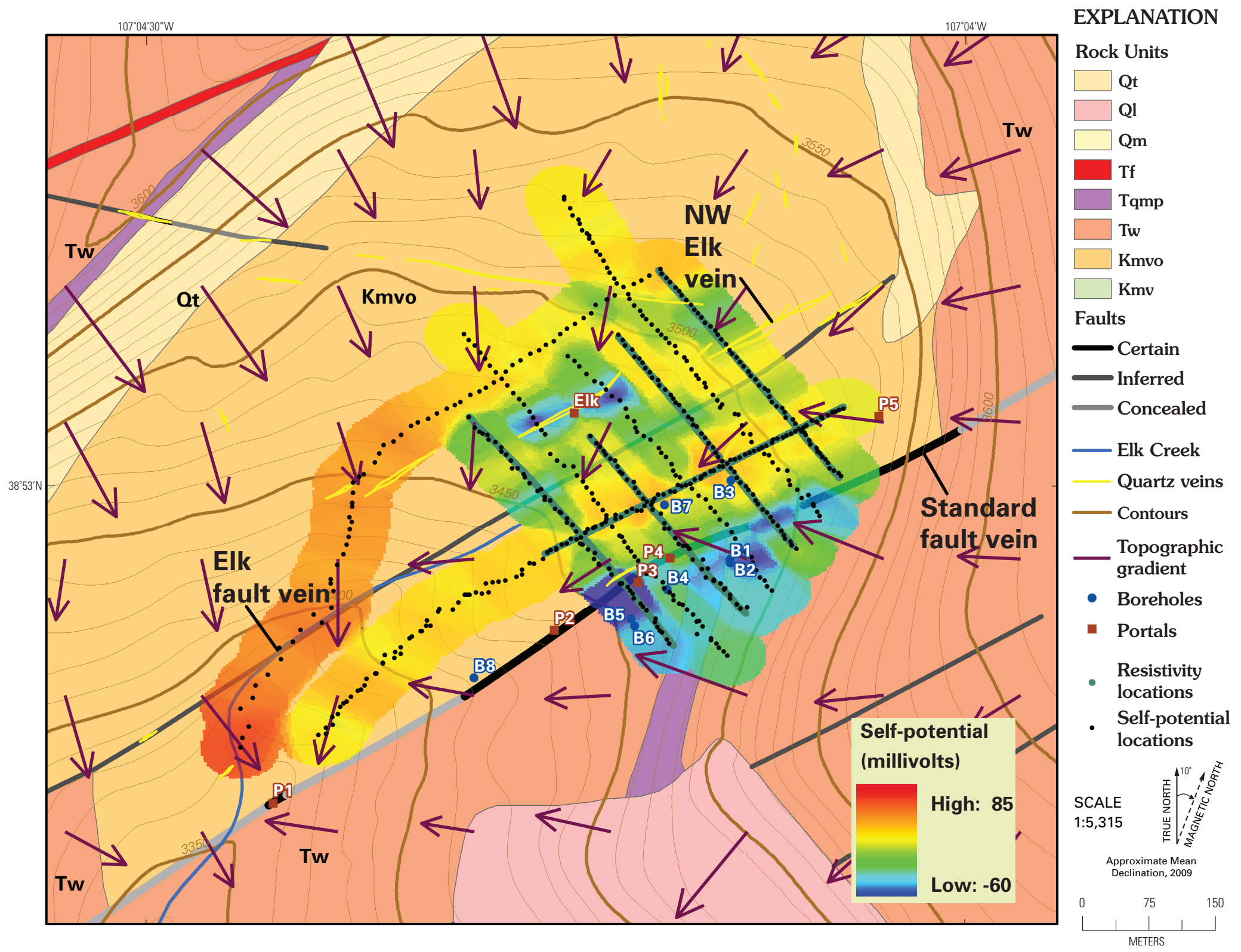

Figure 20. Processed self-potential data over the survey area with overlay of topographic gradient vectors produced by Caine and others

(2010) as a proxy for surface water and possibly shallow groundwater flow directions. Qt, Quaternary talus deposit; Ql, Quaternary talus deposit; Qm, Quaternary glacial deposit; Tf, Tertiary felsite; Tqmp, Tertiary quartz monzonite porphyry; Tw, Tertiary Wasatch Formation; Kmvo, Ohio Creek Member of the Cretaceous Mesaverde Formation; Kmv, Cretaceous Mesaverde Formation. 


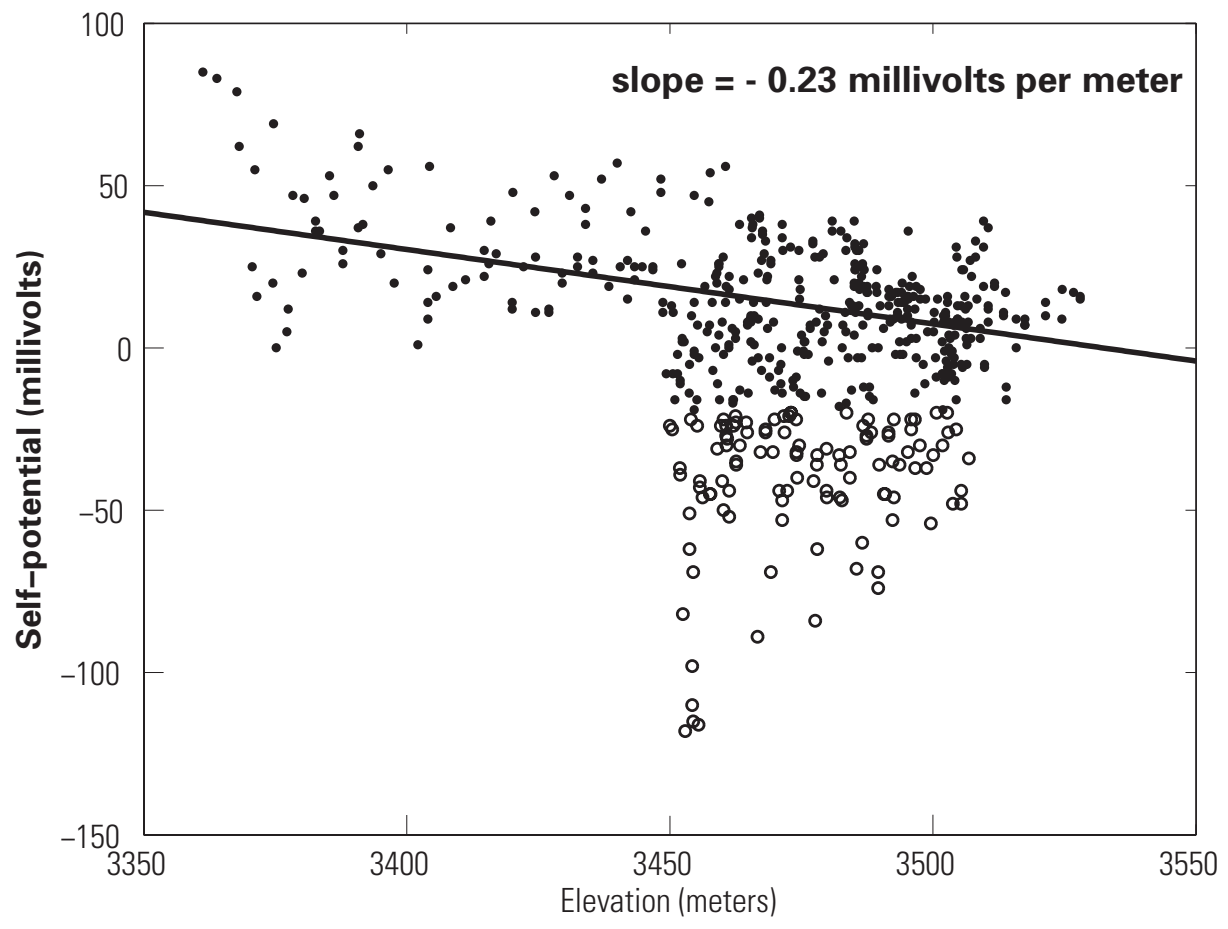

Figure 21. Self-potentials shown as a function of elevation. More negative values likely associated with an electrochemical mechanism are displayed as open circles, while the remaining data (solid dots) exhibit a small negative slope consistent with relatively weak shallow groundwater flow.

Leica RTKGPS, with typical accuracy on the order of 5 to 10 $\mathrm{cm}$. A magnetic base station was set up while data were collected in order to record ambient and diurnal corrections that were applied to the profile data. The corrected magnetic data are illustrated in different formats in figures 23-25.

Figure 23 shows the data from both the top and bottom magnetic sensors as profiles, and is useful in highlighting short wavelength features and changes in character within the data. In figure 24, the data from both magnetic sensors are plotted as a function of UTM Northing (for lines 1 through 4) and Easting (for line 5), which also is useful in highlighting changes in character within the data, as well as the relative magnitude of the signals. Figure 25 shows the data from the top magnetic sensor as a colored grid, and is useful in illustrating the spatially long-wavelength features in the data. Magnetic susceptibility values, taken as the mean of three measurements on each sample, also are displayed as white circles sized proportionally to the susceptibility value in figure 23 and figure 25 and are summarized in table 3 .

The primary observation from the magnetic data is that the total signal range of $\pm 171 \mathrm{nT}$ is generally small, though consistent with the sedimentary geology and mostly nonmagnetic mineralization observed at the site from X-ray diffraction mineralogy analysis (Caine and others, 2010, table 5).
Neither magnetite nor pyrrhotite, both of which typically are associated with strong magnetic signatures, are reported in the mineralogy data. Pyrite, which is present, typically has low values of magnetic susceptibility (table 1); therefore, it does not become strongly magnetized. This low signal strength also agrees with the small magnetic susceptibility values, the majority of which are less than $1.0 \times 10^{-3} \mathrm{SI}$, with a maximum of $21.4 \times 10^{-3} \mathrm{SI}$.

In figure 23 and figure 24, a significant portion (though not all) of the variability in the magnetic data has a relatively short spatial wavelength with large differences between the top and bottom sensors. This is indicative of a relatively shallow (several meters or less) and laterally variable source of the magnetic signal. More importantly, the character of the signal on the southeastern portions of lines 1 through 4 and the northeastern portion of line 5 distinctly is different from the rest of the site. To the northwest, signals generally are flat with a few isolated spikes, while to the southeast the signals are more oscillatory and the oscillations are larger in amplitude. On lines 3 and 4 this change in character coincides well with the contact between the Ohio Creek Member and Wasatch Formation at the Standard fault vein and likely is caused by the Wasatch Formation containing slightly more magnetic minerals than the Ohio Creek Member. However, on lines 1, 

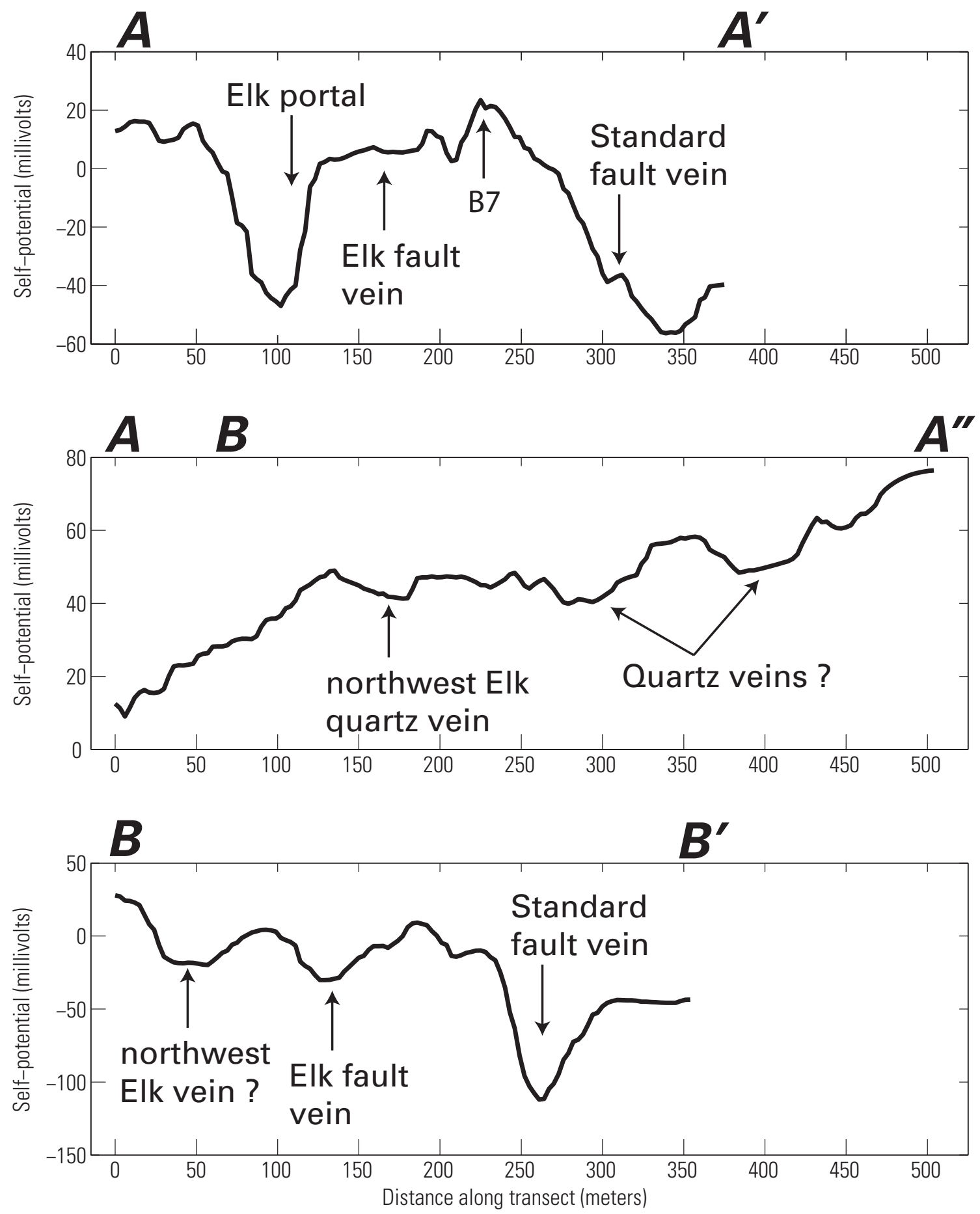

Figure 22. Selected transects extracted from the self-potential map in figure 19 along $(A) A-A^{\prime},(B)$ $A-A^{\prime \prime}$, and $(C) B-B^{\prime}$. 


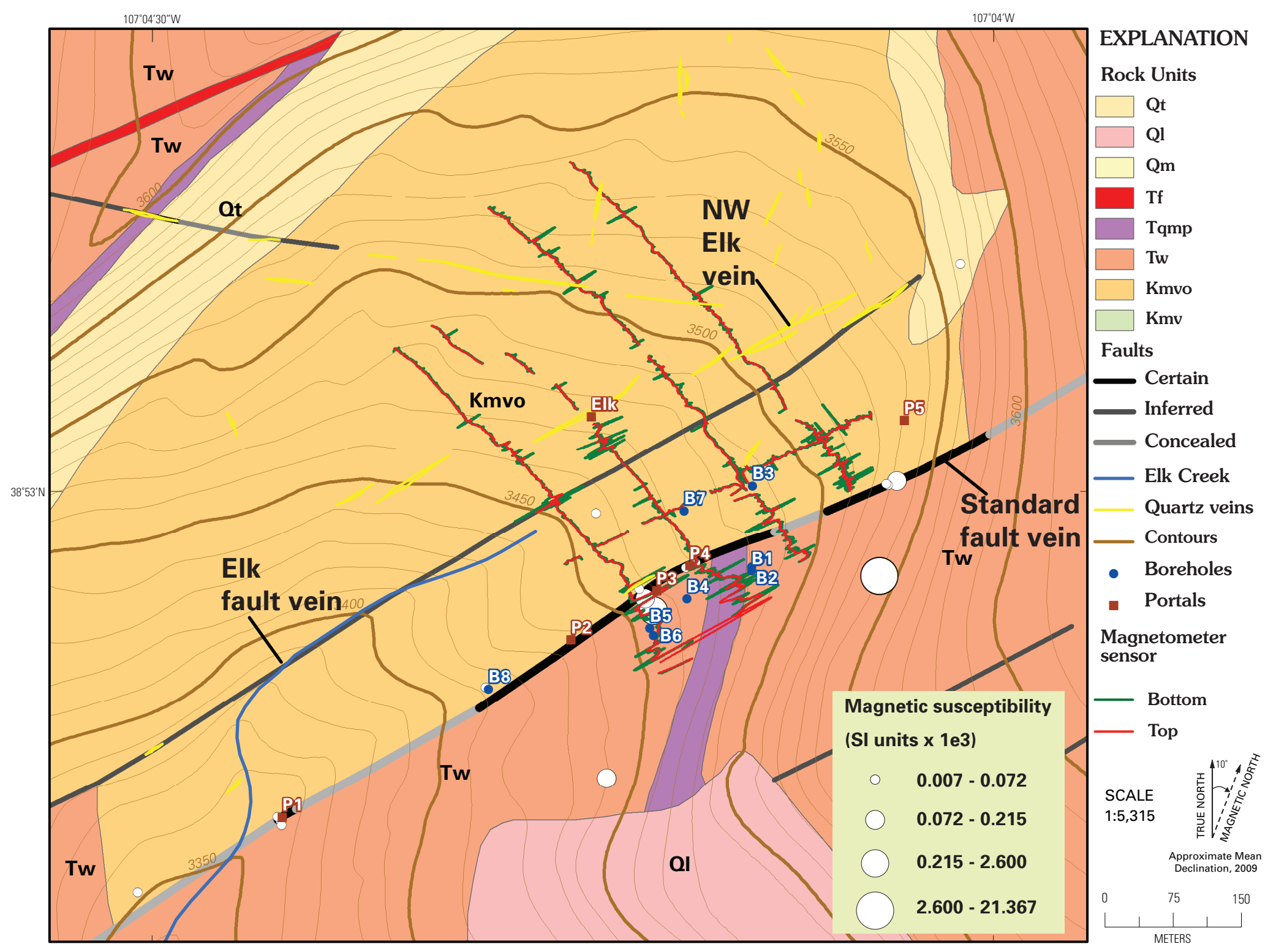

Figure 23. Magnetic gradiometer data overlaid as profiles on the geologic map by Caine and others (2010). Magnetic susceptibility data from rock samples are illustrated as white circles scaled proportionally to the susceptibility value. Qt, Quaternary talus deposit; Ol, Quaternary talus deposit; Qm, Quaternary glacial deposit; Tf, Tertiary felsite; Tqmp, Tertiary quartz monzonite porphyry; Tw, Tertiary Wasatch Formation; Kmvo, Ohio Creek Member of the Cretaceous Mesaverde Formation; Kmv, Cretaceous Mesaverde Formation. 

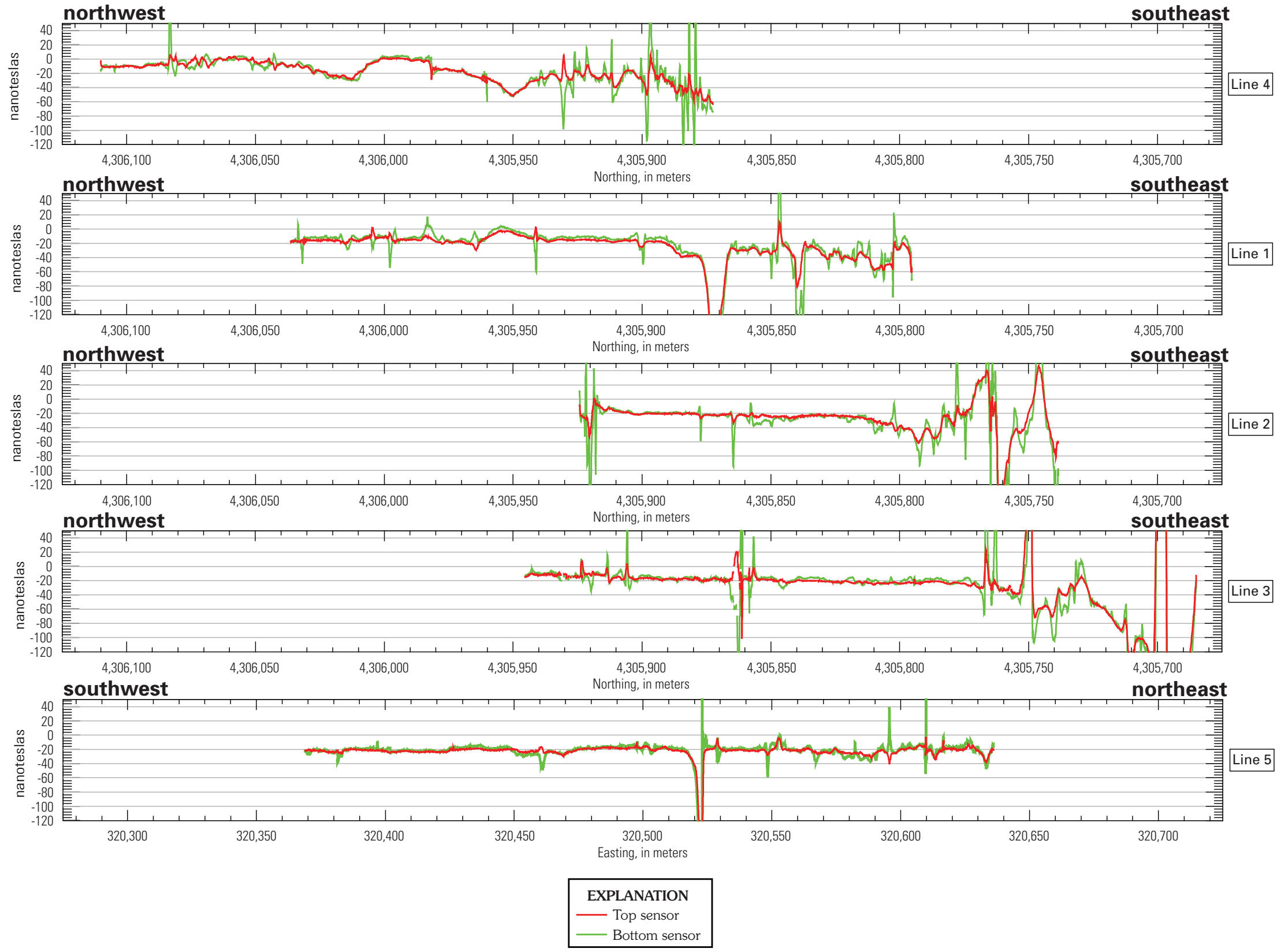

Figure 24. Profiles of all five transects of magnetic data, showing both top (red) and bottom (green) sensors. Lines 1 through 4 are displayed as a function of UTM northing, while line 5 is displayed versus easting 


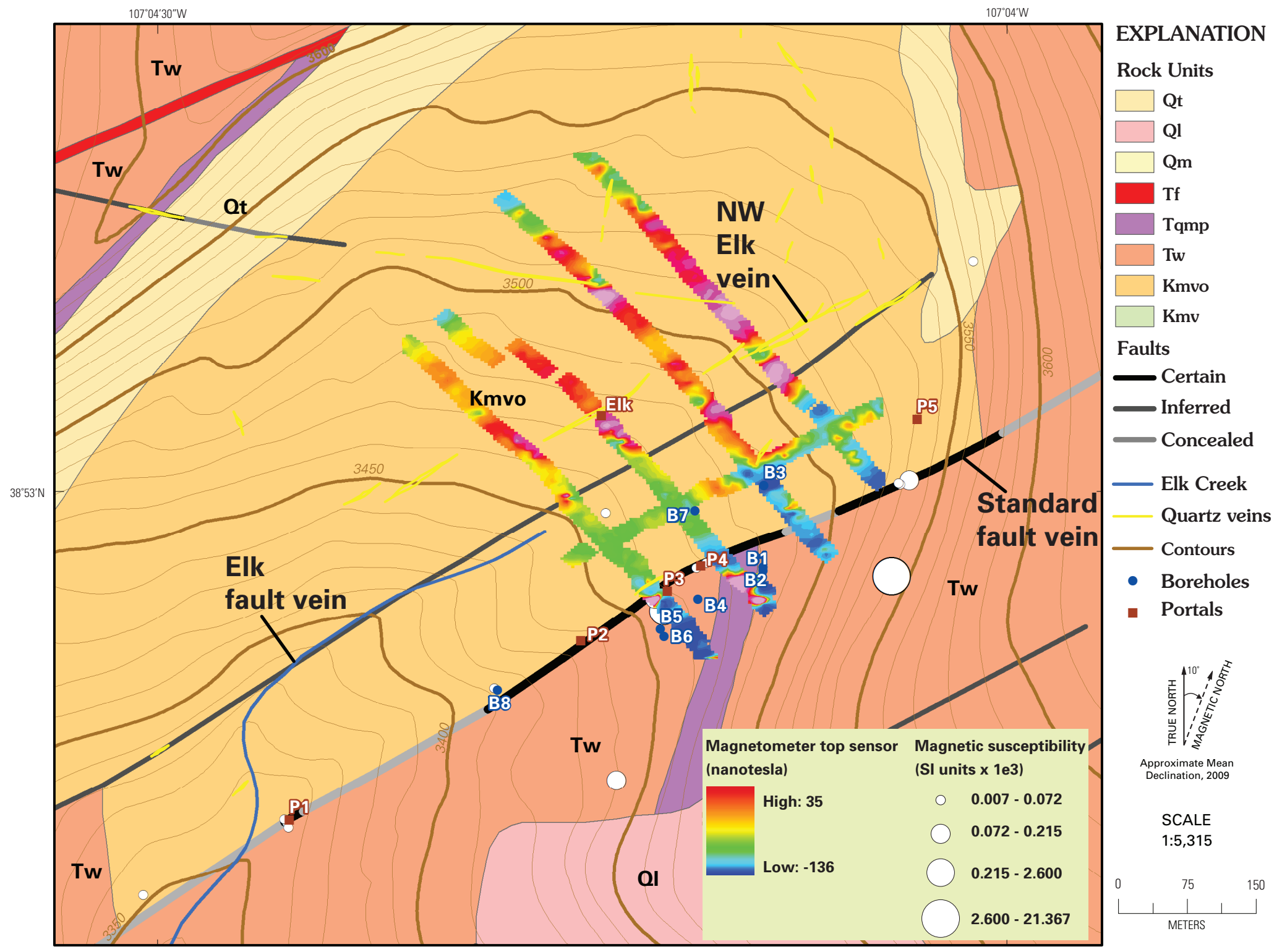

Figure 25. Gridded magnetic data from the top sensor only, which helps to highlight longer wavelength/smaller amplitude variations in the data, on the geologic map by Caine and others (2010). Qt, Quaternary talus deposit; Ql, Quaternary talus deposit; Qm, Quaternary glacial deposit; Tf, Tertiary felsite; Tqmp, Tertiary quartz monzonite porphyry; Tw, Tertiary Wasatch Formation; Kmvo, Ohio Creek Member of the Cretaceous Mesaverde Formation; Kmv, Cretaceous Mesaverde Formation. 
Table 3. Summary of rock-sample descriptions and measured magnetic susceptibilities.

[arg $=$ argillized, $\mathrm{B} 8=$ borehole 8, cata $=$ cataclasite, $\mathrm{crg}=$ clay-rich gouge, $\mathrm{dd}=$ decimal degrees, $\mathrm{dz}=$ damage zone, $\mathrm{flt}=$ fault, $\mathrm{fv}=\mathrm{fault}$ vein, $\mathrm{fw}=\mathrm{footwall}, \mathrm{hw}=$ hanging wall, $\mathrm{Kmvo}=\mathrm{Ohio}$ Creek Member of Mesaverde Formation, $\mathrm{L} 1=$ level $1(3$ and 5$), \min =$ mineralized, $\mathrm{n}=$ north, $\mathrm{nw}=$ northwest, oc $=$ outcrop, ox $=$ oxidized, $\mathrm{pl}=$ protolith, polymet $=$ polymetallic, py $=$ pyrite, $\mathrm{qtz}$ $=$ quartz, $\mathrm{se}=$ southeast, $\mathrm{SI}=$ International System of Units, $\mathrm{sst}=$ sandstone, $\mathrm{std}=$ standard, $\mathrm{sw}=$ southwest, Tqmp $=$ Tertiary quartz monzonite porphyry, Tw $=$ Tertiary Wasatch Formation, unox $=$ unoxidized, WGS84 = World Geodetic System 1984]

\begin{tabular}{|c|c|c|c|c|c|c|c|c|}
\hline Sample & Unit & $\begin{array}{c}\text { Fault } \\
\text { architecture }\end{array}$ & $\begin{array}{l}\text { Simple } \\
\text { lithology }\end{array}$ & $\begin{array}{l}\text { WGS84 } \\
\text { LAT (dd) }\end{array}$ & $\begin{array}{l}\text { WGS84 LON } \\
\text { (dd) }\end{array}$ & $\begin{array}{c}\text { WGS84 } \\
\text { Elevation } \\
\text { (m) }\end{array}$ & $\begin{array}{c}\text { Magnetic } \\
\text { susceptibil- } \\
\text { ity x } 10^{3} \text { (SI) }\end{array}$ & Location \\
\hline $709095 \mathrm{~A}$ & vein & core & qtz vein & 38.8787 & -107.0758 & $3,340.1$ & 0.007 & std mine oc \\
\hline $709096 \mathrm{~A}$ & Tw & hwpl & qtz sst & 38.8786 & -107.0758 & $3,260.0$ & 1.543 & std mine oc \\
\hline $709097 \mathrm{~A}$ & Kmvo & fwpl & qtz sst & 38.8794 & -107.0751 & $3,349.4$ & 0.038 & std mine oc \\
\hline $709098 \mathrm{~A}$ & Tw & hwdz & $\min$ qtz sst & 38.8801 & -107.0737 & $3,367.6$ & 0.054 & std mine $\mathrm{L} 1, \mathrm{fv}, \sim 1 \mathrm{~m}$ se of core \\
\hline $709098 \mathrm{~B}$ & $\mathrm{Tw}$ & hwpl & ox qtz sst & 38.8800 & -107.0737 & $3,367.6$ & 0.024 & std mine $\mathrm{L} 1, \mathrm{fv}, \sim 4 \mathrm{~m}$ se of core \\
\hline $709098 \mathrm{C}$ & Kmvo & fwdz & ox qtz sst & 38.8801 & -107.0738 & $3,367.6$ & 0.021 & std mine $\mathrm{L} 1, \mathrm{fv}, \sim 1 \mathrm{~m}$ nw of core \\
\hline 70909 14A & Kmvo & fwpl & qtz sst & 38.8831 & -107.0706 & $3,440.6$ & 0.039 & std mine $\mathrm{L} 3, \mathrm{fv}, \sim 100 \mathrm{~m} \mathrm{nw}$ of flt \\
\hline 70909 14B & Kmvo & fwdz & qtz sst & 38.8824 & -107.0702 & $3,440.6$ & 0.012 & std mine L3, fv, $\sim 2 \mathrm{~m}$ nw of flt \\
\hline $7090914 \mathrm{C}$ & $\mathrm{Tw}$ & hwdz & qtz sst & 38.8823 & -107.0701 & $3,440.6$ & 0.126 & std mine $\mathrm{L} 3, \mathrm{fv}, \sim 2 \mathrm{~m}$ se of flt \\
\hline 70909 14D & $\mathrm{Tw}$ & hwpl & qtz sst & 38.8822 & -107.0700 & $3,440.6$ & 2.600 & std mine $\mathrm{L} 3, \mathrm{fv}, \sim 20 \mathrm{~m}$ se of flt \\
\hline $720091 \mathrm{~A}$ & Tqmp & fwpl & porphry & 38.8783 & -107.0765 & $3,356.6$ & 0.138 & std mine oc \\
\hline $721093 \mathrm{~A}$ & $\operatorname{crg}$ & core & Kmvo cata & 38.8826 & -107.0697 & $3,440.6$ & 0.014 & std mine L3, fv, $7 \mathrm{~m} \mathrm{n}$ of MSTD34 \\
\hline $721094 \mathrm{~A}$ & $\operatorname{crg}$ & core & $\operatorname{crg}$ & 38.8826 & -107.0696 & $3,440.6$ & 0.045 & std mine $\mathrm{L} 3, \mathrm{fv}, \mathrm{n}$ end tunnel \\
\hline $722091 \mathrm{~A}$ & $\operatorname{crg}$ & core & py crg & 38.8834 & -107.0677 & $3,360.8$ & 0.037 & std mine L5, fv, $51 \mathrm{~m}$ ne of portal \\
\hline 72209 1B & Kmvo & fwdz & qtz sst & 38.8834 & -107.0677 & $3,360.8$ & 0.011 & std mine L5, fv, $51 \mathrm{~m}$ ne of portal, $\sim 1 \mathrm{~m}$ from core \\
\hline $722091 \mathrm{C}$ & $\mathrm{Tw}$ & hwdz & qtz sst & 38.8834 & -107.0676 & $3,360.8$ & 0.133 & std mine L5, fv, $60 \mathrm{~m}$ ne of portal, $\sim 1 \mathrm{~m}$ from core \\
\hline $7220910 \mathrm{~A}$ & Tw & hwpl & unox qtz sst & 38.8825 & -107.0678 & $3,526.5$ & 21.367 & elk basin oc \\
\hline $7220911 \mathrm{~A}$ & Kmvo & fwpl & ox qtz sst & 38.8856 & -107.0670 & $3,559.5$ & 0.068 & elk basin oc \\
\hline $7220914 \mathrm{~A}$ & Tqmp & hwpl & unox porphyry & 38.8805 & -107.0705 & $3,405.3$ & 0.215 & elk basin oc \\
\hline $7240943 \mathrm{~A}$ & Tw veins & hwdz & $\arg \mathrm{Tw}$ & 38.8799 & -107.0779 & $3,435.5$ & 0.020 & elk fault oc sw tip \\
\hline B8 22.9m & Kmvo & fwdz & qtz sst & 38.8814 & -107.0717 & $3,415.5$ & 0.048 & std drill core B8 \\
\hline B8 $34.4 \mathrm{~m}$ & Kmvo & fwdz & polymet vein & 38.8814 & -107.0717 & $3,415.5$ & 0.072 & std drill core B8 \\
\hline
\end{tabular}


2 and 5 , the change in the character of the magnetic signal is observed well within the Ohio Creek. The most likely explanation for this observation is that surficial materials that contain eroded Wasatch Formation have been deposited on top of the Ohio Creek Member in this location.

Another feature of interest is a relatively isolated segment of line 2 between the Elk portal and the Elk fault vein where the signal oscillations increase in amplitude and frequency. Similar anomalies are observed on line 3 immediately southwest of the NW Elk vein where it intersects the Elk portal, but with significantly reduced amplitude, as well as an isolated anomaly on line 3 that coincides exactly with the Elk fault vein. The erratic occurrence of magnetic anomalies at or near the NW Elk vein and Elk fault vein is consistent with these structures being discontinuous and highly variable in their mineralogy.

Figure 25, which is an interpolated display of the top magnetic sensor only, illustrates some of the low amplitude/ longer wavelength features in the data. This also is evident in figure 24, where more subtle variations (on the order of $20 \mathrm{nT}$ ) occur on both top and bottom sensors over distances of tens of meters. These features may be related to deeper (tens of meters or more) subsurface units that are not exposed, as well as subtle compositional differences within the near-surface formations. The Tertiary quartz monzonite porphyry (Tqmp), for example, appears to have a distinct magnetic signature compared to the Wasatch Formation on line 2.

In summary, the magnetic data are weakly varying but capable of discriminating some of the main geologic units. A limiting factor of the magnetic data is that it cannot be uniquely tied to observed bedrock geologic units. For example, the signal characteristic of the Wasatch Formation locally is observed over the Ohio Creek Member of the Mesaverde Formation, most likely because of Wasatch-rich surficial deposits. Additionally, the NW Elk vein and Elk fault vein structures only occasionally have unique magnetic signatures. This makes sense given their discontinuous geometry and heterogeneous mineralogy, but it would complicate any attempt to map these structures through the use of magnetic data alone.

\section{Summary of Key Observations and Hypotheses}

1. Resistivity: The resistivity data provide fairly dense spatial information about the Standard and Elk fault veins, near-surface saturation, and variability in subsurface properties to depths of 20 to $25 \mathrm{~m}$. The overall picture agrees very well with the geologic observations made by Caine and others (2010). Primary features of the resistivity data include:

- The Standard fault vein appears as a high-resistivity feature to the northwest juxtaposed with a low resistivity feature to the southeast. This agrees well with the fault architecture discussed by Caine and others (2010). The quartz vein is probably the resistive feature, and increased clay minerals due to argillic alteration, which may also hold water, or conductive minerals within the fault probably produce the low resistivity feature. While the dipping low resistivity feature may be associated with increased water content, additional data are needed to determine whether this water is held within clays or is infiltrating into the subsurface along the fault. The Elk fault vein appears as an irregular, high-resistivity feature of varying form in the near-surface on the four lines that cross it. Its variable expression suggests that it may be a discontinuous and disorganized structure. The Standard and Elk fault veins are significant lateral discontinuities, though it is not evident to what extent they act as hydraulic barriers or conduits to flow. While the highly resistive veins may have a relatively low porosity, their permeability may be similar to surrounding bedrock due to cross-cutting joints.

- Numerous vertically thin (2 to $3 \mathrm{~m}$ ) low-resistivity layers are observed in the near-surface that coincide with observed surface saturation and surface water flow, mostly on the northwest portion of the survey area. These interrupt what is primarily a resistive 3 to $10 \mathrm{~m}$ thick near-surface layer apparently associated with the unsaturated zone. These low-resistivity features are clearly associated with areas of high near-surface saturation, and for the most part appear to be perched zones disconnected from deeper low-resistivity zones. They probably occur where shallow flow is running downhill within the surficial soils and the uppermost (weathered and/or highly fractured) bedrock, on top of less permeable bedrock. While localized pathways between the surface water and deeper groundwater cannot be ruled out given the heterogeneous distribution of joints and fractures, this does not appear to be prevalent within the dataset.

- Low resistivity is generally observed at depth and probably corresponds to the saturated zone. The depth of the top of this zone is similar to the depth of the water table in adjacent wells. This feature is sometimes broken by more intermediate resistivity values that may be associated with zones of lower porosity in the subsurface. The lower porosity could be explained by a higher degree of silicification, given that silicified zones are observed at the surface, or a reduction in joint intensity.

- Very high resistivity is observed on the southeastern portion of lines 1 through 3 within the Wasatch Formation. This feature extends to depths of up to about $10 \mathrm{~m}$, becoming thicker with increasing distance up the hill slope. The feature is likely caused 
by a combination of unsaturated conditions and the relatively low porosity of the Wasatch Formation.

2. Self-potential: The most prominent result of the selfpotential survey is the clear expression of the Standard fault vein, the NW Elk vein, and to a lesser extent several of the other mapped veins in the self-potential data. These features are distinguishable as pronounced lows in the self-potential field. These lows are probably caused by local electrochemical effects that are in turn caused by elevated concentrations of sulfide minerals within these features. It is also possible that the large negative selfpotential anomalies are to some degree caused by high rates of downward vertical groundwater flow associated with localized fault-related zones of enhanced faultparallel permeability. However, the component of the negative anomalies caused by this mechanism is probably minor because the self-potential lows correlate with both fault veins and veins, and there is little hydrogeological reason to expect veins to have enhanced vertical permeability. A small background component of the selfpotential signal is apparently contributed by a shallow groundwater flow system with relatively modest groundsurface-parallel volumetric flow rates within the survey area, which appear to reach a maximum in the vicinity of Elk Creek, though shallow flow may exhibit significant seasonal variability.

3. Magnetics: The magnetic data show overall weak variability due to the predominantly non-magnetic character of the host rocks, hydrothermal alteration, and mineralization, which is confirmed by magnetic susceptibility measurements and X-ray diffraction analysis (Caine and others, 2010) of rock samples from the site. The data show a definite change in character that distinguishes the Ohio Creek Formation from the Wasatch Formation, and may also identify the Tqmp dike. One caveat in using the magnetic data to identify the Ohio Creek/Wasatch contact is that it cannot be uniquely tied to bedrock geologic units. For example, a signal characteristic of the Wasatch Formation is locally observed over the Ohio Creek Formation, most likely because of the presence of surface materials that contain eroded Wasatch Formation and have been deposited on top of the Ohio Creek Formation. Additionally, the NW Elk vein and Elk fault-vein structures only occasionally have unique magnetic signatures. This is consistent with these structures having discontinuous geometry and heterogeneous mineralogy, but it would complicate any attempt to map these structures through the use of magnetic data alone.

\section{Acknowledgments}

This work was carried out in cooperation with the U.S. Environmental Protection Agency. We are grateful for the overall support and field assistance provided by Christina Progess, as well as additional field assistance provided by Gail Heath. Discussions with Tien Grauch and Jeff Phillips provided valuable insights into the magnetic data. We also thank Michael Powers and Matt Burgess for their reviews of this report.

\section{References Cited}

Advanced Geosciences Inc., 2008, Instruction manual for EarthImager2D version 2.3.0-resistivity and IP inversion software: Advanced Geosciences, Inc., Austin, TX.

Archie, G.E., 1942, The electrical resistivity $\log$ as an aid in determining some reservoir characteristics: Trans. Amer. Inst. Mining Metallurgical and Petroleum Engineers, v. 146, p. 54-62.

Binley, A., and Kemna, A., 2005, DC resistivity and induced polarization methods, in Rubin, Y., and Hubbard, S.S., eds., Hydrogeophysics: Netherlands, Springer, p. 129-156.

Caine, J.S., Manning, A.H., Berger, B.R., Kremer, Y., Guzman, M.A., Eberl, D.D., and Schuller, K., 2010, Characterization of geologic structures and host rock properties associated with the hydrogeology of the Standard Mine in Elk Creek Basin, Colorado: U.S. Geological Survey Open-File Report 2010-1008, 56 p.

Castermant, J., Mendonça, C.A., Revil, A., Trolard, F., Bourrié, G., and Linde, N., 2008, Redox potential distribution inferred from self-potential measurements associated with the corrosion of a burden metallic body: Geophysical Prospecting, v. 56, no. 2, p. 269-282.

Clark, D.A., 1997, Magnetic petrophysics and magnetic petrology: Aids to geological interpretation of magnetic surveys: AGSO Journal of Australian Geology and Geophysics, v. 17, p. 83-103.

Coogan, J.C., Stork, A., and Fillmore, R., 2005, Geologic map of the Almont Quadrangle, Gunnison County, Colorado: Colorado Geological Survey OF05-05, scale 1:24,000.

Corwin, R.F., 1990, The self-potential method for environmental and engineering applications, in Ward, S.H., ed., Geotechnical and Environmental Geophysics: Tulsa, Society of Exploration Geophysicists, p. 127-146. 
Fournier, C., 1989, Spontaneous potentials and resistivity surveys applied to hydrogeology in a volcanic area-Casehistory of the Chaine-Des-Puys (Puy-De-Dome, France): Geophysical Prospecting, v. 37, no. 6, p. 647-668.

Gaskill, D.L., Godwin, L.H., and Mutschler, F.E., 1967, Geologic map of the Oh-Be-Joyful quadrangle, Gunnison County, Colorado: U.S. Geological Survey Geologic Quadrangle Map GQ-578, scale 1:24,000.

Hamilton, S.M., 2000, Spontaneous potentials and electrochemical cells, in Hale, M., ed., Handbook of exploration geochemistry, volume 7, Geochemical remote sensing of the sub-surface (Volume 7 ed.), Elsevier Science B.V., p. 81-119.

Hansen, R.O., Racic, L., and Grauch, V.J.S., 2005, Magnetic methods in near-surface geophysics, in Butler, D.K., ed., Near surface geophysics: Investigations in geophysics, no. 13: Tulsa, Oklahoma, Society of Exploration Geophysicists, p. 151-171.

Ishido, T., and Mizutani, H., 1981, Experimental and theoretical basis of electrokinetic phenomena in rock-water systems and its applications to geophysics: Journal of Geophysical Research, v. 86, no. NB3, p. 1763-1775.

Johnson, R.C., and May, F.E., 1980, A study of the Cretaceous-Tertiary unconformity in the Piceance Creek basin, Colorado; the underlying Ohio Creek Formation (Upper Cretaceous) redefined as a member of the Hunter Canyon or Mesaverde Formation: U.S. Geological Survey Bulletin 1482-B.

Keller, G.V., and Frischknecht, F.C., 1966, Electrical methods in geophysical prospecting: Oxford, Pergamon Press, 519 p.

Lesmes, D.P., and Friedman, S.P., 2005, Relationships between the electrical and hydrogeological properties of rocks and soils, in Rubin, Y., and Hubbard, S.S., eds., Hydrogeophysics: Netherlands, Springer, p. 87-128.

Loke, M.H., and Barker, R.D., 1996, Rapid least-squares inversion of apparent resistivity pseudosections by a quasiNewton method: Geophysical Prospecting, v. 44, no. 1, p. 131-152.

Ludington, S., and Ellis, C.E., 1983, Mineral resource potential of the Oh-Be-Joyful wilderness study area, Gunnison County, Colorado: U.S. Geological Survey Miscellaneous Field Studies Map 1582-A, 7 p.

Manning, A.H., Verplanck, P.L., Mast, M.A., and Wanty, R.B., 2007, Hydrogeochemical investigation of the Standard Mine vicinity, upper Elk Creek Basin, Colorado: U.S. Geological Survey: Scientific Investigations Report 2007-5265.

Minsley, B.J., 2007, Modeling and inversion of self-potential data: Cambridge, Massachusetts, Massachusetts Institute of Technology, Ph.D. dissertation, 251 p.
Minsley, B.J., Coles, D.A., Vichabian, Y., and Morgan, F.D., 2008, Minimization of self-potential survey mis-ties acquired with multiple reference locations: Geophysics, v. 73 , no. 2, p. F71-F81.

Morgan, F.D., Williams, E.R., and Madden, T.R., 1989, Streaming potential properties of Westerly Granite with applications: Journal of Geophysical Research-Solid Earth and Planets, v. 94, no. B9, p. 12449-12461.

Obradovich, J.D., Mutschler, F.E., and Bryant, B., 1969, Potassium-Argon ages bearing on the igneous and tectonic history of the Elk Mountains and vicinity, Colorado: A preliminary report: Geological Society of America Bulletin, v. 80 , no. 9, p. 1749-1756.

Oldenburg, D.W., and Li, Y., 1994, Inversion of induced polarization data: Geophysics, v. 59, no. 9, p. 1327-1341.

Palacky, G.J., 1987, Resistivity characteristics of geologic targets, in Nabighian, M.N., ed., Electromagnetic methods in applied geophysics: Voume 1, theory: Tulsa, Society of Exploration Geophysicists.

Petiau, G., 2000, Second generation of lead-lead chloride electrodes for geophysical applications: Pure and Applied Geophysics, v. 157, no. 3, p. 357-382.

Revil, A., Pezard, P.A., and Glover, P.W.J., 1999, Streaming potential in porous media 1 . Theory of the zeta potential: Journal of Geophysical Research-Solid Earth, v. 104, no. B9, p. 20021-20031.

Revil, A., Naudet, V., and Meunier, J.D., 2004, The hydroelectric problem of porous rocks: Inversion of the position of the water table from self-potential data: Geophysical Journal International, v. 159, no. 2, p. 435-444.

Reynolds, J.M., 1997, An introduction to applied and environmental geophysics: Chichester, England, John Wiley \& Sons, $796 \mathrm{p}$.

Reynolds, R.L., Rosenbaum, J.G., Hudson, M.R., and Fishman, N.S., 1990, Rock magnetism, the distribution of magnetic minerals in the Earth's crust, and aeromagnetic anomalies, in Hanna, W.F., ed., Geologic Applications of Modern Aeromagnetic Surveys: U.S. Geological Survey Bulletin 1924, U.S. Geological Survey, p. 24-25 [available online at http://pubs.er.usgs.gov/djvu/B/bull_1924.djvu].

Sato, M., and Mooney, H.M., 1960, The electrochemical mechanism of sulfide self-potentials: Geophysics, v. 25, no. 1, p. 226-249.

Sharp, J.E., 1978, A molybdenum mineralized breccia pipe complex, Redwell Basin, Colorado: Economic Geology, v. 73, no. 3, p. 369-382, doi: 10.2113/gsecongeo.73.3.369.

Sill, W.R., 1983, Self-potential modeling from primary flows: Geophysics, v. 48, no. 1, p. 76-86. 
Sivenas, P., and Beales, F.W., 1982a, Natural geobatteries associated with sulfide ore-deposits, 2. Field studies at the Viburnum Trend, Southeast Missouri, United-States: Journal of Geochemical Exploration, v. 17, no. 2, p. 145-160.

Sivenas, P., and Beales, F.W., 1982b, Natural geobatteries associated with sulfide ore-deposits, 1 . Theoretical-studies: Journal of Geochemical Exploration, v. 17, no. 2, p. $123-143$.

Telford, W.M., Geldart, L.P., and Sheriff, R.E., 1990, Applied Geophysics (2nd ed.): Cambridge [England] ; New York, Cambridge University Press, 770 p. p.

Thomas, J.A., and Galey, J.T., 1982, Exploration and geology of the Mt. Emmons molybdenite deposits, Gunnison County, Colorado: Economic Geology, v. 77, no. 5, p. 1085-1104, DOI: 10.2113/gsecongeo.77.5.1085.

U.S. Environmental Protection Agency, 2009, Environmental Protection Agency Standard Mine Website: accessed December 29, 2009, at http://www.epa.gov/region08/ superfund/co/standard/.

Verplanck, P.L., Manning, A.H., Graves, J.F., McCleskey, R.B., Todorov, T., and Lamothe, P.J., 2010, Geochemistry of Standard Mine waters, Gunnison County, Colorado, August 2009: U.S. Geological Survey Open File Report 2009-1292, $21 \mathrm{p}$.

Wood, R.H.I., and Oerter, E.J., 2007, History, geology, and environmental setting of the Micawber Mine and Elk Load in the Ruby Mining District, Gunnison National Forest, Gunnison County, Colorado: Colorado Geological Survey Open-File Report 08-10.

Zhang, J., Mackie, R.L., and Madden, T.R., 1995, 3-D resistivity forward modeling and inversion using conjugate gradients: Geophysics, v. 60, no. 5, p. 1313-1325.

Zlotnicki, J., Boudon, G., Viodé, J.P., Delarue, J.F., Mille, A., and Bruére, F., 1998, Hydrothermal circulation beneath Mount Pelee inferred by self potential surveying. Structural and tectonic implications: Journal of Volcanology and Geothermal Research, v. 84, no. 1-2, p. 73-91. 
Intended to be a blank page 


\section{Appendix}

The following figures 26-30 illustrate the observed and final modelpredicted data for each of the resistivity lines. Data are presented in pseudosection form, where each point represents an individual four-electrode measurement. The fact that the predicted data mostly agree with the measured data suggests that the inverted models (presented separately in the report) are consistent with the data. 

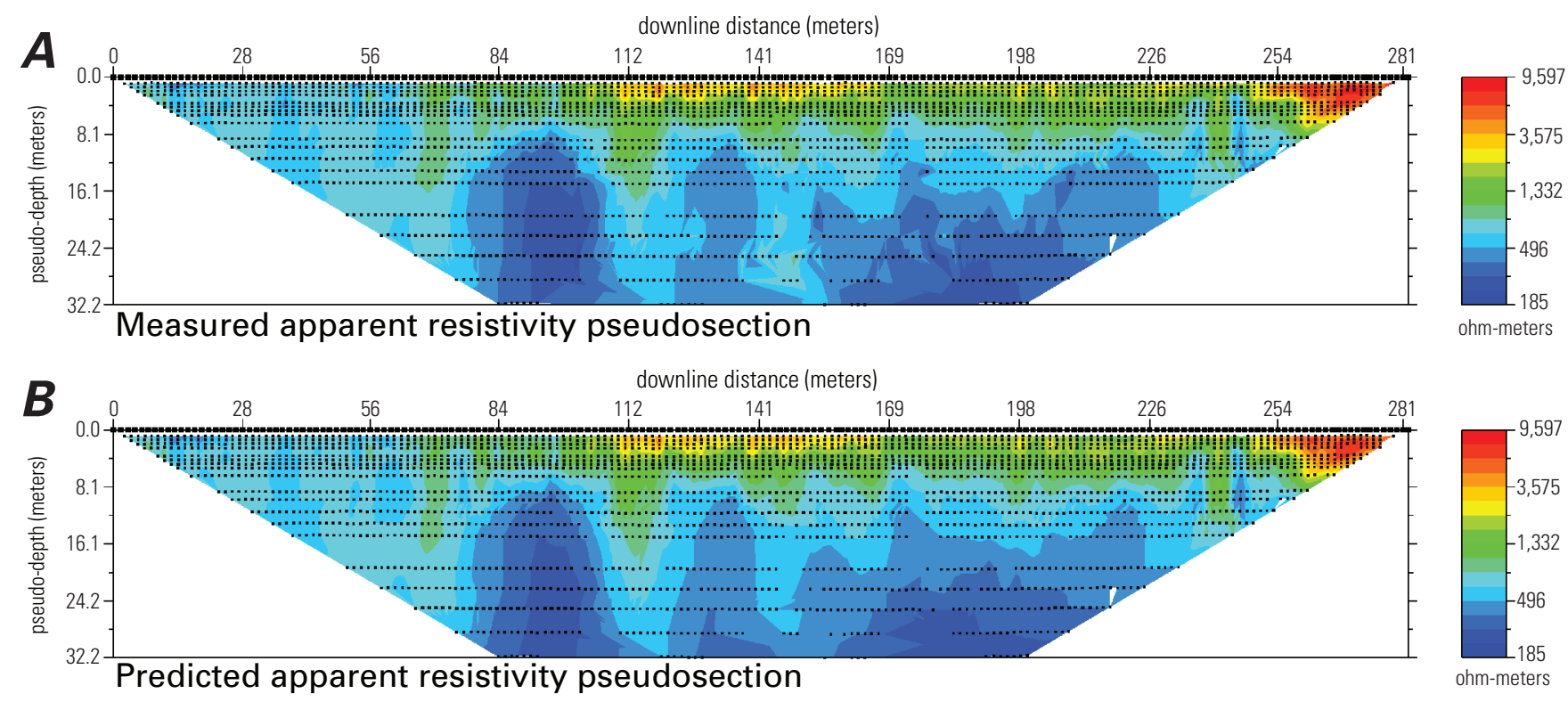

Figure 26. Measured $(A)$ and model-predicted $(B)$ apparent resistivity pseudosections for $D C$ resistivity line 1. Black dots represent individual four-electrode measurements. Note that the vertical "pseudo-depth" axis denotes approximate depths in the subsurface representative of a given data point.
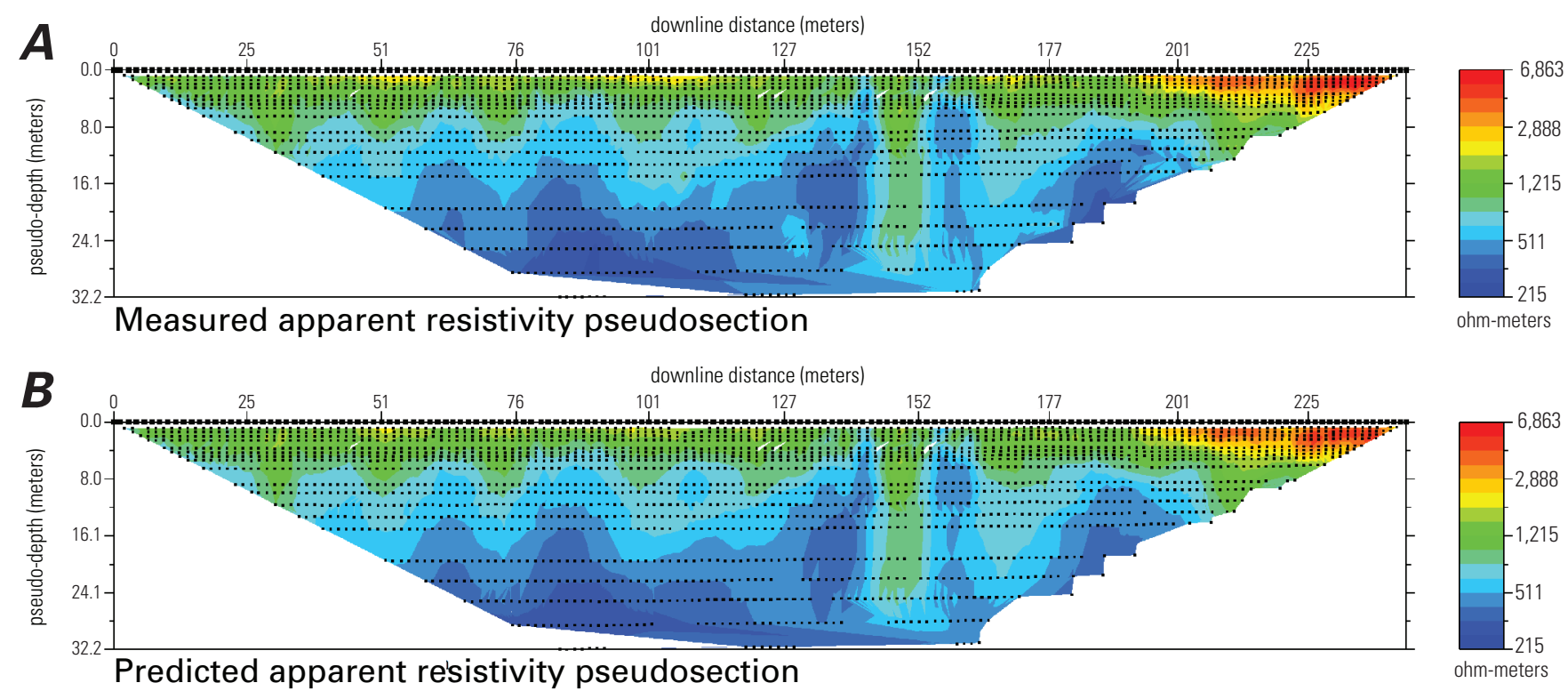

Figure 27. Measured $(A)$ and model-predicted $(B)$ apparent resistivity pseudosections for DC resistivity line 2. Black dots represent individual four-electrode measurements. Note that the vertical "pseudo-depth" axis denotes approximate depths in the subsurface representative of a given data point. 


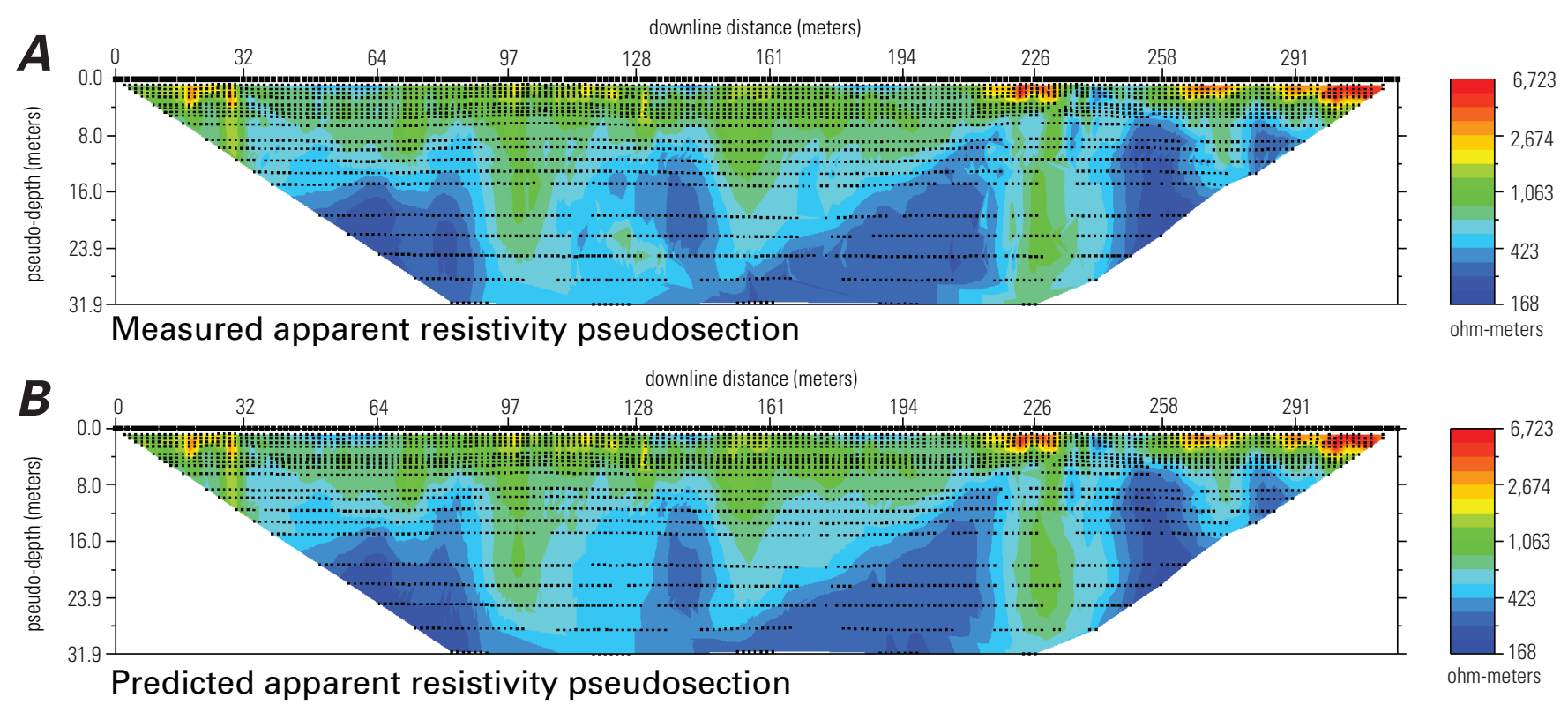

Figure 28. Measured $(A)$ and model-predicted $(B)$ apparent resistivity pseudosections for DC resistivity line 3. Black dots represent individual four-electrode measurements. Note that the vertical "pseudo-depth" axis denotes approximate depths in the subsurface representative of a given data point

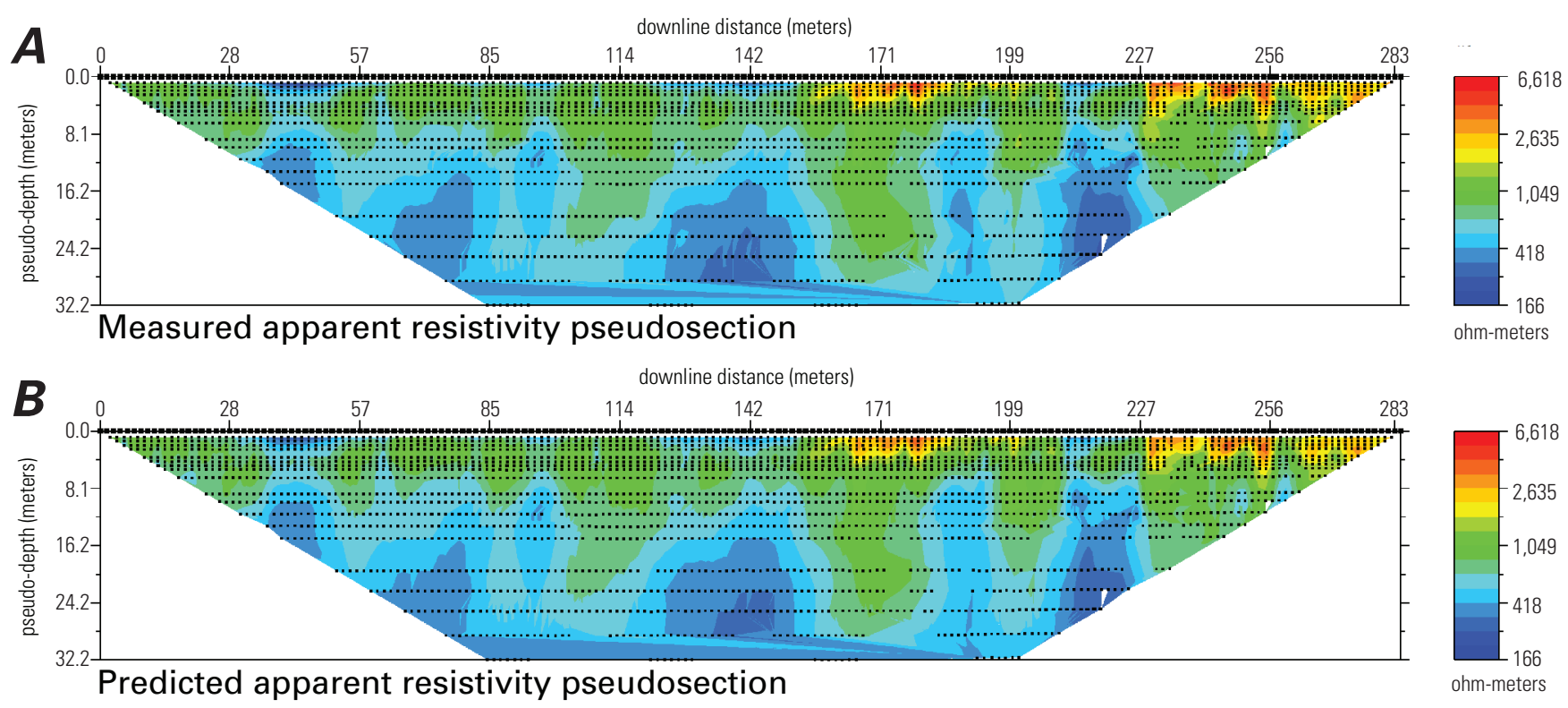

Figure 29. Measured $(A)$ and model-predicted $(B)$ apparent resistivity pseudosections for DC resistivity line 4 . Black dots represent individual four-electrode measurements. Note that the vertical "pseudo-depth" axis denotes approximate depths in the subsurface representative of a given data point. 


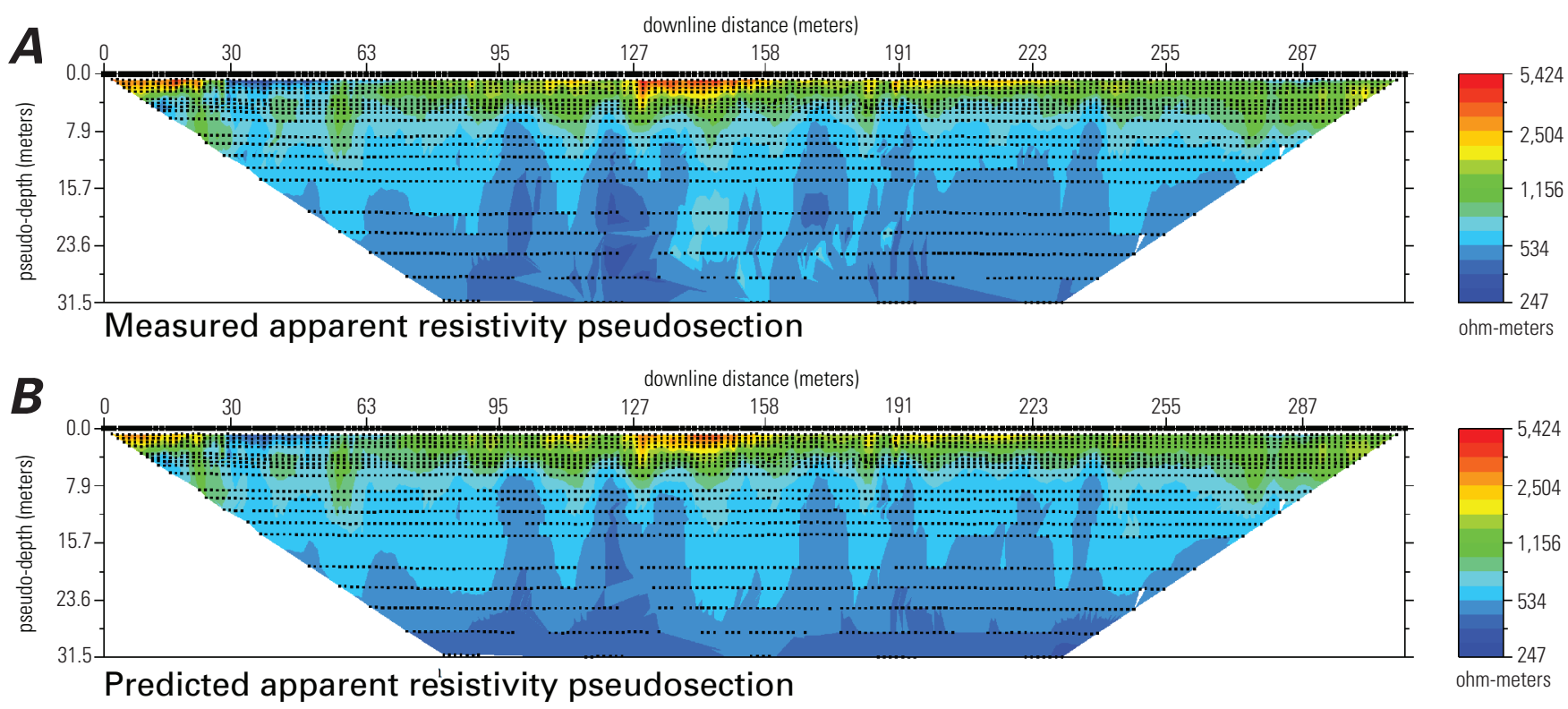

Figure 30. Measured $(A)$ and model-predicted $(B)$ apparent resistivity pseudosections for DC resistivity line 5 . Black dots represent individual four-electrode measurements. Note that the vertical "pseudo-depth" axis denotes approximate depths in the subsurface representative of a given data point.

Publishing support provided by:

Denver Publishing Service Center

For more information concerning this publication, contact:

Team Chief Scientist, USGS Crustal Imaging and Characterization

Box 25046, Mail Stop 964

Denver, CO 80225

(303) 236-1312

Or visit the Crustal Imaging and Characterization Team Web site at: http://crustal.usgs.gov/ 